\title{
Functional and structural determinants of vascular dysfunction in experimental diabetes : focus on advanced glycation end products
}

Citation for published version (APA):

Crijns, F. R. L. (2000). Functional and structural determinants of vascular dysfunction in experimental diabetes : focus on advanced glycation end products. [Doctoral Thesis, Maastricht University]. Datawyse / Universitaire Pers Maastricht. https://doi.org/10.26481/dis.20000629fc

Document status and date:

Published: 01/01/2000

DOI:

10.26481/dis.20000629fc

Document Version:

Publisher's PDF, also known as Version of record

Please check the document version of this publication:

- A submitted manuscript is the version of the article upon submission and before peer-review. There can be important differences between the submitted version and the official published version of record.

People interested in the research are advised to contact the author for the final version of the publication, or visit the DOI to the publisher's website.

- The final author version and the galley proof are versions of the publication after peer review.

- The final published version features the final layout of the paper including the volume, issue and page numbers.

Link to publication

\footnotetext{
General rights rights.

- You may freely distribute the URL identifying the publication in the public portal. please follow below link for the End User Agreement:

www.umlib.nl/taverne-license

Take down policy

If you believe that this document breaches copyright please contact us at:

repository@maastrichtuniversity.nl

providing details and we will investigate your claim.
}

Copyright and moral rights for the publications made accessible in the public portal are retained by the authors and/or other copyright owners and it is a condition of accessing publications that users recognise and abide by the legal requirements associated with these

- Users may download and print one copy of any publication from the public portal for the purpose of private study or research.

- You may not further distribute the material or use it for any profit-making activity or commercial gain

If the publication is distributed under the terms of Article $25 \mathrm{fa}$ of the Dutch Copyright Act, indicated by the "Taverne" license above, 
ISBN 90-5278-277-6

Scientific studies in this thesis were made possible by financial support of Alteon inc., Novo Nordisk Farma B.V. Nederland and Diabetes Fonds Nederland.

Publication of this thesis was financially supported by Novo Nordisk Farma B.V. Nederland, Diabetes Fonds Nederland and dr. Saal van Zwanenbergstichting. 


\title{
Functional and structural determinants of vascular
}

\author{
dysfunction in experimental diabetes
}

Focus on advanced glycation end products

\section{PROEFSCHRIFT}

ter verkrijging van de graad van doctor aan de Universiteit Maastricht, op gezag van de Rector Magnificus, Prof. dr. A.C. Nieuwenhuijzen Kruseman, volgens het besluit van het College van Decanen, in het openbaar te verdedigen op donderdag 29 juni 2000 om 12.00 uur

door

\author{
Francine R.L. Crijns
}

geboren op 16 augustus 1967 te Genk (Belgiê)

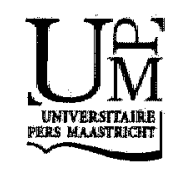




\section{Promotores}

Prof. dr. H.A.J. Struijker-Boudier

Prof. dr. J.G.R. De Mey

\section{Co-promotor}

Dr. B.H.R. Wolffenbuttel

\section{Beoordelingscommissie}

Prof. dr. P.W. de Leeuw (voorzitter)

Prof. dr. A. Cerami (The Kenneth S. Warren Laboratories, Tarrytown NY, USA) Prof. dr. M.J.A.P. Daemen

Dr. B.I. Lévy (INSERM Unité 141, Hôspital Lariboisière, Paris)

Prof. dr. G.J. van der Vusse 
Do not believe something because it's in a great book or a sage has told you it is sogo and examine it for yourself.

from Buddha's Teachings 
$\because \quad \because \quad \cdots$

:

. 


\section{Contents}

Chapter 1 General introduction 9

Chapter 2 Arteriolar reactivity in conscious diabetic rats. Influence of aminoguanidine treatment 41

Chapter 3 Mechanical properties of mesenteric arteries in diabetic rats: consequences of outward remodeling $\mathbf{5 7}$

Chapter 4 Altered cyclic GMP production in carotid arteries of streptozotocininduced diabetic rats 71

Chapter 5 Hemodynamics in conscious streptozotocin-induced diabetic rats: influence on vascular morphology 87

Chapter 6 Breakers of advanced glycation end products restore large artery properties in experimental diabetes 101

Chapter 7 General Discussion 117

Chapter 8 Summary and concluding remarks 125

Chapter 9 Samenvatting 131

Dankwoord 135

Publicaties 139

Curriculum Vitae 143 

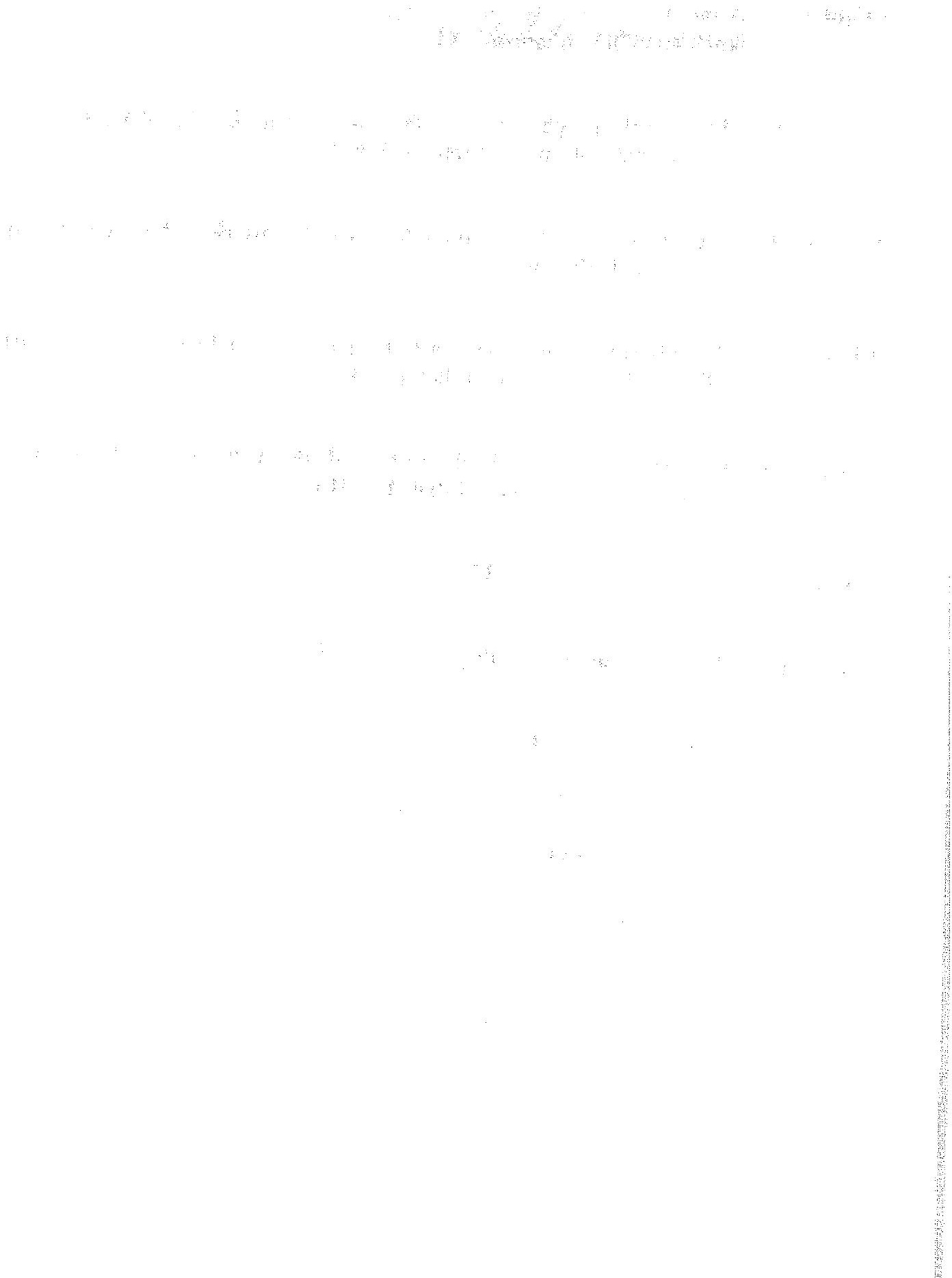


\section{Chapter 1}

\section{General introduction}

FRL Crijns 


\section{General aspects of diabetes mellitus}

\section{Epidemiology and etiology}

Diabetes mellitus is a syndrome which is characterized by chronic hyperglycemia and disturbances of carbohydrate, fat and protein metabolism ${ }^{1}$. It affects more than 300000 people in the Netherlands. The incidence of people with diabetes is still rising ${ }^{2,3}$. The disease is caused by a decreased production of insulin by the beta cells of the Islets of Langerhans in the pancreas, and/or an impaired action of insulin. Two types of diabetes are distinguished: an insulin-dependent form (type 1) and an insulin-independent form (type 2). Type 1 diabetes generally starts before adulthood. Autoimmune destruction of pancreatic beta cells, which produce insulin, is the most common cause ${ }^{4}$. Without insulin suppletion, these persons develop severe hyperglycemia, leading to glucosuria, dehydration and ketoacidosis, eventually leading to cerebral disturbances and coma. Type 2 diabetes is generally diagnosed in people over the age of 40 years. It may occur with similar symptoms as type 1 diabetes, but it is often asymptomatic. Despite the presence of hyperglycemia, the concentrations of ketone bodies in the blood and urine are low. Type 2 diabetes is caused by a combination of reduced sensitivity for insulin, due to abnormalities at the cell surface (insulin receptor) or within the cell (signal transduction), and a reduction in insulin secretion, which is less severe than in type 1 diabetes'.

\section{Cardiovascular complications in humans with diabetes mellitus}

Diabetic cardiovascular complications are a combination of specific disorders and an acceleration of abnormalities that are also found in nondiabetic subjects. The principal factors that initiate and promote the progression of diabetic complications are hyperglycemia, insulin deficiency or resistance, hypertension and dyslipidemia ${ }^{5}$. Persons with diabetes are at high risk to develop microvascular abnormalities and dysfunctions. A hallmark of diabetic microangiopathy is thickening of the basement membrane, which develops in proportion to the duration of diabetes and the degree of hyperglycemia. An increase in extracellular matrix proteins, mainly type IV collagen, laminin and fibronectin reduces the elasticity and alters the filtration properties of the basement membrane $e^{6}$. In addition, extended exposure to hyperglycemia results in glycation of the extracellular matrix proteins, which reduces their elasticity and turn-over rate (see further).

Diabetic microangiopathy leads to clinical features such as retinopathy and nephropathy, and contributes to the development of neuropathy?

The initial stage of diabetic retinopathy, non-proliferative retinopathy, is characterized by pericyte loss, formation of microaneurysms, increased vascular 
permeability, and capillary closure. These microvascular abnormalities can lead to areas of non-perfusion and ischaemia. In response to the resulting hypoxia, the retina will increase the production of vascular endothelial-derived growth factor, which promotes neovascularisation and therefore the progression into proliferative retinopathy. New capillaries and arterioles are formed, which contain few pericytes and do not form a proper blood border, leading to an increased risk of bleeding and enhanced extravasation of proteins ${ }^{8}$.

In glomeruli of diabetic patients, thickening of capillary basement membranes plays an important role in kidney dysfunction. Expansion of the mesangium in glomeruli is accompanied by a gradual loss of capillary surface area, with declining glomerular filtration rate and albuminuria ${ }^{8}$. A subclinical increase in urinary albumin excretion (microalbuminuria) early in the course of type 1 diabetes is a powerful predictor of the later development of persistent proteinuria, progress in reduction of renal function and - eventually - renal failure?. The presence of microalbuminuria is also a significant risk factor for mortality both in type 1 and type 2 diabetes $^{10}$.

In diabetic neuropathy, epineural and endoneural microangiopathy with endothelial cell hyperplasia and basement membrane thickening have been demonstrated. These changes, together with arteriovenous shunting and haemorheological abnormalities, may lead to reduced endoneural blood flow. The "vascular hypothesis" suggests that this reduction in blood flow leads to ischaemia, hypoxia and functional loss of nerve tissue ${ }^{11}$.

Most of the effects of diabetes mellitus on the macrovasculature are the result of an acceleration of atherosclerosis and an increase in thrombosis. The major risk factors for macroangiopathy in diabetes include alterations in lipoprotein concentration and composition, hyperinsulinemia, hypertension, non-enzymatic glycation of proteins and genetic factors.

Epidemiological and prospective studies have suggested a relationship between hyperglycaemia or the degree of metabolic control and the pathophysiology of micro- and macrovascular complications ${ }^{12,13}$. As demonstrated by the Diabetic Control and Complications Trial (DCCT), chronic hyperglycemia, measured as the concentration of glycosylated haemoglobin $\left(\mathrm{HbA}_{1 \mathrm{c}}\right)$, is the most important factor in the development and progression of microvascular complications ${ }^{14}$. Intensive insullin therapy to improve metabolic control in type 1 diabetes reduced microvascular complications such as retinopathy, neuropathy and nephropathy ${ }^{15}$. The recent data of the UK Prospective Diabetes Study indicated that optimal glycemic control also reduces the incidence of microvascular complications in type 2 diabetes, whereas adequate blood pressure control reduces both micro- and macrovascular complications ${ }^{16}$.

Several mechanisms have been suggested to account for the deleterious effects of 
hyperglycemia, such as an increased flux through the polyol pathway ${ }^{17}$, enhanced oxidative stress ${ }^{14,19}$ and the formation of advanced glycation end products ${ }^{20,21}$ (see further). However, tight glycemic control is often difficult to obtain and can lead to adverse events, such as severe hypoglycemia ${ }^{14}$. The relevance of investigating the mechanisms behind hyperglycemia-induced vascular complications lies in the possibility to inhibit the development of these complications by additional measures than solely glycemic control.

\section{Features of diabetic cardiovascular disease}

\section{Vascular reactivity}

Studies on vascular reactivity to vasoactive substances are often used to detect early vascular dysfunctions related to cardiovascular diseases. In particular, endothelial dysfunction is characterized by defective endothelium-dependent vasodilatation. Agents such as acetylcholine and bradykinin, stimulate the endothelial NO-synthase to produce NO from its precursor $\mathrm{L}$-arginine ${ }^{22}$. NO then activates soluble guanylate cyclase to produce $3^{\prime}, 5$ '-cyclic guanosine monophosphate (cGMP), which induces relaxation of arterial smooth muscle cells by protein phosphorylation ${ }^{23}$. In experimental diabetes, decreases in endothelium-dependent relaxation are a common feature in conduit and resistance arteries, as well as in arterioles ${ }^{24.30}$. Although this may be regarded as a general pathologic phenomenon in diabetes, in some studies opposite findings are presented ${ }^{31,32}$. An extensive study performed by Pieper ${ }^{25}$ demonstrated that there exists a triphasic response of increased, unaltered and impaired endothelium-dependent relaxation dependent on the diabetes-duration. In aortic rings contracled with norepinephrine, relaxation to acetylcholine was increased at $24 \mathrm{~h}$ after streptozotocin injection to induce hyperglycemia. Relaxation was normal 1 and 2 weeks after diabetes-induction, and impaired at 8 weeks of disease. These observations may explain conflicting data in the literature.

Almost without exception, studies that have shown impaired endothelium-dependent relaxation have found normal relaxation to nitrovasodilators or NO-donor ${ }^{33}$. These agents relax vascular smooth muscle by direct $\mathrm{NO}$ production and subsequent activation of guanylate cyclase, but do not require the presence of the endothelium. Thus, the intrinsic property to activate vascular smooth muscle guanylate cyclase appears not to be altered by experimental diabetes.

Impaired endothelium-dependent relaxation of blood vessels has been confirmed in IDDM patients in vivo and in isolated arteries in vitro ${ }^{34-36}$. However, severall studies in humans report no defect ${ }^{37.39}$. Also with respect to the endotheliumindependent relaxation in IDDM patients, controversial results have been published. Normal relaxation ${ }^{34-36,38,40}$ as well as attenuated responses to nitrovasodilators ${ }^{37,41}$ have been observed. One possible explanation for this discrepancy relates to 
primary nitrate tolerance, since responses to nitroglycerin but not sodium nitroprusside were diminished in diabetic patients ${ }^{42}$. Furthermore, ambient glucose concentrations, fluctuations in insulin levels, presence of microalbuminuria, and potential influence of gender might account for the opposite results in human studies. In association with the impaired endothelium-dependent relaxation, arteries and arterioles often show enhanced responses to vasoconstrictor agents in experimental diabetes ${ }^{43-50}$. However, in a limited number of studies in rats with a rather short diabetes-duration (2-3 weeks), no difference in contractility between arteries of diabetic and control rats was observed ${ }^{31}$. In type 1 diabetic patients, enhanced $^{51}$, unchanged ${ }^{34,39}$ as well as depressed responsiveness ${ }^{35}$ to vasoconstrictor agents was observed. These opposite results may be related to the same factors as already described to explain contradictory vasorelaxation results in IDDM. A critical evaluation of the diabetic patients used in these studies may lead to the conclusion that there are many different diabetic patient subpopulations: presence of microalbuminuria or not, mixed-gender populations, elimination, limitation or not of vasoactive medication or other drugs such as caffeine, nicotine and alcohol etc. Multiple factors may contribute to the disturbances in vascular reactivity. Most of the mechanistic studies have been performed in experimental models for diabetes.

In type 1 diabetes, it is likely that vascular dysfunction is caused by the metabolic consequences of acutely or chronically elevated glucose concentrations and/or fluctuating insulin levels. Various hypotheses have been put forward to explain the adverse effects of diabetes on the vascullar system through an effect of hyperglycemia on vascular cells, in particular the endothelium. In paragraph 3, some possible molecular mechanisms of dysregulation by hyperglycemia are described.

\section{Vascular mechanical properties}

The proximal part of the arterial system is a complex network of elastic tubes which, at one end, accepts spurts of blood from the left ventricle of the heart, and at its numerous ramifications, passes this on in a steady stream into the resistance vessels, which perfuse the organs and tissues of the body ${ }^{52}$. The proximal part of the arterial system has both a conduit function and a cushioning function: it delivers blood with a minimal fall in pressure to peripheral tissues and it reduces pressure fluctuations imposed by the intermittent cardiac action. The aorta and large arteries buffer the intermittent output of the heart into a more or less continuous flow. This buffering capability of a vessel can be expressed as the change in volume (V) divided by the change in pressure (P). The intrinsic elastic properties of the walls can be expressed as distensibility (dV/VdP) ${ }^{53}$.

A normally compliant system can store a considerable volume of blood in the aorta and the large arteries during systole. As the arterial system becomes less distensible, the storage capacity of the aorta and arteries will diminish for any 
given pulse pressure ${ }^{54}$.

Diabetes mellitus is associated with structural and functional changes in the conduit arteries; which may account for changes in vascular mechanical properties and contribute to an enhanced atherosclerotic risk. Several studies in diabetic patients demonstate that large arteries exhibit a reduced elasticity, measured by means of a reduced compliance and/or distensibility ${ }^{54-36}$. One of the possible mechanisms put forward to explain the reduced elasticity of the vascular system is an accumulation of advanced glycation end products (AGEs) on extracellular matrix proteins in the vascular wall of subjects exposed to chronic hyperglycaemia. In experimental diabetes, large artery elasticity could be enhanced by aminoguanidine treatment, a drug that reduces the accumulation of AGEs on proteins ${ }^{57}$ (see further).

Mechanical properties of peripheral arteries and arterioles are not so much an expression of buffering capacity of the arterial system, but rather a reflection of structural and functional changes that may take place under certain circumstances. Hill and Ege $^{45}$ showed that experimental diabetes is associated with a decreased passive distensibility (increased stiffening) of cremaster arterioles. Chronic treatment with aminoguanidine prevented this mechanical disturbance ${ }^{45}$.

\section{Hemodynamic changes}

Numerous clinical and epidemiological reports have confirmed that human diabetic patients appear particularly susceptible to heart failure, which is the leading cause of death in these patients ${ }^{58}$. The cardiac problems include a reduction in stroke volume, cardiac index and ejection fraction, and a higher left ventricular end diastolic pressure ${ }^{59,60}$. In perfused hearts of diabetic rats, a significant reduction in cardiac output, contractility and maximal relaxation rate was observed ${ }^{6 i-63}$. Furthermore, redistribution of cardiac output takes place in experimental diabetes. Hill and Larkins ${ }^{64}$ showed that in streptozotocin-diabetic rats blood flow to the small intestine is markedly increased compared to age-matched control rats, whereas skin and skeletal muscle blood flow are significantly reduced.

There is a markedly increased prevalence of hypertension in the diabetic population, with as many as $60-80 \%$ of the patients affected ${ }^{65,66}$. The pathogenesis of hypertension in human diabetes is most likely multifactorial: a relationship to both high and low renin levels has been noted, along with changes associated with abnormal free water clearance in damaged kidneys, and a possible association with increased glycoprotein and connective tissue infiltration in the walls of resistance vessels, making them less compliant ${ }^{67}$. A strong association exists between diabetes, hypertension and congestive heart failure. Comparison of the hearts of age-matched patients with hypertension or diabetes or a combination of these two pathologic conditions, there was significantly more heart failure in the hypertensive-diabetic group ${ }^{67}$.

Several etiological factors have been put forward to explain the development of 
diabetic cardionyopathy. They include microangiopathic changes ${ }^{6}$, abnormalities in vascular sensitivity and reactivity to various agonists ${ }^{24,33}$, altered cardiac autonomic function $^{68}$, increased stiffness of the ventricular wall associated with perivascular thickening of basement membranes and interstitial accumulation of connective tissue and glycoproteins ${ }^{69}$, changes in contractile proteins ${ }^{70}$ and changes in subcellular organelles which control ion movements, specifically intracellular calcium ${ }^{71}$.

\section{Molecular mechanisms underlying vascular dysfunction in diabetes}

Hyperglycemia is the major causal factor in the development of diabetic vascular complications. The mechanisms by which hyperglycaemia causes the complications are not completely clear. However, it is very likely that hyperglycaemia is mediating its adverse effects through multiple mechanisms. Table 1.1 summarizes the molecular mechanisms that have been put forward during the last decade to contribute to diabetes-induced complications.

Table 1.1 Molecular mechanisms underlying vascular complications in diabetes

Enhanced activity of protein kinase C (PKC), in particular the PKC-BII isoform ${ }^{72,73}$

Altered redox state linked to a change in $N A D H / N A D^{+}$ratio ${ }^{7}$

Increased phosphoinositide metabolism

Enhanced formation of vasoconstrictor prostanoids ${ }^{35-77}$

Accumularion of sorbito ${ }^{3-80}$

Increased axidative stress ${ }^{\text {so, sh }}$

Formation of advanced glycation end production (see page 17)

The metabolism of glucose in vascular cells has recently been clarified, showing that the main glucose transport into the vascular cells is mediated by the glucose transporter GLUT1 ${ }^{82}$. Most of the glucose transported is then metabolized through the glycolysis pathway, with a minor component $(<5 \%)$ being metabolized through other pathways.

Some of the mechanisms cited in table 1.1 will be discussed in more detail.

\section{Protein kinase C (PKC) activation}

Elevated levels of glucose will increase the level of diacylglycerol (DAG), which in turn activates $\mathrm{PKC}^{83}$. Studies from the group of King have shown that hyperglycaemia increases the level of DAG through de novo synthesis and that the 
PKC isoform $\beta \mathrm{II}$ is preferentially elevated in tissues of diabetic rats ${ }^{7,83}$ " The consequences of activation of PKC are multiple and can easily cause vascular functional changes leading to abnormalities of permeability, flow, contractility and relaxation, basement membrane thickening, cell growth and neovascularisation ${ }^{84} .88$.

\section{The polyol pathway}

Several studies have shown that exposure to elevated glucose levels causes an increase in intracellular sorbitol and fructose content due to aldose reductase and sorbitol dehydrogenase activity ${ }^{89}$ (Figure 1.1).

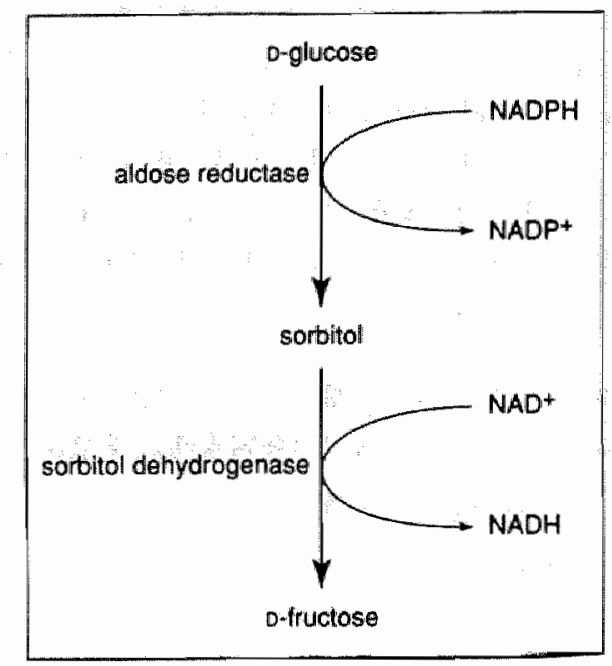

Figure 1.1 The polyol pathway

Alterations in sorbitol and fructose metabolism are implicated as factors contributing to vascular complications in diabetes mellitus ${ }^{90}$. Oxidation of sorbitol to fructose is coupled to reduction of $\mathrm{NAD}^{+}$to $\mathrm{NADH}$. An increase in $\mathrm{NADH} / \mathrm{NAD}^{+}$ratio is observed in tissues exposed to elevated glucose levels ${ }^{74}$. Functional consequences associated with this redox imbalance include impaired myocyte contractile function, impaired vascular relaxation, increased vascular permeability and increased blood flow early after the onset of diabetes, but decreased blood flow later in the course of diabetes. All of these early changes in tissues of diabetic animals are prevented by inhibitors of aldose reductase ${ }^{74,91}$. However, studies in humans with diabetes treated with aldose reductase inhibitors are rather controversial ${ }^{92-94}$. 


\section{Increased oxidative stress}

During diabetes, persistent hyperglycaemia causes increased production of free radicals via autoxidation of glucose, via nonenzymatic protein glycation and via an enhanced flux of glucose through the polyol pathway ${ }^{95}$. Increased oxidative stress may contribute to micro- and macrovascular late complications ${ }^{19,96,97}$. Oxidation of plasma lipids may stimulate autoxidative reactions of sugars, enhancing damage to both lipids and proteins in the circulation and the vascular wall. In this way, the cycle of oxidative stress and damage is continued and reinforced ${ }^{19}$.

Furthermore, glucose is believed to infuence endothelial cells indirectly by the synthesis of growth factors, in particular transforming growth factor $\beta$ (TGF $\beta$ ) and vascular endothelial growth factor (VEGF) ${ }^{98,99}$, and by acting on the coagulation cascade, leading to trombophilia ${ }^{100}$. In addition, the diabetic state is often accompanied by dyslipidemia, which has been proven to influence endothelial function ${ }^{101,102}$.

\section{Advanced glycation end products (AGEs)}

\section{Formation of AGEs}

Glucose and other circulating reducing sugars react non-enzymatically with the amino groups of macromolecules (proteins, lipids and nucleic acids) to produce a heterogenous group of irreversibly bound moieties called advanced glycation end products $^{103}$. Formation of AGEs is a non-enzymatic reaction which was first described by Maillard in $1912^{104}$ (Figure 1.2). Reducing sugars such as glucose and fructose form a Schiff base by covalent addition to free amino groups. Rearrangement of this Schiff base leads to the formation of reversible Amadori products, such as fructose-lysine. These products are more stable and achieve equilibrium in vivo over a period of 6-7 weeks. Rearrangement of Amadori products can lead to the formation of highly reactive dicarbonyl compounds such as 3-deoxyglucosone ${ }^{\text {10s }}$. Further dehydration and condensation finally results in the production of irreversible "cross-links" that persist for the lifetime of the modified substrate $^{106}$ and are collectively referred to as AGEs. Possible substrates for AGEs can be proteins, but also other kinds of macromolecules that contain a free aminogroup such as lipids ${ }^{107}$ and nucleic acids ${ }^{108}$.

An Amadori product which is frequently measured in diabetic patients is glycated haemoglobin $\left(\mathrm{HbA}_{10}\right)$. This parameter reflects the integral of blood glucose concentrations over a period of 3-4 weeks. The AGE-modified form of haemoglobin is more difficult to measure, but seems a better indicator of long-term circulating glucose concentrations ${ }^{109}$. 
AGEs form a large group of heterogenous compounds of which only a few have been identified yet. Some of the characterized AGEs are $\mathrm{N}^{5}$-(carboxymethyl)lysine $(\mathrm{CML})^{110}$, pentosidine ${ }^{111}$, pyrraline ${ }^{112}$ and crossline ${ }^{113}$ (Figure 1.3). CML and pentosidine are known to be glycoxidation products which means that they require oxidation reactions for their formation from glucose $\mathrm{e}^{19}$. CML is produced by metalcatalyzed oxidative fragmentation and autoxidation of glucose $e^{110,14}$ or ascorbate ${ }^{115}$.

$$
\begin{aligned}
& \text { TIME: hours } \longrightarrow \text { days } \longrightarrow \text { weeks months }
\end{aligned}
$$



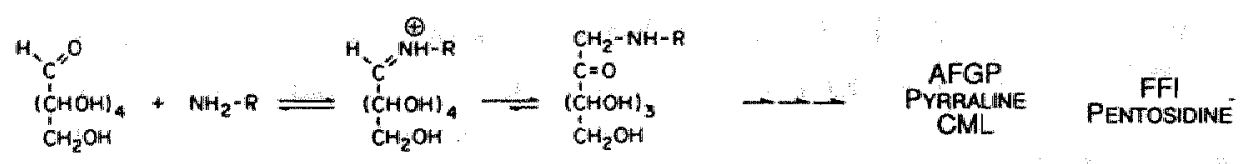

Figure 1.2 The formation of advanced glycation end products. From Bucala et al. (1994)<smiles>CCn1c(C=O)ccc1CO</smiles>

Pyrraline

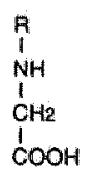

CML<smiles>[R]Nc1nc2ccc[n+](P)c2[nH]1</smiles>

Pentosidine<smiles>[R]N1CC(O)C(O)C2C(C(O)C(O)CO)=C[NH+]([2H])CC21</smiles>

Crossline

Figure 1.3 Characterized advanced glycation end products. From Bucala et al. (1994)

Glycation of proteins and AGE formation was originally thought to specifically tag senescent proteins and to provide a marker for subsequent degradation ${ }^{116}$. In recent years, an increasing number of AGE-receptors have been identified and characterized, such as Receptor for AGE (RAGE), AGE-R ${ }_{1}, A G E-R_{2}$ and AGE- 
$\mathrm{R}_{3}{ }^{117}$. It turned out that receptors for AGEs not only act as scavenger receptors, but also mediate intracellular signalling and induce changes in cellular function ${ }^{118-120}$ The receptor for AGE (RAGE) is described to exist in a complex with lactoferrinlike protein ${ }^{121}$. The binding of physiological AGE-modified proteins to RAGE in endothelial cells induces activation of nuclear factor $-k B(N F-k B)^{122}$. In this way, release of cytokines and growth factors can be induced, initiating tissue repair and protein tumover ${ }^{123}$, but also the development of vascular disease and diabetic complications ${ }^{120,124}$. Other specific AGE-receptors are Oligosaccharyl Transferase Complex Protein 48 (OST-48) or AGE-R1, 80K-H Protein or AGE-R2 and Galectin-3 or AGE-R3 ${ }^{117}$.

\section{Characteristics and pathogenic effects of AGEs}

AGEs accumulate especially on proteins with a long half-life such as collagen, but they also occur on short-lived proteins, forming "second generation AGEs" ${ }^{21}$. In diabetic patients increased AGE levels have been found in dermall connective tissue, small blood capillary walls and vessel walls of arterioles and arteries ${ }^{114.125}$. Serum AGEs were increased in diabetic patients compared to controls ${ }^{114,125 \cdot 127}$.

Vlassara and co-workers ${ }^{128}$ administered AGE-modified albumin to healthy nondiabetic rats and rabbits. After 2-4 weeks of AGE-administration, animals displayed diabetes-like vascular complications: a significant increase in vascular permeability, significant mononuclear cell migration in subendothelial and periarteriolar spaces and a defective endothelium-dependent and -independent vasodilatation. Furthermore, glomerulosclerosis and albuminuria, comparable to diabetic nephropathy are seen in control rats receiving daily injection with AGEs ${ }^{129}$.

Table 1.2 summarizes some of the pathogenic effects of AGEs relevant in diabetic vascular dysfuntion.

AGE-formation on the extracellular matrix results in a decreased elasticity and increased thickness and rigidity of the vascular wall and in narrowing of the vessel lumen $^{57,130}$. Airaksinen and co-workers ${ }^{131}$ showed that the diminished arterial elasticity in humans with diabetes was related to enhanced AGE-formation. AGEs formed on vascular matrix proteins mediate defective endothelium-dependent vasodilatation by quenching nitric oxide ${ }^{132}$. Moreover, incubations of rat aorta segments with high-glycosylated human hemoglobin inhibited endotheliumdependent relaxation in this vessel ${ }^{133}$.

Lipoprotein modification by AGEs contributes to the dyslipidemia frequently observed in diabetic patients ${ }^{142}$. This modification of low density lipoproteins (LDL) in diabetes may render the LDL particle more atherogenic, thereby increasing the atherogenic risk for diabetic patients ${ }^{144}$. Park and $\mathrm{CO}-$-workers showed that administration of the soluble extracellular domain of the receptor for AGEs 
(RAGE) completely suppressed diabetic atherosclerosis in streptozotocin-diabetic apolipoprotein E-deficient mice, in a manner independent of the level of glucose and lipids ${ }^{14 S}$.

Table 1.2 Pathogenic effects of AGEs

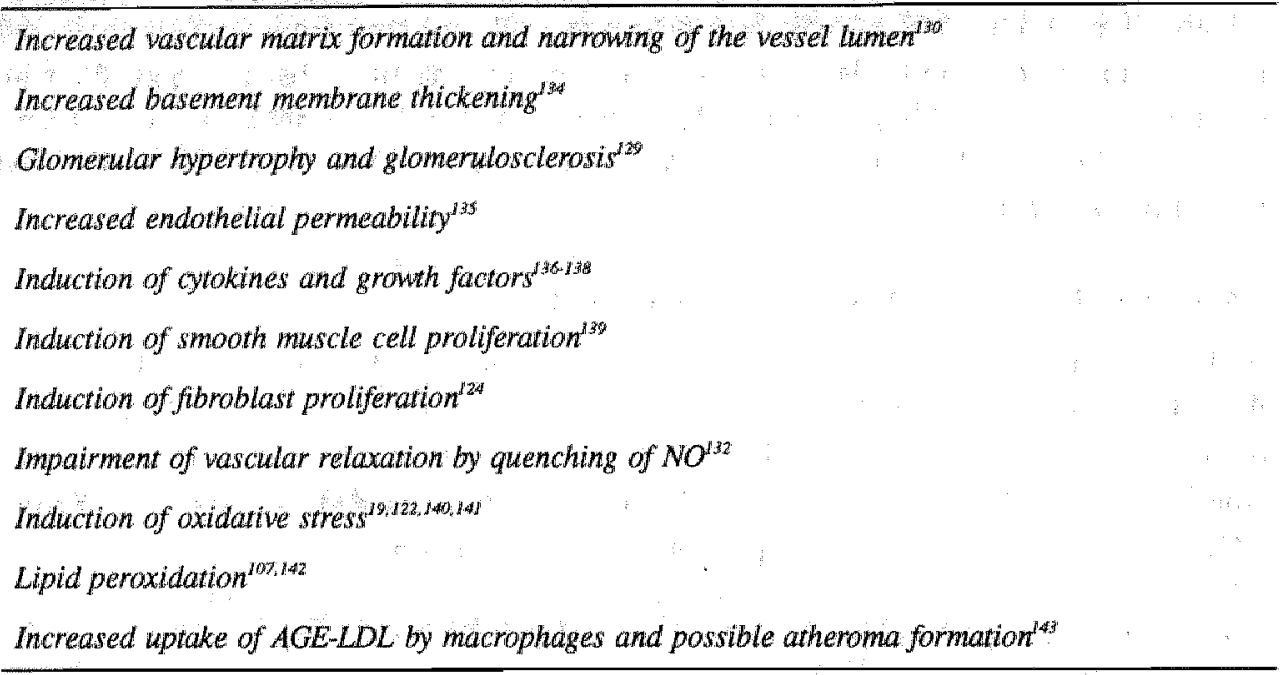

Multiple studies have shown that AGEs are important factors in the pathogenesis of nephropathy. Makita et al. showed that the increase in circulating AGE-peptides of diabetic patients correlates with the severity of renal function impairment ${ }^{125}$. Pharmacological inhibition of AGE-formation by aminoguanidine prevented the development of kidney lesions ${ }^{146}$, albuminuria and mesangial expansion in diabetic rats $^{147}$. Also the development of diabetes-related abnormalities of the retina could be prevented by this compound, indicating a prominent role for AGEs in this complication $^{148}$. Beisswenger and colleagues showed that formation of AGEs measured by ELISA in skin biopsies preceded and correlated with early manifestations of retinopathy as well as nephropathy ${ }^{149}$. Furthermore, arninoguanidine treatment reduced experimental diabetic neuropathy, as shown by a significant improvement of the reduced motor nerve conduction velocity, partially through the correction of the endoneurial microcirculation ${ }^{150}$.

Taking all this together, considerable evidence exists supporting that AGEs contribute prominently to the development and exacerbation of diabetic macro- and microvascular disease.

\section{Markers of advanced glycation}

Although the importance of studies on AGEs in diabetic complications has been acknowledged for several years, research on this topic has been hampered by the 
lack of methods to measure AGEs in blood and tissue samples, which are commonly available, adequate and easy to perform. Therefore, lots of hypotheses are based on experiments performed with AGE-inhibitors. Below; the methods are discussed which are used most frequently in the literature.

\section{Fluorescence}

AGEs exhibit a yellow-brown pigmentation and a characteristic fluorescence pattern, with excitation in the range $350-390 \mathrm{~nm}$ and fluorescence emission at 440 $470 \mathrm{~nm}$. In this way, AGEs have been measured by the use of fluorescence spectroscopy in serum and urine $\mathrm{e}^{151,152}$, but also in different kinds of tissues ${ }^{147}$.

However, the specificity of this method is rather low, because of the presence of non-AGE protein adducts, such as glucose- or lipid-derived oxidation products, with similar fluorescence spectra, because of interference by non-protein tissue components and because not all AGEs exhibit fluorescent properties ${ }^{153,154}$. Modifications of this classical approach have recently been proposed, using the combination of an on-line spectrophotometric and spectrofluorometric detection in a flow system ${ }^{155}$.

\section{High Performance Liquid Chromatography (HPLC)}

AGEs with known structures, such as pentosidine and CML, can be measured with a high degree of specificity using HPLC ${ }^{110,156}$. However, the AGEs with a known biochemical structure might only account for a small portion of the total amount of circulating and tissue AGEs. Whether the AGEs with known structure are representative for all the AGEs that are involved in the development and exacerbation of diabetic complications is also unclear.

\section{Collagen solubility}

The extracellular matrix protein collagen is highly prone to AGE-formation. The susceptibility of collagen to digestion by pepsin has been shown to provide an index of protein cross-linking ${ }^{157.159}$. In this method, often tissues are used with high amounts of collagen, like rat tail tendon, to increase specificity of the measurement. Therefore, this method only provides an indication of tissue AGE accumulation.

\section{Radioreceptor assay}

Radoff and co-workers ${ }^{160}$ developed a competitive radioreceptor assay based on AGE-specific receptors on the macrophage-like tumour cell line RAW 264.7. This assay has not been widely used, possibly due to the strong interference in this assay with polyanions such as heparin. 


\section{Immunoassays}

More frequently used techniques, nowadays, to measure circullating or tissue AGEs are immunochemical detection methods, using antibodies against AGEs. Nakkayama et al. ${ }^{161}$ were the first to produce and characterize antibodies raised against keyhole limpet haemocyanine-bound AGEs. The latter was prepared by incubating keyhole limpet haemocyanine with glucose for 28 days and used as AGE-immunogen to immunize guinea pigs. This resulted in a polyclonal anti-AGE antiserum that was used in an ELISA. Later, immunochemical detection of AGEs in vivo was performed using antibodies raised against bovine serum albumin (BSA)-AGE or RNase-AGE ${ }^{125,162}$. In this way, AGEs could be detected that were immunochemically different from characterized AGEs such as $\mathrm{CML}$, pentosidine and pyrraline ${ }^{126}$. Whether these antibodies recognize all AGEs produced in vivo is not certain yet. Horiuschi et al,${ }^{162}$ have suggested that there is a common structure in AGE modified macromolecules that interact with polyclonal antibodies. On the other hand, polyclonal antibodies against AGE-BSA or AGE-RNase failed to recognize $\mathrm{CML}^{126}$, which is claimed to be a dominant $\mathrm{AGE}$ in human serum albumin ${ }^{163}$ and in tissue proteins ${ }^{164}$.

On the contrary, Ikeda and co-workers demonstrated that polyclonal antibodies against AGE-BSA indeed recognized $C M L^{123}$. Some disadvantages of this method are that the polyclonal antibody is not commercially available, and that recently Dorrian et al. have found that there are factors in human serum which interfere with the measurement ${ }^{165}$. Also a method using monoclonal antibodies against CML to detect CML in an immunochemical way, is less reliable due to these factors ${ }^{165}$.

\section{Pharmacological interventions}

In view of the large impact on diabetic complications which is assigned to AGEs, the search for adlequate inhibitors has become a main topic in diabetes research. Even before precise methods for quantification of AGEs had been developed, the first inhibitors were available. Therefore, in multiple studies the effects of AGEinhibition have been evaluated to describe the possible role of AGEs in diabetic complications.

In 1986, Brownlee et al ${ }^{166}$ showed that aminoguanidine prevented both the formation of fluorescent AGEs and the formation of glucose-derived collagen crosslinks in vitro. Furthermore, administration of the drug to diabetic rats prevented fluorescent AGE-formation and cross-linking of arterial wall connective tissue protein in vivo. Aminoguanidine, a nucleophilic hydrazine compound, was previously used as an inhibitor of diamine oxidase, preventing the degradation of histamine ${ }^{167}$.

In table 1.3 possible sites of action of aminoguanidine are summarized.

Aminoguanidine prevents the formation of AGEs by reacting with Amadori-derived reactive intermediates (Figure 1.4). Incubation of model Amadori products with 
aminoguanidine produces a triazine compound which forms by the reaction of aminoguanidine with an amino-dideoxyosone, a reactive intermediate from Amadori products ${ }^{168}$. Aminoguanidine, however, does not interfere with already formed AGEs. Since its first description as a powerful tool to prevent AGEformation, multiple studies have been performed to evaluate its use in preventing diabetic micro- and macrovascular complications.

Amudion Product


Aminoguanatatine

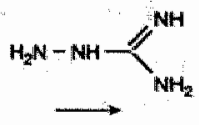

Triazane

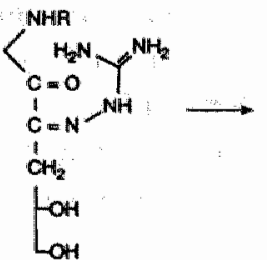

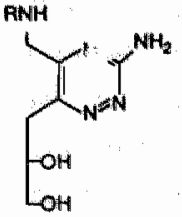

Figure 1.4 Prevention of AGE-formation by aminoguanidine. Adapted from Chen and Cerami ${ }^{168}$.

Apart from the above described action, aminoguanidine has been shown to reduce NO formation through inhibition of NO-synthase. Several studies claim that aminoguanidine selectively inhibits inducible NO-synthase ${ }^{169-172}$. However, Lazlo et al. ${ }^{173}$ showed that aminoguanidine inhibits both constitutive and inducible NOsynthase in the intestinal microvasculature in rats. Furthermore, treatment with aminoguanidine may also reduce oxidative stress by its action as a free radical scavenger ${ }^{174,175}$.

Although some authors contribute the beneficial effects of aminoguanidine in preventing diabetic complications to its NO-synthase inhibiting actions ${ }^{176,177}$ or its properties as a free radical scavenger ${ }^{174,175}$, most of the studies performed during the last decade accentuate that the AGE-preventing effects of aminoguanidine are the most likely in preventing complications in experimental diabetes.

Table 1.3 Possible sites of action of aminoguanidine

Prevention of formation of $A G E s^{\text {is }}$

Inhibition of inducible NO-synthase $e^{169-172}$

Inhibition of constitutive and inducible NO-synthase ${ }^{173}$

Scavenger of free radicals ${ }^{174,175}$

Prevention of histamine-degradation ${ }^{167.173}$

Studies in experimental diabetes have revealed that aminoguanidine treatment prevented or reduced nephropathy. Reduction of AGE accumulation ${ }^{179}$, 
albuminuria $^{147,16}$ and kidney lesions ${ }^{146}$ were established. Furthermore, the development of experimental diabetic retinopathy was inhibited by aminoguanidine treatment. Prevention of abnormal endothelial cell proliferation and microaneurysms, and reduction in pericyte dropout were established ${ }^{148}$. Moreover, aminoguanidine has beneficial effects on diabetic neuropathy. Increase in motor nerve conduction velocity, partially through correction of endoneurial microcirculation ${ }^{30}$, normalization of nerve blood flow and improvement of nerve conduction $^{181}$ were demonstrated. So it seems that treatment with aminoguanidine has beneficial effects on the prevention or reduction of all the principal microvascular complications, at least in experimental diabetes. Clinical studies with aminoguanidine are still in progress. The first preliminary data on aminoguanidine treatment in type 1 diabetic patients indicate a reduction in microvascular complications such as microalbuminuria and retinopathy (Alteon inc, personal communication).

In addition, aminoguanidine interferes with the development of atherosclerotic lesions: increasing elasticity and decreasing fluid filtration in large arteries ${ }^{57}$, decreasing levels of total cholesterol, triglycerides and LDL-cholesterol in diabetic patients treated with aminoguanidine ${ }^{144}$. Other aminoguanidine-like compounds, without an influence on NO-synthase, have recently been described. They exhibit similar effects as aminoguanidine: 2,3-diaminophenazine attenuated the development of diabetic mesenteric hypertrophy ${ }^{182}$; 4-amino-3-hydrazino-5isopropyl 4H-1,2,4-triazole and 3,5-diamino-4-hydroxy-benzoic acid dihydrochloride increased tail tendon collagen solubility in treated rats ${ }^{158}$.

In 1996, Vasan and collegues described a new compound that cleaves glucosederived protein cross-links in vitro and in vivo ${ }^{183}$. Its action is based on the assumption that AGEs are formed in a pathway involving reactive $\alpha$-dicarbonyl intermediates (Figure 1.5).

The AGE-breaker, N-phenacylthiazolium bromide, is able to break this $\alpha$ dicarbonyl bond, and can thereby remove established AGE-crosslinks (Figure 1.5).

We performed the first in vivo study in rats; showing that chronic treatment with an AGE-breaker restored large artery properties in experimental diabetes ${ }^{184}$ (see chapter 6). In 1999, Khalifah et al. described a novel group of inhibitors of the conversion of Amadori intermediates to AGEs, named "Amadorins" ${ }^{185}$. The therapeutic potential of these drugs is currently being investigated. 


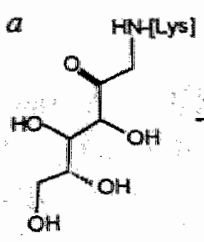

1<smiles>CC(O)C[C@H](O)C[C@@H](O)CO</smiles>

II

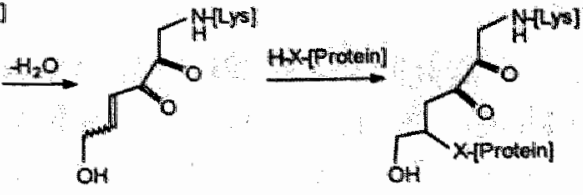

॥II
IV

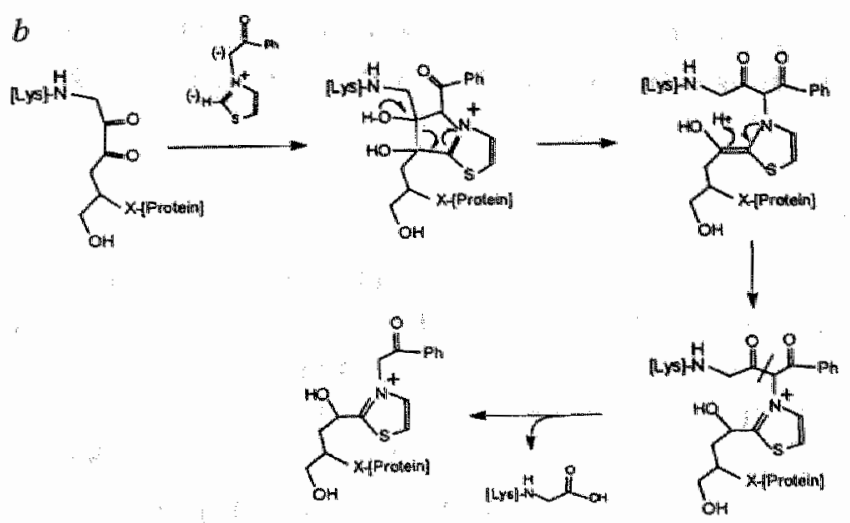

Figure 1.5 Scheme for the formation of glucose-derived protein crosslinks from Amadori products (AP) and cleavage by a thiazolium-based AGE breaker. From Vasain et al. ${ }^{189}$

$a$, Successive dehydration by $\beta$-elimination of protein-bound (lysine) Amadori products (I) to AP-dione (II), AP-ene-dione, (III), and reaction with a protein nucleophile (X-[Protein]) to form a stable protein-protein crosslink (IV).

b. Proposed reaction scheme for the cleavage of an AP-ene-dione-derived, proteinprotein crosslink by $\mathrm{N}$-phenacylthiazolium bromide (PTB).

\section{This thesis}

\section{Scope}

The aim of the present thesis was to get more insights in vascular dysfunction and hemodynamic changes in experimental diabetes. More specifically, the role of advanced glycation end products (AGEs) in diabetic complications was studied. To describe vascular dysfunction in diabetes, microvascular function, mechanical properties of small arteries and central hemodynamic characteristics were studied in streptozotocin-induced diabetic rats. Insights in the underlying mechanisms of vascular dysfunction were obtained by investigating vascular morphology, cyclic GMP production and by using pharmacological tools, interfering with the accumulation of advanced glycation end products. 


\section{The model}

Because it is impossible to perform the current experiments in diabetic patients, we used a rat model that approximates the human situation. The streptozotocin-induced diabetic rat is a widely used model to study vascular dysfunction in type 1 diabetes. Streptozotocin is an antibiotic extracted from Streptomyces acromogenes. Its action is charactarized by massive beta cell degranulation and necrosis ${ }^{186}$. Within $48 \mathrm{~h}$ hypoinsulinemia and hyperglycaemia develops. The dose of streptozotocin used in our studies $(70 \mathrm{mg} / \mathrm{kg})$ to induce diabetes in rats, aged 6 to 12 weeks, induces severe hyperglycaemia $(16-30 \mathrm{mmol} / \mathrm{l})$ without a need to supply insulin for survival.

\section{Research objectives}

Diabetes mellitus is associated with the development of micro- and macrovascular complications. In chapter 2 , the effect of 6 weeks $^{5}$ steptozotocin-induced diabetes on arteriolar reactivity was investigated. The arteriolar responses to vasoconstrictor agents (angiotensin II and norepinephrine) as well as vasodilators (acetylcholine and levcromakalim) were measured to characterize in vivo changes of microvascular reactivity. Aminoguanidine-treated diabetes and control groups were included to be able to speculate on the underlying mechanisms of the attenuated responses in diabetic rats.

Apart from alterations in microvascular reactivity, diabetic angiopathy may be characterized by changes in arterial mechanical properties. We therefore studied the elastic properties of mesenteric small arteries in diabetic and control rats by measuring cross-sectional compliance and distensibility (chapter 3).

In chapter 4, in vitro experiments were performed to investigate the signal transduction pathway of NO-mediated vascular relaxation in diabetic rats. Carotid artery segments were stimulated with endothelium-dependent or -independent vasodilators and subsequently the second messenger cyclic GMP was determined. The influence of an intact versus a disrupted endothelial layer was investigated and possible beneficial effects of aminoguanidine treatment were evaluated.

Apart from diabetes-induced cardiomyopathy, vascular changes in diabetes have an influence on central hemodynamics. In chapter 5, several central hemodynamic parameters, such as cardiac output and mean arterial pressure, were measured in conscious diabetic and control rats. Furthermore, morphological changes were evaluated in various arteries along the vascular tree. An attempt was made to search for a relationship between hemodynamic properties and vascular morphological changes in diabetes.

In anaesthetized diabetic rats, similar hemodynamic parameters were investigated (chapter 6). The underlying mechanism of disturbances in hemodynamics was unraveled by including a diabetic group that was curatively treated with an AGE- 
breaker.

Finally, data obtained in the different studies in this thesis are discussed in relation to each other and to the pathophysiology of diabetic complications (chapter 7).

\section{Research questions}

The questions investigated in this thesis were:

1 Does a six weeks period of hyperglycaemia lead to changes in microvascular reactivity in the streptozotocin-induced diabetic rat and is AGE accumulation involved?

2 Is the NO-dependent cyclic GMP production in the carotid artery influenced by long-term diabetes and does AGE accumulation play a prominent role in this ?

3 Does an intact endothelium play a protective role in vascular complications in experimental diabetes?

4 What is the effect of hemodynamic changes and AGE accumulation on arterial mechanical properties in experimental diabetes ?

5 Are hemodynamic mechanisms responsible for the adaptations in vascular morphology during experimental diabetes?

6 Is it possible to reverse disturbances in hemodynamics during experimental diabetes by means of pharmacological interference with AGE metabolism ? 


\section{References}

1. Bennett PH. Definition, diagnosis, and classification of diabetes mellitus and impaired glucose tolerance. In: Joslin's Diabetes Mellitus. 13th ed. (Kahn, CR, Weir,GC) Lea \& Febiger, Philadelphia 1994;193-200.

2. Ruwaard D, Hirasing RA, Reeser HM, Van Buuren $S$, Bakker $K$, Heine RJ, Geerdink RA, Bruining GI, Vaandrager GJ, Verloove-Vanhorick SP. Increasing incidence of type I diabetes in the Netherlands. Diabetes Care 1994;17:599-601.

3. Ruwaard D, Gijsen R, Bartelds AIM, Hirasing RA, Verkleij H, Kromhout D. Is the incidence of diabetes increasing in all age-groups in the Netherlands? Diabetes Care $1996 ; 19: 214-18$.

4. Atkinson MA, Maclaren NK. What causes diabetes? Scientific Am 1990;263:42-49.

5. Feener EP, King GL. Vascular dysfunction in diabetes mellitus. The Lancet 1997;350 (suppl.1):S19-S113.

6. Shami SK, Chittenden SJ. Microangiopathy in diabetes mellitus: II. Features, complications and investigation. Diabetes Res 1991;17:157-68.

7. Kreisberg JI. Hyperglycemia and microangiopathy. Direct regulation by glucose of microvascular cells. Laboratory Investigation 1992;416-26.

8. King GL, Banskota NK, Mechanisms of diabetic microvascular complications. In: Joslin's diabetes mellitus. 13 th ed. (Kahn,CR, Weir,GC) Lea \& Febiger, Philadelphia 1994;631-47.

9. Viberti GC, Hill RD, Jarrett RJ, Argyropoulos A, Mahmud U, Keen H. Microalbuminuria as a predictor of clinical nephropathy in insulin-dependent diabetes mellitus. Lancet 1982;1:1430-32.

10. Mattock MB, Morrish NJ, Viberti G, Keen H, Fitzgerald AP, Jackson G. Prospective study of microalbuminuria as predictor of mortality in NIDDM. Diabetes 1992;41:736-41.

11. Dejgaard A. Pathophysiology and treatment of diabetic neuropathy. Diabetic Med 1998; 15:97-112.

12. Fu CC, Wu TJ, Chang CJ, Wu HP, Tseng CH, Chuang LM, Chen MS, Chen CJ, Kao CS, Tai TY. Development of macrovascular dideases in NIDDM patients in Northern Taiwan. Diabetes Care 1993;16:137-43.

13. Kuusisto J, Mykkanen L, Pyorala K, Laakso M. NIDDM and its metabolic control predict coronary heart disease in elderly subjects. Diabetes 1994;43:960-67.

14. The Diabetes Control and Complications Trial Research Group. The effect of intensive trreatment of diabetes on the development and progression of long-term complications in insulin-dependent diabetes mellitus. New Engl J Med 1993;329: 977-86.

15. Wolffenbuttel BHR. The DCCT - metabolic control matters. Neth J Med 1993;43: $241-45$.

16. Turner RC, Millns H, Neil HAW, Stratton IM, Manley SE, Matthews DR, Holman RR. Risk factors for coronary artery disease in non-insulin-dependent diabetes mellitus: United Kingdom Prospective Diabetes Study (UKPDS:23). Br Med J 1998;316:823-28. 
17. Tomlinson DR, Stevens EJ, Diemel LT. Aldose reductase inhibitors and their potential for the treatment of diabetic complications. TPS 1994,15:293-97.

18. Tesfamariam B, Cohen RA. Free radicals mediate endothelial cell dysfunction caused by elevated glucose. Am J Physiol 1992;263:H321-26.

19. Baynes IW. Role of oxidative stress in development of complications in diabetes. Diabetes $1991 ; 40: 405-12$.

20. Brownlee M. Advanced protein glycosylation in diabetes and aging. Annu Rev Med $1995 ; 46: 223-34$.

21. Vlassara H. Recent progress in advanced gllycation endproducts and diabetic complications. Diabetes 1997;46 (suppl. 2):S19-25.

22. Rees DD, Palmer RMJ, Schulz $R$, Hodson HF, Moncada $S$. Characterization of three inhibitors of endothelial nitric oxide synthase in vitro and in vivo. $\mathrm{Br}$ Pharmacol 1990; 101:746-52.

23. Walter U. Physiological role of cGMP and oGMP-dependent protein kinase in the cardiovascular system. Rew Physiol Biochem Pharmacol 1989;113:41-88.

24. Kamata K, Miyata N, Abiru T, Kasuya Y. Functional changes in vascular smooth muscle and endothelium of arteries during diabetes mellitus. Life Sci 1992;50: 1379-87.

25. Pieper GM. Enhanced, unaltered and impaired nitric oxide-mediated endotheliumdependent relaxation in experimental diabetes mellitus: importance of disease duration. Diabetologia 1999;42:204-13.

26. Waldron GJ, Garland CJ. Contribution of both nitric oxide and a change in membrane potential to acetylcholine-induced relaxation in the rat small mesenteric artery. Br J Pharmacol 1994:112:831-36.

27. Taylor PD, Graves JE, Poston L. Selective impairment of acetylcholine-mediated endothelium-dependent relaxation in isolated resistance arteries of the streptozotocininduced diabetic rat. Clin Sci 1995;88:519-24.

28. Durante W, Sen $A K$, Sunahara FA. Impairment of endothelium-dependent relaxation in aortae from spontaneously diabetic rats. Br J Pharmacol 1988;94: 463-68.

29. Furman BL, Sneddon P. Endothelium-dependent vasodilator responses of the isolated mesenteric bed are preserved in long-term streptozotocin diabetic rats. Eur J Pharmacol 1993;232:29-34.

30. Mayhan WG. Impairment of endothelium-dependent dilatation of cerebral arterioles during diabetes mellitus. Am J Physiol 1989;256:H621-25.

31. Mulhern M, Docherty JR. Effects of experimental diabetes on the responsiveness of rat aorta. Br J Pharmacol 1989;97:1007-12.

32. Heesen BJ. Pharmacoiogical modulation of vascular abnormaluties in experimental diabetes. Thesis, University Maastricht 1996;143.

33. Pieper GM. Review of alterations in endothelial nitric oxide production in diabetes. Protective role of arginine on endothelial dysfunction. Hypertension 1998;31: 1047-70. 
34. Johnstone MT, Creager SJ, Scales KM, Cusco JA, Lee BK, Creager MA. Impaired endothelium-dependent vasodilation in patients with insulin-dependent diabetesmellitus. Circulation 1993;88:2510-16.

35. McNally $P G$, Watt $P A C$, Rimmer $T$, Burden $A C$, Hearnshaw JR Thurston $H$. Impaired contraction and endothelium-dependent relaxation in isolated resistance vessels from patients with insulin-dependent diabetes mellitus. Clin Sci 1994;87:31-36.

36. Mákimattila S, Virkamäki A, Groop PH, Cockcroft J, Utriainen T, Fagerudd J, Yki-Järvinen $\mathrm{H}$. Chronic hyperglycemia impairs endothelial function and insulin sensitivity via different mechanisms in insulin-dependent diabetes mellitus. Circulation 1996;94:1276-82.

37. Calver A, Collier $J$, Vallence $P$ : Inhibition and stimulation of nitric oxide synthesis in the human forearm arterial bed of patients with insulin-dependent diabetes. J Clin Invest $1992 ; 90: 2548-54$.

38. Smits P, Kapma IA, Jacobs MC, Lutterman J, Thien $T$. Endothelium-dependent vascular relaxation in patients with type I diabetes. Diabetes 1993;42:148-53.

39. Huvers FC, De Leeuw PW, Houben AJHM, De Haan CHA, Hamulyak K, Schouten $H$, Wolffenbuttel BHR, Schaper NC. Endothelium-dependent vasodilatation, plasma markers of endothelial function, and adrenergic vasoconstrictor responses in type 1 diabetes under near-normoglycemic conditions. Diabetes 1999;48:1300-07.

40. Elliott TG, Cockroft JR, Groop PH, Viberti GC, Ritter JM. Inhibition of nitric oxide synthesis in forearm vasculature of insulin-dependent diabetic patients: blunted vasoconstriction in patients with microalbuminuria. Clin Sci Colch 1993;85:687-93.

41. Lambert J, Aarsen M, Donker AJM, Stehouwer CDA. Endothelium-dependent and -independent vasodilation of large arteries in normoalbuminuric insulin-dependent diabetes mellitus. Arterioscler Thromb Vasc Biol 1996;705-11.

42. McVeigh G, Brennan G, Hayes R, Johnston D. Primary nitrate tolerance in diabetes mellitus. Diabetologia $1994 ; 37: 115-17$.

43. Tomlinson $\mathrm{KC}$, Gardiner SM, Hebden RA, Bennet T. Functional concequences of streptozotocin-induced diabetes mellitus, with particular reference to the cardiovascular system. Pharm Rev 1992;44:103-50.

44. Lash $\mathbf{J}$, Bohlen HG. Structural and functional origins of suppressed acetylcholine vasodilation in diabetic rat intestinal arterioles. Circ Res 1991;69:1259-68.

45. Hill MA, Ege EA. Active and passive mechanical properties of isolated arterioles from STZ-induced diabetic rats. Effect of aminoguanidine treatment. Diabetes 1994;43:1450-56.

46. Chang KS, Stevens WC. Endothelium-dependent increase in vascular sensitivity to phenylephrine in long-term streptozotocin diabetic rat aorta. $\mathrm{Br} \mathrm{J}$ Pharmacol 1992;107:983-90.

47. Hill MA, Larkins RG. Altered microvascular reactivity in streptozotocin-induced diabetes in rats. Am J Physiol 1989;257:H1438-45. 
48. Taylor PD, Oon $\mathrm{BB}$, Thomas $\mathrm{CR}$, Poston $\mathrm{L}$. Prevention by insulin treatment of endothelial dysfunction but not enhanced noradrenaline-induced contractility in mesenteric resistance arteries from streptozotocin -induced diabetic rats. $\mathrm{Br} \mathrm{J}$ Pharmacol 1994;111:35-41.

49. Abebe W, MacLeod KM. Enhanced arterial contractility to noradrenaline in diabetic rats is associated with increased phosphoinositide metabolism. Can J Physiol Pharmacol 1991;69:355-61.

50. Chang KC, Chung SY, Chong WS, Suh JS, Kim SH, Hoh HK, Seong BW, Ko HJ, Chun KW. Possible superoxide radical-induced alteration of vascular reactivity in aortas from streptozotocin-treated rats. J Pharmacol Exp Ther 1993;266:992-1000.

51. Christlieb AR, Janka HU, Kraus B, Gleason RE, licasas-Cabral EA, Aiello LM, Cabral BV, Solano A. Vascular reactivity to angiotensin II and to norepinephrine in diabetic subjects. Diabetes 1976;25:268-74.

52. O'Rourke MF, Brunner HR. Introduction to arterial compliance and function. $J$ Hypertens 1992;10 (suppl 6):S3-S5.

53. Yin FCP, Ting CT. Compliance changes in physiological and pathological states. $J$ Hypertens 1992;10 (suppl 6):S31-S33.

54. Mc Veigh GE. Arterial compliance in hypertension and diabetes mellitus. Am J Nephrol 1996;16:217-22.

55. Megnien JL, Simon A, Valensi P, Flaud P, Merli I, Levenson J. Comparative effects of diabetes mellitus and hypertension on physical properties of human large arteries. J Am Coll Cardiol 1992;20:1562-68.

56. Hu J, Wallensteen $M$, Gennser $G$. Increased stiffness of the aorta in children and adolescents with insulin-dependent diabetes mellitus. Ultrasound in Med \& Biol 1996;22:537-43.

57. Huijberts MSP, Wolffenbuttel BHR, Struijker Boudier HAJ, Crijns FRL, Nieuwenhuijzen Kruseman AC, Poitevin P, Lévy BI. Aminoguanidine treatment increases elasticity and decreases fluid filtration of large arteries from diabetic rats. J Clin Invest 1993;92:1407-11.

58. Kannel WB, McGee DL. Diabetes and cardiovascular disease. The Framingham study. JAMA 1979;241:2035-38.

59. D'Elia JA, Weinrauch LA, Healy RW, Libertino JA, Bradley RF, Leland OS. Myocardial dysfunction without coronary artery disease in diabetic renal failure. Am J Cardiol 1979;43:193-99.

60. Hamby RI, Zoneraich S, Sherman L. Diabetic cardiomyopathy. JAMA 1974;229: 1749-54.

61. Penpargkul S, Schaible T, Yipintsoi T, Scheuer J. The effect of diabetes on performance and metabolism of rat hearts. Circ Res 1980;47:911-21.

62. Rodrigues $\mathrm{B}, \mathrm{McNeill} \mathrm{JH}$. Cardiac dysfunction in isolated perfused hearts from spontaneously diabetic BB rats. Can J Physiol Pharmacol 1990;68:514-18.

63. Smith JM, Paulson DJ, Romano FD. Inhibition of nitric oxide synthase by LNAME improves ventricular performance in streptozotocin-diabetic rats. J Mol Cell Cardiol 1997;29:2393-2402. 
64. Hill MA, Larkins RG. Alterations in distribution of cardiac output in experimental diabetes in rats. Am J Physiol 1989;257:H571-80.

65. Christlieb AR. Diabetes and hypertensive vascular disease. Mechanisms and treatment. Am J Cardiol 1973;32:592-606.

66. Drury PL. Diabetes and arterial hypertension. Diabetologia 1983;24:1-9.

67. Factor SM, Borczuk A, Charron MJ, Fein FS, van Hoeven KH, Sonnenblick EH. Myocardial alterations in diabetes and hypertension. Diab Res Clin Pract 1996;31 (suppl.):S133-S42.

68. Ewing DJ. Diabetic autonomic neuropathy and the heart. Diab Res Clin Pract 1996;30 (suppl.):\$31-\$36.

69. Rodrigues B, McNeill JH. The diabetic heart: metabolic causes for the development of a cardiomyopathy. Cardiovase Res 1992;26;913-22.

70. Malhotra A, Sanghi V. Regulation of contractile proteins in diabetic heart. Cardiovasc Res 1997;34:34-40.

71. Pierce GN, Russell JC. Regulation of intracellular $\mathrm{Ca} 2+$ in the heart during diabetes. Cardiovase Res 1997;34:41-47.

72. Lee TS, Saltsman KA, Ohashi $H$, King GL. Activation of protein kinase C by elevation of glucose concentration: proposal for a mechanism in the development of diabetic vascular complications. Proc Natl Acad Sci USA 1989;86:5141-45.

73. Inoguchi T, Battan R, Handler E, Sportsman JR, Heath W, King GL. Preferential elevation of protein kinase $\mathrm{C}$ isoform beta II and diacylglycerol levels in the aorta and heart of diabetic rats: differential reversibility to glycemic control by islet cell transplantation. Proc Natl Acad Sci USA 1992;89:11059-63.

74. Williamson JR, Chang $K$, Frangos $M$, Hasan K, Ido $Y$, Kawamura T, Nyengaard JR, Van den Enden M, Kilo C, Tilton RG. Hyperglycemic pseudohypoxia and diabetic complications. Diabetes 1993;42:801-13.

75. Dai FX, Diederich A, Skopec J, Diederich D. Diabetes-induced endothelial dysfunction in streptozotocin-treated rats - role of prostaglandin endoperoxides and free radicals. J Am Soc Nephrol 1993;4:1327-36.

76. Keeley FW, Elmoselhi A, Leenen FHH. Enalapril suppresses normal accumulation of elastin aand collagen in cardiovascular tissues of growing rats. Am J Physiol 1992;262:H1013-21.

77. Tesfamariam B, Brown ML, Deykin D, Cohen RA. Elevated glucose promotes generation of endothelium- derived vasoconstrictor prostanoids in rabbit aorta. J Clin Invest 1990;85:929-32.

78. Tomlinson DR, Willars $\mathrm{GB}$, Carrington $\mathrm{AL}$. Aldose reductase inhibitors and diabetic complications. Pharmac Ther 1992;54:151-94.

79. Pugliese G, Tilton RG, Speedy A, Oates PJ, Williamson JR. Effects of combined insulin and sorbinil treatment on diabetes-induced vascular dysfunction in rats. Metabolism 1994;43:492-500.

80. Otrer DJ, Chess-Williams R. The effects of aldose reductase inhibition with ponalrestat on canges in vascular function in streptozotocin diabetic rats. $\mathrm{Br} J$ Pharmacol 1994;113:576-80. 
81. Brownlee $M$, Cerami $A$, Vlassara $H$. Advanced products of nonezymatic glycosylation and the pathogenesis of diabetic vascular disease. Diabetes/Metab Rev $1988 ; 4: 437.51$.

82. Kaiser N, Sasson S, Feener EP, Boukobza-Vardi N, Higashi $S$, Moller DE, Dabidheiser S, Prsybylski RJ, King GL. Differential regulation of ghcose transport and transporters by glucose in vascular endothelial and smooth muscle cells. Diabetes 1993;42:80-89.

83. Xia P, Inoguchi T, Kern TS, Engerman RL, Oates PJ, King GL. Characterisation of the mechanism for the chronic activation of diacylglycerol-protein kinase $\mathrm{C}$ pathway in diabetes and hypergalactosemia. Diabetes 1994;43:1122-29.

84. Geng YJ, Wu Q, Hansson GK. Protein kinase C activation inhibits cytokine-induced nitric oxide synthesis in vascular smooth muscle cells. Biochimica et Biophysica Acta $1994 ; 1223: 125-32$.

85. Hill MA, Falcone $\mathrm{JC}$, Meininger GA. Evidence for protein kinase $\mathrm{C}$ involvement in arteriolar myogenic reactivity. Am J Physiol 1990;259:H1586-94.

86. Hemperl A, Maasch C, Heintze U, Lindschau $C$, Dietz $\mathbb{R}$, Luft FC, Haller $H$. High glucose concentrations imcrease endothelial cell permeability via activation of protein kinase C alfa. Circ Res 1997;81:363-71.

87. Wolf BA, Williamson JR, Easom RA, Chang $\mathrm{K}$, Sherman WR, Turk J. Diacylglycerol accumulation and microvascular abnormalities induced by elevated glucose levels. J Clin Invest 1991;87:31-38.

88. King GL, Kunisaki M, Nishio $\mathrm{Y}$, Inoguchi $T$, Shiba T, Xia P. Biochemical and molecular mechanisms in the development of diabetic vascular complications. Diabetes 1996;45:S105-S8.

89. Hawthorne GC, Bartlett $\mathrm{K}$, Hetherington CS, Alderti KGMM. The effect of high glucose on polyol pathway activity and myoinositol metabolism in cultured human endothelial cells. Diabetologia 1989;32:163-66.

90. Greene DA, Lattimer SA, Sima AAF. Sorbitol, phphoinositides, and sodiumpotassium-ATPase in the pathogenesils of diabetic complications. New Engl J Med 1987;316:599-606.

91. Cameron NE, Cotter MA. Contraction and relaxation of aortas from galactosaemic rats and the effects of aldose reductase inhibition. Eur J Pharmacol 1993;243:47-53.

92. Frank RN. Perspectives in diabetes. The aldose reductase controversy, Diabetes 1994;43:169-72.

93. van Gerven JM, Tjon A Tsien AM. The efficacy of aldose reductase inhibitors in the maanagement of diabetic complications. Comparison with intensive insulin treatment and pancreatic transplantation. Drugs Aging 1995;6:9-28.

94. Narayanan S. Aldose reductase and its inhibition in the control of diabetic complications. Ann Clin Lab Sci 1993;23: 148-58.

95. Giugliano D, Ceriello A, Paolisso $G$. Oxidative stess and diabetic vascular complications. Diabetes Care 1996;19:257-67.

96. Sinclair AJ. Free radical mechanisms aannd vascular complications of diabetes mellitus. Diabetes reviews 1993;2:7-10. 
97. Baynes JW, Thorpe SR. Role of oxidative stress in diabetic complications. A new perspective on an old paradigm. Diabetes 1999:48:1-9.

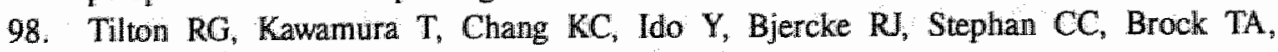
Williamson JR. Vascular dysfunction induces by elevated glucose levels in rats is mediated by vascular endothelial growth factor. I Clin Inwest 1997;99:2192-2202.

99. Aiello LP, Avery RL, Arrigg PG, Keyt BA, Jampel HD, Shah ST, Pasquale LR, Thieme H, Iwamoto MA, Park JE, Nguyen HV, Aiello LM, Ferrara N, King GL. Vascular endothelial growth factor in ocular fluid of patients with diabetic retinopathy and other retinal disorders. New Engl J Med 1994;331:1480-87.

100. Ceriello A. Coagulation activationn in diabetes mellitus: the role of hyperglycaemia and therapeutic prospects. Diabetologia 1993;36:1119-25.

101. Ohgushi $M$, Kugiyama $K$, Fukunaga $K$, Murohara $T$, Sugiyama $S$, Miyamoto $E$, Yasue $H$. Protein kinase $\mathrm{C}$ inhibitors prevent impairment of endothelium-dependent relaxation by oxidatively modified LDL. Arterioscl Thromb 1993;13:1525-32.

102. Galle J, Bassenge $E$, Busse R. Oxidized low density lipoproteins potentiate vasoconstrictions to various agonists by direct interaction with vascular smooth muscle. Circ Res 1990;66:1287-93.

103. Bucala $R$, Vlassara $H$, Cerami $A$. Advanced glycosylation endproducts: role in diabetic and non-diabetic vascular disease. Drug development research 1994;32: $77-89$.

104. Maillard LC. Action des acides aminés sur les sucres; formation des melanoidines par voie methodique. C R Hebd Sceances Acad Sci 1912;154:66-68.

105. Knecht K, Feather MS, Baynes JW. Detection of 3-deoxyfructose and 3deoxyglucosone in human urine and plasma: evidence for intermediate stages of the Maillard reaction in vivo. Archives of Biochemistry and Blophysics 1992;294: 130-37.

106. Brownlee $M$, Vlassara $H$, Cerami A. Nonenzymatic glycosylation and the pathogenesis of diabetic complications. Ann Int Med 1984;101:527-37.

107. Bucala R, Makita Z, Koschinsky T, Cerami A, Vlassara H. Lipid advanced glycosylation: pathway for lipid oxidation in vivo. Proc Natl Acad Sci USA 1993;90:6434-38.

108. Seidel W, Pischetsrieder M. DNA-glycation leads to depurination by the loss of N2carboxyethylguanine in vitro. Cell mol Biol 1998;44:1165-70.

109. Wolffenbuttel BHR, Giordano D, Founds HW, Bucala R. Long-term assessment of glucose control by haemoglobin-AGE measurement. The Lancet 1996;347:513-15.

110. Ahmed MU, Thorpe SR, Baynes JW. Identification of N-Carboxymethyllysine as a degradation product of fructoselysine in glycated protein. $J$ Biol Chem 1986;261:4889-94.

111. Sell DR, Monnier VM. Structure elucidation of a senescence cross-link from human extracellular matrix. J Biol Chem 1989;264:21597-602.

112. Hayase F, Nagaraj RH, Miyata S, Njoroge FG, Monnier VM. Aging of proteins: immunological detection of a glucose-derived pyrrole formed during Maillard reaction in vivo. J Biol Chem 1989;263:3758-64. 
113. Obayashi $H$, Nakano $K$, Shigeta $H$, Yamaguchi $M$, Yoshimori $K$, Fukui $M$, Fujii

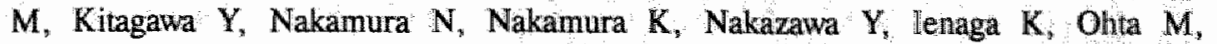
Nishimura M, Fukui I, Kondo M. Formation of Crossline as a fluorescent adwanced glycation end product in vitro and in vivo. Biochem Biophys Res Commun $1996 ; 226: 37-41$.

114. Schleicher ED, Wagner E, Nerlich AG. Increased accurmulation of the glycoxidation product $\mathrm{N}$-(carboxymethyl)lysine in human tissues in diabetes and aging. I Clin Invest 1997;99:457-68.

115. Dunn JA, Ahmed MU, Murtiashaw MH, Richardson JM, Walla MD, Thorpe SR, Baynes JW. Reaction of ascorbate with lysine and protein under autoxidizing conditi ons: formation of $\mathrm{N}$-(carboxymethyl)lysine by reaction between lysine and products of autoxidation of ascorbate. Biochemistry 1990;29:10964-70.

116. Vlassara $H$, Brownlee $M$, Cerami $A$. High affinity receptor mediated uptake and degradation of glucose modified proteins: a potential mechanism for the removal of scenescent macromolecules. Proc Natl Acad Sci USA 1985;82:5588-92.

117. Thornalley PI. Cell activation by glycated proteins. AGE receptors, receptor recognition factors and functional classification of AGEs. Cell mol Biol 1998;44: $1013 \times 23$.

118. Schmidt AM, Hasu M, Popov D, Zhang JH, Chen J, Yan SD, Brett $J$, Cao R, Kuwabaara K, Costache G, Simionescu S, Simionescu M, Stern D. Receptor for advanced glycation end products (AGEs) has a central role in vessel wall interactions and gene activity in response to circulating AGE proteins. Proc Natl Acad Sci USA 1994;91:8807-11.

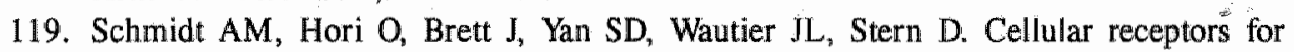
advanced glycation endproducts. Implications for induction of oxidant stress and cellular dysfunction in the pathogenesis of vascular lesions. Arterioscl Thromb 1994; 14:1521-28.

120. Schmidt AM, Yan SD, Stern DM. The dark side of glucose. Nature Med 1995;1: 1002-4.

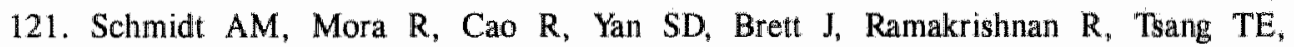
Simionescuu M, Stern D. The endothelial cell binding site for advanced glycation endproducts consists of a complex: An integral membrane protein and a lactoferrinlike polypeptide. J Biol Chem 1994;269:9882-88.

122. Yan SD, Schmidt AM, Anderson GM, Zhang J, Brett J, Zou YS, Pinsky D, Stern D. Enhanced cellular oxidant stress by the interaction of advanced glycation end products with their receptors/binding proteins. J Biol Chem 1994;269:9889-97.

123. Ikeda $K$, Higashi $T$, Sano $H$, Jinnouchi $Y$, Yoshida $M$, Araki $T$, Ueda $S$, Horiuchi S. $N$-(Carboxymethyl)lysine protein adduct is a major immunological epitope in proteins modified with advanced glycation end products of the Maillard reaction. Biochemistry 1996;35:8075-83.

124. Vlassara $H$, Bucala $\mathbb{R}$, Striker $L$. Pathogenic effects of advanced glycosylation: biochemical, biologic, and clinical implications for diabetes and aging. Laboratory Investigation 1994;70:138-51. 
125. Makita $Z_{*}$ Radoff $S_{n}$ Rayfield $E$, Yang $Z$; Skoinik $E$, Delanay $V$, Friedman EA, Cerami A, Vlassara H. Advanced glycosylated end products in patients with diabetic nephropathy. New Engl J Med 1991;325:836-42.

126. Makita $Z$, Vlassara $H$, Cerami $A$, Bucala $R$. Immunochemical detection of advanced glycosylation end products in vivo. J Biol Chem 1992;267:5133-38.

127. Berg TJ, Dahl- \ørgensen $K$, Torjesen PA, Hanssen KF. Increased serum levels of advanced glycation end products (AGEs) in children and adolescents with IDDM. Diabetes Care 1997;20:1006-8.

128. Vlassara H, Fuh H, Makita Z, Krungkrai S, Cerami A, Bucala R. Exogenous advanced glycosylation end products induce complex vascular dysfunction in normal animals: a model for diabetic and aging complications. Proc Natl Acad Sci USA 1992;89: 12043-47.

129. Vlassara H, Striker LJ, Teichberg S, Fuh H, Li YM, Steffes M. Advanced glycation end products induce glomerular sclerosis and albuminuria in normal rats. Proc Natl Acad Sci USA 1994;91:11704-08.

130. Rumble IR, Cooper ME, Soulis T, Cox A, Wu L, Youssef S, Jasik M, Jerums G, Gilbert RE. Vascular hypertrophy in experimental diabetes: Role of advanced glycation end products. $J$ Clin Invest 1997;99:1016-27.

131. Airaksinen KEJ, Salmela PI, Linnaluoto MK, Ikăheimo MJ, Ahola K, Ryhänen LJ. Diminished arterial elasticity in diabetes: association with fluorescent advanced glycosylation end products in collagen. Cardiovasc Res 1993;27:942-45.

132. Bucala R, Tracey KJ, Cerami A. Advanced glycosylation products quench nitric oxide and mediate defective endothelium-dependent vasodilatation in experimental diabetes. J Clin Invest 1991;87:432-38.

133. Rodríguez-Mañas L, Arribas $S$, Girón $C$, Villamor J, Sánchez-Ferrer $\mathrm{CF}$, Marín J. Interference of glycosylated human hemoglobin with endothellum-dependent responses. Circulation 1993;88:2111-16.

134. Brownlee $\mathrm{M}$, Cerami A, Vlassara $\mathrm{H}$. Advanced glycosylation end products in tissue and the biochemical basis of diabetic complications. New Engl J Med 1988;318: $1315-21$.

135. Esposito C, Gerlach H, Brett J, Stern D, Vlassara H. Endothelial receptor-mediated binding of glucose-modified albumin is associated with increased monolayer permeability and modulation of cell surface coagulant properties. I Exp Med $1989 ; 170: 1387-1407$.

136. Kirstein M, Aston C, Hintz R, Vlassara H. Receptor-specific induction of insulinlike growth factor $\mathrm{I}$ in human monocytes by advanced glycosylation end productmodified proteins. J Clin Invest 1992;90:439-46.

137. Vlassara $H$, Brownlee $M$, Manogue KR, Dinarello CA, Pasagian A. Cachectin/TNF and IL-1 induced by glucose-modified proteins: role in normal tissue remodeling. Science $1988 ; 240: 1546-48$.

138. Yang $\mathrm{CW}$, Vlassara $\mathrm{H}$, Peten EP, He CJ, Striker GE, Striker LJ. Advanced glycation end products up-regulate gene expression found in diabetic glomerular disease. Proc Natl Acad Sci USA 1994;91:9436-40. 
139. Hogan $M$, Cerami $A$, Bucala R. Advanced glyeosylation endproducts block the antiproliferative effect of nitric oxide. Role in the vascular and renal complications of diabetes mellitus. I Chin Invest 1992;90:1110-15.

140. Wolff SP. Diabetes mellitus and free radicals. British Medical Bulletin 1993; 49 : $642-52$.

141. Kashiwagi A, Asahina T, Nishio $Y$, Ikebuchi $M$, Tanaka $Y$, Kikkawa $R$, Shigeta $Y$. Glycation, oxidative stress, and scavenger activity. Glucose metabolism and radical scavenger dysfunction in endothelial cells. Diabetes 1996;45:S84-86.

142. Bucala $R$, Makita $Z$, Vega $G$, Grundy $S$, Koschinsky $T$, Cerami A, Vlassara $H$. Modification of low density lipoprotein by advanced glycation end products contributes to the dyslipedemia of diabetes and renal insufficiency. Proc Natl Acad Sci USA 1994;91:9441-45.

143. Dobrian A, Lazar V, Tirziu D, Simionescu M. Increased macrophage uptake of irreversibly glycated albumin modified-low density lipoproteins of normal and diabetic subjects is mediated by non-saturable mechanisms: Biochimica et Biophysica Acta 1996;1317:5-14.

144. Bucala R. Lipoprotein modification by advanced glycosylation endproducts (AGEs): Role in atherosclerosis. Trends Cardiowasc Med 1997;7:39-47.

145. Park L, Raman KG, Lee KJ, Lu Y, Ferran LJ, Chow WS, Sternm D, Schmidt AM. Suppression of accelerated diabetic atherosclerosis by the soluble receptor for advanced glycation endproducts. Nature Med 1998;4:1025-31.

146. Kumari $K$, Murthy PSR, Sahib MK. Monoaminoguanidine prevents sorbitol accumulation, nonenzymatic protein glycosylation and development of kidney lesions in diabetic rats. Experientila 1991;47:252-54.

147. Soulis-Liparota $T$, Cooper M, Papazoglou D, Clarke B, Jerums G. Retardation by aminoguanidine of development of albuminuria, mesangial expansion, and tissue fluorescence in streptozocin-induced diabetic rat. Diabetes 1991;40:1328-34.

148. Hammes HP, Martin S, Federlin K, Geisen K, Brownlee M. Aminoguanidine treatment inhibits the development of experimental diabetic retinopathy. Proc Natl Acad Sci USA 1991;88:11555-58.

149. Beisswenger PJ, Makita $Z$, Curphey TJ, Moore LL, Jean $S_{*}$ Brinck-Johnsen $T$, Bucala $R$, Vlassara $H$. Formation of immunochemical advanced glycosylation end products precedes and correlates with early manifestations of renal and retinal disease in diabetes. Diabetes 1995;44:824-29.

150. Sugimoto $\mathrm{K}$, Yagihashi $\mathrm{S}$. Effects of aminoguanidine on structural alterations of microvessels in peripheral nerve of streptozotocin diabetic rats. Microvasc Res 1997;53:105-12,

151. Makita Z, Bucala R, Rayfield EJ, Friedman EA, Kaufman AM, Korbet SM, Barth RH, Winston JA, Fuh $H$, Manogue KR, Cerami A, Vlassara H. Reactive glycosylation endproducts in diabetic uraemia and treatment of renal faillure. Lancet $1994 ; 343: 1519-22$. 
152. Thome J, Muinch $G$, Müller $R$, Schinzzel $R$, Kornhuber $J$, Blum-Degen $D$, Sitzmarin L, Rösler $M$, Heidland A, Riederer $P$. Advanced glycation endproductsassociated parameters in the peripheral blood of patients with Alzheimer's disease. Life Sei 1996;59:679-85.

153. Brennan $M$. Changes in solubility, non-enzymatic glycation, and fluorescence of collagen in tail tendons from diabetic rats. J Biol Chem 1989;264:20947-209522.

154. Hammer C, Braum E. Quantification of age pigments (lipofuscin). Comp Biochem Pliysiol [B] 1988;90:7-17.

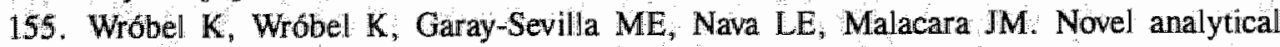
approach to monitoring advanced glycosylation end products in human serum with on-line spectrophotometric and spectrofluorometric detection in a flow system. Clin Chem 1997;43:1563-69.

156. Tákahashi $M$, Hoshino $H$, Kushida $K$, Inoue T. Direct measurement of crosslinks, pyridinoline, deoxypyridinoline, and pentosidine, in the hydrolysate of tissues using high-performance liquid chromatography. Anal Biochem 1995;232:158-62.

157. Brennan $M$. Changes in the cross-linking of collagen from rat tail tendons due to diabetes. J Biol Chem 1989;264:20953-60.

158. Kochakian M, Manjula BN, Egan JJ. Chronic dosing with aminoguanidine and novel advanced glycosylation end product-formation inhibitors ameliorates crosslinking of tail tendon collagen in STZ-induced diabetic rats. Diabetes 1996;45: 1694-1700.

159. Monnier VM, Kolnn RR, Cerami A. Accelerated age-related browning of human collagen in diabetes mellitus. Proc Natl Acad Sci USA 1984;81:583-87.

160. Radoff S, Makita Z, Vlassara H. Radioreceptor assay for advanced glycosylation end products. Diabetes 1991;40:1731-38.

161. Nakayama H, Taneda S, Kuwajima S, Aoki S, Kuroda Y, Misawa K, Nakagawa S. Production and characterization of antibodies to advanced glycation products on proteins. Biochem Biophys Res Commun 1989;162:740-45.

162. Horiuchi $S$, Araki $N$, Morino $Y$. Immunochemical approach to characterize advanced glycation end products of the Maillard reaction. J Biol Chem 1991;266: 7329-32.

163. Takanashi $M$, Sakurai $T$, Tsuchiya $S$. Identification of the carboxymethyllysine residue in the advanced stage of glycated human serum albumin. Chem Pharm Bull 1992;40:705-8.

164. Reddy S, Bichler J, Wells-Knecht KJ, Thorpe SR, Baynes JW. N-(Carboxymethyl)lysine is a dominant advanced glycation end product (AGE) antigen in tissue proteins. Biochemistry 1995;34:10872-78.

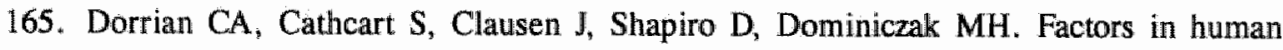
serum interfere with the measurement of advanced glycation endproducts. Cell mol Biol 1998;44:1069-79.

166. Brownlee $M$, Vlassara $H$, Kooney $A$, Ulrich $P$, Cerami A. Aminoguanidine prevents diabetes-induced arterial wall protein cross-linking. Science 1986;232:1629-32. 
167. Arunlakshana O, Mongar JL, Schild HO Potentiation of pharmacological effects of histamine by histaminase inhibitors. J Physiol 1954;123:32-54.

168. Chen HJC, Cerami A. Mechamism of inhibition of advanced glycosylation by aminoguanidine in witro. J Carbohydrate Chem $1993 ; 12: 731-42$.

169. Hasan K, Heesen BJ, Corbett JA, McDaniel ML, Chang K, Allison W, Wolffenbuttel BH, Williamson JR, Tilton RG. Inhibition of nitric-oxide formation by guanidines. Eur J Pharmacol 1993;249; 101-6.

170. Misko TP, Moore WM, Kasten TP, Nickols GA, Corbett JA, Tilton RG, McDaniel ML, Williamson JR, Currie MG. Selective-inhibition of the inducible nitric-oxide synthase by aminoguanidine. Eur J Pharmacol 1993;233:119-25.

171. Griffiths MJ, Messent M, Macallister RJ, Evans TW. Aminoguanidine selectively inhibits inducible nitric-oxide synthase. Br J Pharmacol 1993;110;963-68.

172. Wolff DJ, Lubeskie A. Aminoguanidine is an isoform-selective, mechanism-based inactivator of nitric oxide synthase. Archives of Biochemistry and Biophysics 1995;316:290-301.

173. Laszlo F, Evans SM, Whittle BJR. Aminoguanidine inhibits both constitutive and inducible nitric oxide synthase isoforms in rat intestinal microvasculature in vivo. Eur J Pharmacol 1995;272:169-75.

174. Kedziora-Kornatowska $K Z$, Luciak $M$, Blaszzcyk $J$, Pawlak $W$. Effect of aminoguanidine on the generation of superoxide anion and nitric oxide by peripheral blood granulocytes of rats with streptozotocin-induced diabetes. Clin Chim Acta $1998 ; 278: 45-53$.

175. Kedziora-Kornatowska KZ, Luciak M, Blaszcyk J, Pawlak W. Effect of aminoguanidine on erythrocyte lipid peroxidation and activities of antioxidant enzymes in experimental diabetes. Clin Chem Lab Med 1998;36:771-75.

176. Corbett JA, Tilton RG, Chang K, Hasan KS, Ido $Y$, Wang JL, Sweetland MA, Lancaster JR, Williamson JR, McDaniel ML. Aminoguanidine, a novel inhibitor of nitric oxide formation, prevents diabetic vascular dysfunction. Diabetes $1992 ; 41$ : $552-56$.

177. Tilton RG, Chang $K$, Hasan KS, Smith SR, Petrash JM, Misko TP, Moore WM, Currie MG, Corbett JA, McDaniel ML, Williamson JR. Prevention of diabetic vascular dysfunction by guanidines. Inhibition of nitric oxide synthase versus advanced glycation end-product formation. Diabetes 1993;42:221-32.

178. Nilsson $\mathrm{BO}$, Kockum $\mathrm{I}$, Rosengren $\mathrm{E}$. Effects of aminoguanidine and L-Name on histamine-induced blood pressure drop in the rat. Acta Physiol Scand 1997"161: 339-44.

179. Soulis T, Cooper ME Vranes D, Bucala R, Jerums G. Effects of aminoguanidine in preventing experimental diabetic nephropathy are related to duration of treatment. Kidney Int 1996;50:627-34.

180. Nyengaard JR, Chang $K$, Berhorst $S$, Reiser $K M$, Williamson JR, Tilton RG. Discordant effects of guanidines on renal structure and function and on regional vascular dysfunction and collagen changes in diabetic rats. Diabetes 1997;46: 94-106. 
181. Kihara M, Schmelzer JD, Poduslo JF, Curran GL, Nickander KK. Aminoguanidine effects on nerve blood flow, vascular permeability, electrophysiology, and oxygen free radicals. Proc Natl Acad Sci USA 1991;88:6107-11.

182. Soulis $T$, Sastra $S$, Thallas $V$, Mortensen $S B$, Wilken $M$, Clausen JT, Bjerrum OJ, Petersen H, Lau 1 Jeruns G, Boel E, Cooper ME. A novel inhibitor of advanced glycation end-product formation inhibits mesenteric vascular hypertrophy in experimental diabetes. Diabetologia 1999;42:472-79.

183. Vasan $S$, Zhang $X$, Zhang $X$, Kapurniotu $A$, Bernhagen J, Teichberg $S$, Basgen J, Wagle D, Shih. D, Terlecky I, Bucala R, Cerami A, Egan J, Uirich P. An agent cleaving glucose-derived protein crosslinks in vitro and in vivo. Nature 1996;382; $275-78$.

184. Wolffenbuttel BHR, Boulanger CM, Crijns FRL, Huijberts MSP, Poitevin P, Swennen GNM, Vasan $S$, Egan J, Uirich P, Cerami A, Lévy BI. Breakers of advanced glycation end products restore large artery properties in experimental diabetes. Proc Natl Acad Sci USA 1998;95:4630-34.

185. Khalifah RG, Baynes JW, Hudson BG. Amadorins: novel post-Amadori inhibitors of advanced glycation reactions. Biochem Biophys Res Commun 1999;257:251-58.

186. Junod A, Lambert AE, Orci L, Pictet R, Gonet AE, Renold AE. Studies of the diabetogenic action of streptozotocin. Proc Soc Exp Biol Med 1967;126:201-05. 


\section{Chapter 2}

\section{Arteriolar reactivity in conscious diabetes rats. Influence of aminoguanidine treatment}

FRL Crijns, HAJ Struijker Boudier, BHR Wolffenbuttel.

Diabetes 1998;47:918-923 


\section{Abstract}

The effect of 6 weeks streptozotocin (STZ)-induced $\left(70 \mathrm{mg} \cdot \mathrm{kg}^{-1}\right.$ ) diabetes and aminoguanidine (AG) treatment (50 mg. $\mathrm{kg}^{-1}$ s.c. or $250-750 \mathrm{mg} \cdot \mathrm{l}^{-\mathrm{r}}$ in drinking water) on arteriolar reactivity to vasoactive substances was investigated in conscious rats. Studies were performed in untreated control rats $(n=13)$, STZ-induced diabetic rats $(n=11)$, $A G$ treated control rats $(n=12)$ and AG-treated diabetic rats $(n=12)$. Rats were provided with a dorsal microcirculatory chamber that allowed intravital microscopy of striated muscle arterioles of varying diameter ( $\mathrm{A} 1$, large; $\mathrm{A} 2$, intermediate; $\mathrm{A} 3$, small arterioles) in conscious animals. The mean arterial pressure (MAP) and arteriolar diameter responses to intravenous infusion of the following drugs were examined: the endothelium-dependent vasodilator acetylcholine (ACh; 3, 10 and $\left.30 \mu \mathrm{g} \cdot \mathrm{kg}^{-1} \cdot \mathrm{min}^{-1}\right)$, the potassium-channel opener leveromakalim ( $\mathrm{LC} ; 30 \mu \mathrm{g} \cdot \mathrm{kg}^{-1}$ ), and the vasoconstrictor agents angiotensin II (AngI; 0.1 and $0.3 \mu \mathrm{g} \cdot \mathrm{kg}^{-1} \cdot \mathrm{min}^{-1}$ ) and noradrenaline (NA; $0.2,0.6$, and $\left.2.0 \mu \mathrm{g} \cdot \mathrm{kg}^{-1} \cdot \mathrm{min}^{-1}\right)$. Baseline MAP was lower in both diabetes groups versus the nondiabetic groups $(P<0.05)$. AG treatment had no influence on baseline MAP. The absolute change in MAP after drug infusion tended to be lower in the diabetic rats than in their nondiabetic littermates. Arteriolar vasodilatory responses to $\mathrm{ACh}$ and $\mathrm{LC}$ were attenuated in the diabetic animals ( $1 \pm 7$ vs. $19 \pm 7 \%(P<0.05)$ and $7 \pm 3$ vs. $34 \pm 8 \%,(P<0.01)$ in $A 2$, respectively). AG treatment of diabetic animals did not prevent the development of this disturbance. Vasoconstrictor responses were not influenced by the diabetic state. In the intermediate arterioles of AG-treated control rats, a hyperresponse was observed after AngII infusion $(-10 \pm 2$ vs $-2 \pm 2 \% ; P<0.05)$ and a hyporesponse was observed after $\mathrm{ACh}$ and $\mathrm{LC}$ infusion ( $2 \pm 3$ and $15 \pm 6 \%$ respectively; $P<0.05$ vs. untreated control rats). These data indicate that 6 weeks of experimental diabetes is associated with a decreased endotheliumdependent and -independent vasodilatation. Aminoguanidine treatment had no beneficial effect on this disturbance. 


\section{Introduction}

Diabetes mellitus is associated with a high risk for the development of micro- and macrovascular complications. Impaired vascular reactivity to vasoactive substances is an important marker of early vascular dysfunction in diabetes mellitus. However, most available studies have involved macrovascular disturbances, and only a few reports exist about early in vivo diabetes-related microvascular dysfunction. Arteriolar responses to endothelium-dependent vasodilators appear to be impaired in diabetic rats ${ }^{1-3}$. Furthermore, noradrenaline and angiotensin II have been shown to induce hyperconstriction in the smaller cremaster arterioles of streptozotocin (STZ)-induced diabetic rats ${ }^{4,5}$. Yet all these studies were performed in anesthetized animals. Because anesthesia per se and the kind of anesthesia used are known to have a profound effect on vascular reactivity, there is a need to study diabetesrelated microvascular disturbances in conscious animals $\mathrm{s}^{6,7}$. Kiff et al, reported that acetylcholine ( $\mathrm{ACh}$ )-induced vasodilatation was normal in the hindquarters of conscious diabetic rats, whereas relaxation to bradykinin was markedly impaired ${ }^{8}$. However, in this model total hindquarter flow was measured, which is predominantly determined by resistance arteries and not by the more distally located arterioles. The first purpose of the present study was to investigate the effect of experimental diabetes on microvascular reactivity in conscious rats.

The pathogenesis of vascular disturbances in diabetes mellitus has not yet been fully elucidated. It has been suggested that the defective endothelium-dependent vasodilatation in diabetes is mediated by an increased formation of advanced glycation end products (AGEs) $)^{9}$. Treatment with aminoguanidine (AG), an inhibitor of AGE formation, has been shown to prevent or reduce several macro- and microvascular complications in experimental diabetes ${ }^{10-12}$. However, some authors $^{10,13}$ have suggested that the beneficial effect of $A G$ in reducing diabetic complications may be due to its inhibition of nitric oxide synthase. The second purpose of this study was, therefore, to investigate the influence of chronic AG treatment on microvascular function in experimental diabetes.

\section{Research design and methods}

\section{Animals}

Inbred male Wistar Rp rats (Central Animal Services, Maastricht University, Maastricht, The Netherlands) were studied. All rats were caged individually and had free access to drinking water and normal rat diet. Rats were at random divided into four groups 2 weeks after implantation of the dorsal microcirculatory chamber (see below): an untreated control group $(\mathrm{n}=13)$, an untreated diabetic group 
$(\mathrm{n}=11)$, an $\mathrm{AG}$-treated control group $(\mathrm{n}=12)$, and an $\mathrm{AG}$-treated diabetic group $(\mathrm{n}=12)$. Diabetes was induced by an intraperitoneal injection of STZ $(70 \mathrm{mg} / \mathrm{kg})$ dissolved in citrate buffer ( $\mathrm{pH} 4.5$ ). Control animals received vehicle only. Aminoguanidine hemisulphate was administered daily by subcutaneous injections ( $50 \mathrm{mg}, \mathrm{kg}^{-1}$ day ${ }^{-1}$ ) or in the drinking water $(750 \mathrm{mg} / \mathrm{f}$ for control animals, $250 \mathrm{mg} /$ for diabetic animals). The dosage in the drinking water was three times lower for the diabetic animals because their water intake is three times higher than that of nondiabetic animals. Treatment started as soon as diabetes was established (i.e., within $48 \mathrm{~h}$ ). Rats developing blood glucose levels $>15 \mathrm{mM}$, as measured using a Haemogluko test kit (Bcehringer Mannheim, Almere, The Netherlands), were included in the diabetes groups. Six weeks after diabetes induction, blood glucose and $\mathrm{HbA}_{\mathrm{I}}$ levels were measured by hexokinase and high-performance liquid chromatography methods, respectively, and arteriolar reactivity was assessed. In the literature, there is convineing evidence that microvascular complications already exist at 6 weeks $^{3,5}$. The experimental procedures were performed according to institutional guidelines and approved by the Ethical Committee for the Use of Experimental Animals of the Maastricht University.

\section{Dorsal microcirculatory chamber preparation}

The dorsal microcirculatory chamber was implanted in rats weighing 130-140 g. This model allows measurements of striated muscle arterioles in conscious rats and is described in detail elsewhere ${ }^{14,15}$. Briefly, rats were anesthetized with ketamine and xylazine ( 5 and $1 \mathrm{mg} / \mathrm{kg} \mathrm{i.m.,} \mathrm{respectively)} \mathrm{and} \mathrm{pentobarbital} \mathrm{(30} \mathrm{mg/kg} \mathrm{i.p.).}$ The cutaneous maximus muscle on the dorsal side of the rat was gently seperated from the covering skin and placed in a thermoneutral polycarbonate chamber.

Conscious rats were placed in a rodent restrainer during microvascular measurements. They had been intensively trained to sit in this restrainer for 1-2 hours so that they would be unstressed during the experiment. The microvasculature was observed through an intra-vital microscope coupled to a video system. Arterioles of the cutaneous maximus muscle were classified according to branching order and internal diameter at baseline. According to this classification, A1 arterioles $(80-140 \mu \mathrm{m})$ are the primary perfusion arterioles, and their branches are designated second order (A2; 40-80 $\mu \mathrm{m})$ and third order arterioles (A3; 20-40 $\mu \mathrm{m}$ ).

\section{Experimental protocol}

One day before the start of the experiments, a venous catheter was inserted in a femoral vein for infusion of vasoactive drugs, and an arterial catheter was inserted in a femoral artery for on-line registration of arterial pressure. Experiments were performed on two seperate days. On one day, either vasodilator drugs (ACh $[3,10$, $\left.30 \mu \mathrm{g} \cdot \mathrm{kg}^{-1} \cdot \mathrm{min}^{-1}\right]$ followed by the potassium channel opener levcromakalim (LC; 
$30 \mu \mathrm{g} / \mathrm{kg}$ bolus) or vasoconstrictor drugs (NA $\left[0.2,0.6,2 \mu \mathrm{g} \cdot \mathrm{kg}^{-1} \cdot \mathrm{min}^{-1}\right]$ and AngII $\left[0.1,0.3 \mu \mathrm{g} \cdot \mathrm{kg}^{-1} \cdot \mathrm{min}^{-1}\right]$ given at random) were infused intravenously in a random order except that $\mathrm{LC}$ was always administered after $\mathrm{ACh}$ because of its relatively long duration of action. In a pilot experiment, it was verified that saline infusion with the same infusion rate and during the same observtion period had no influence on arteriolar diameters. Video recordings were made of each class of arteriole-first, baseline video recordings of each selected arteriole were made, and then, as increasing dosages of a drug were infused, video recordings of the same selected arterioles were made after each dose. After the first drug, a washout period of 30 min was allowed before the second drug was infused on the same day. Internal diameters were analysed off-line with an image shearing device.

\section{Mean arterial blood pressure measurement}

Mean arterial blood pressure (MAP) was monitored continuously during the experiment. The arterial catheter was connected to a low-volume displacement pressure transducer (CP-01; Century Technology, Inglewood, CA). After low-pass filtering of the signal, MAP was recorded on a Grass 7D polygraph (Grass Instruments, Quincy; MA).

\section{Drugs}

STZ, aminoguanidine hemisulphate, NA and AngII were supplied by Sigma" (St. Louis, MO). ACh was supplied by Dispersa (Winterthur, Switzerland). LC was a gift from SmithKline Beecham (Harlow, Essex, UK).

\section{Statistics}

In each animal, several vessel segments per arteriolar class were studied. Mean diameter calculations of 14-34 segments per treatment group are shown. Because no differences in arteriolar function or MAP were detected between daily subcutaneous injections of $\mathrm{AG}$ and the addition of the drug to drinking water, results from these treatment groups were combined. Differences between groups were tested by analysis of variance Student-Newman-Keuls correction for multiple comparisons. Data are expressed as mean \pm SE. $P<0.05$ was considered statistically significant.

\section{Results}

\section{Animal characteristics}

Both untreated and AG-treated diabetic rats showed marked hyperglycaemia, 
significantly higher $\mathrm{HbA}_{\mathrm{ic}}$ levels, and significantly lower body weights compared with untreated or AG-treated control groups (Table 2.1). MAP before infusion of drugs was slightly but significantly lower $(P<0.05)$ in both groups of diabetic animals compared with their nondiabetic littermates (Table 2:1). AG treatment had no significant effect on body weight, glucose levels, or MAP in control or diabetic animals.

Table 2.1 Animal characteristics

\begin{tabular}{|c|c|c|c|c|}
\hline 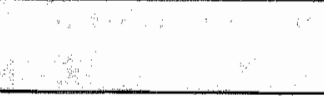 & $\begin{array}{c}\text { Untreated } \\
\text { control rats }\end{array}$ & $\begin{array}{c}\text { Untreated } \\
\text { diabetic rats }\end{array}$ & $\begin{array}{l}\text { AG-treated } \\
\text { control rats }\end{array}$ & $\begin{array}{l}\text { AG-treated } \\
\text { diabetic rats }\end{array}$ \\
\hline Body weight (g) & $251 \pm 6$ & $179 \pm 5^{t}$ & $237 \pm 6$ & $171 \pm 7^{4}$ \\
\hline Blood glucose (mmolli) & $6.8 \pm 0.6$ & $24.0 \pm 1.4^{t}$ & $7.3 \pm 0.5$ & $23.4 \pm 1.11$ \\
\hline $\mathrm{HbA}_{\mathrm{ic}}(\%)$ & $1.3 \pm 0.1$ & $3.8 \pm 0.5^{t}$ & $1.2 \pm 0.1$ & $2.9 \pm 0.4$ \\
\hline $\mathrm{MAP}(\mathrm{mmHg})$ & $124 \pm 1$ & $117 \pm 2^{*}$ & $126 \pm 2$ & $121 \pm 2^{*}$ \\
\hline
\end{tabular}

Data are means $\pm \mathrm{SE},{ }^{*} P<0.001$ vs. untreated control animals; ${ }^{\ddagger} P<0.05$, $P<0.01$, and $\mathbb{P}<0.001$ vs. $\mathrm{AG}$-treated control animals.

Table 2.2 Change in MAP (mmHg) after infusion of vasoactive substances.

\begin{tabular}{|c|c|c|c|c|}
\hline & $\begin{array}{l}\text { Untreated } \\
\text { control rats }\end{array}$ & $\begin{array}{l}\text { Untreated } \\
\text { diabetic rats }\end{array}$ & $\begin{array}{l}\text { AG-treated } \\
\text { control rats }\end{array}$ & $\begin{array}{l}\text { AG-treated } \\
\text { diabetic rats }\end{array}$ \\
\hline \multicolumn{5}{|c|}{ ANG II $\left(\mu \mathrm{g} \cdot \mathrm{kg}^{-1} \cdot \min ^{-1}\right)$} \\
\hline 0.1 & $28 \pm 5$ & $28 \pm 5$ & $33 \pm 5$ & $23 \pm 3$ \\
\hline 0.3 & $46 \pm 4$ & $42 \pm 3$ & $49 \pm 4$ & $34 \pm 3^{t}$ \\
\hline \multicolumn{5}{|c|}{ Noradrenaline $\left(\mu \mathrm{g} \cdot \mathrm{kg}^{-1} \cdot \mathrm{min}^{-1}\right)$} \\
\hline 0.2 & $9 \pm 3$ & $4 \pm 1$ & $6 \pm 1$ & $4 \pm 1$ \\
\hline 0.6 & $18 \pm 4$ & $12 \pm 4$ & $24 \pm 2$ & $11 \pm 2^{t}$ \\
\hline 2 & $36 \pm 5$ & $29 \pm 3$ & $40 \pm 3$ & $25 \pm 3^{t}$ \\
\hline \multicolumn{5}{|c|}{ Acetylcholine $\left(\mu \mathrm{g} \cdot \mathrm{kg}^{-1} \cdot \mathrm{min}^{-1}\right)$} \\
\hline 3 & $-2 \pm 1$ & $0 \pm 1$ & $-2 \pm 1$ & $0 \pm \mathbb{1}$ \\
\hline 10 & $-5 \pm 1$ & $-2 \pm 1$ & $4 \pm 1$ & $-2 \pm 1$ \\
\hline 30 & $-9 \pm \mathbb{1}$ & $-3 \pm 2^{*}$ & $-9 \pm 1$ & $-3 \pm 1^{*}$ \\
\hline \multicolumn{5}{|c|}{ Levcromakalim $\left(\mu \mathrm{g} \cdot \mathrm{kg}^{-1}\right)$} \\
\hline 30 & $-15 \pm 2$ & $-8 \pm 2$ & $-13 \pm 2$ & $-11 \pm 2$ \\
\hline
\end{tabular}

Data are means $\pm \mathrm{SD} . * P<0.05$ ws. untreated control animals; ${ }^{\dagger} P<0.05$ vs. AG-treated control
animals.

\section{MAP response to vasoactive drugs}

Table 2.2 summarizes the effects of AngII, NA, ACh and LC infusions on the absolute change in MAP. AngII as well as NA caused a dosage-dependent increase in MAP in all groups of animals. Untreated diabetic rats tended to have lower blood pressure rises than control animals, but this difference was not statistically 
significant. In the $\mathrm{AG}$-treated diabetic rats, the increase in MAP due to the highest Angll dosage and the two highest NA dosages was significantly smaller than that of the AG-treated nondiabetic animals. However, AG treatment per se had no effect on pressure changes.

Infusion of $\mathrm{ACh}$ lowered MAP to a small extent but in a dosage-dependent manner. The decrease in MAP was significantly smaller during infusion of the highest dose of $\mathrm{ACh}$ in the two groups of diabetic animals compared with their nondiabetic controls. A bolus injection of $30 \mu \mathrm{g} / \mathrm{kg} \mathrm{LC}$ caused a decrease in MAP, which tended to be smaller in the diabetic animals but did not reach statistical significance. $A G$ treatment had no significant effect on blood pressure changes in control and diabetic rats compared with the untreated animals.

\section{Arteriolar diameter response to vasoactive drugs}

Mean base-line diameters before the start of drug administration ranged from $93 \pm$ $3 \mu \mathrm{m}$ to $111 \pm 4 \mu \mathrm{m}$ for A1 arterioles, $57 \pm 3 \mu \mathrm{m}$ to $67 \pm 3 \mu \mathrm{m}$ for A2 arterioles, and $30 \pm 1 \mu \mathrm{m}$ to $35 \pm 1 \mu \mathrm{m}$ for $\mathrm{A} 3$ arterioles. There were no significant differences in baseline values between the four groups of animals.

AngII infusion resulted in arteriolar constriction in all groups of animals (Figure 2.1).

Angiotensin $\|$
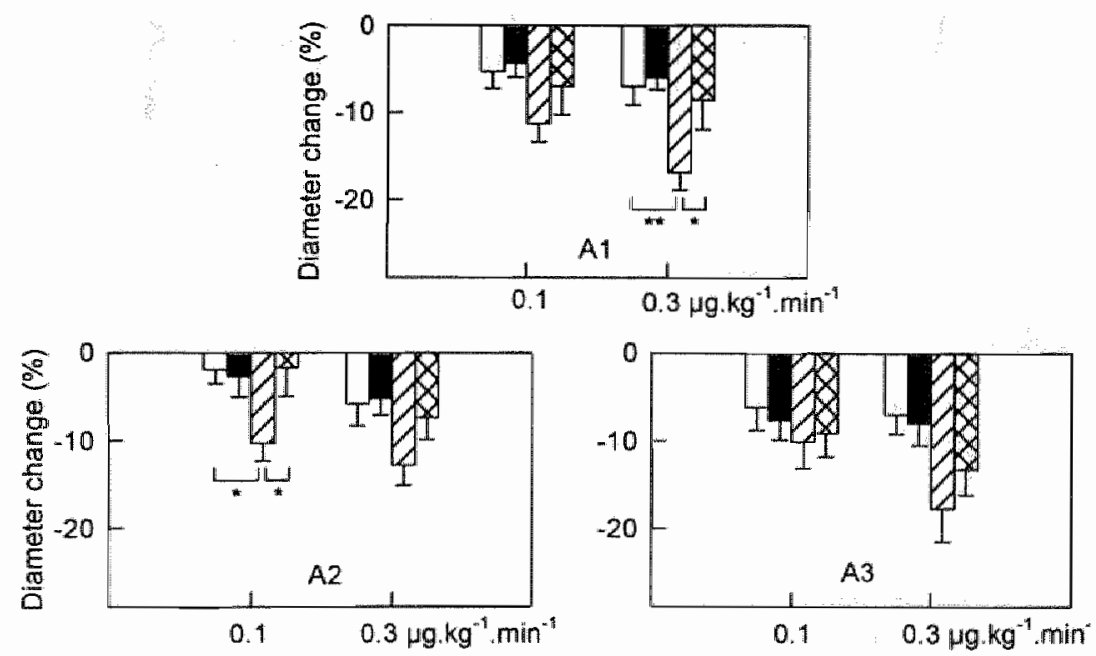

Figure 2.1 Influence of AngII infusion $\left(0.1\right.$ and $\left.0.3 \mu \mathrm{g} \cdot \mathrm{kg}^{-1} \cdot \mathrm{min}^{-1} \quad \mathrm{i} . \mathrm{v}_{\mathrm{v}}\right)$ on arteriolar diameters in the cutaneous maximus muscle of conscious rats. Open bars represent mean percentage decrease in diameter for untreated control rats, filled bars for untreated diabetic rats, hatched bars for aminoguanidine treated control rats and cross-hatched bars for aminoguanidine treated diabetic rats. $" P<0.05,{ }^{* *} P<0.01$. 
The amount of arteriolar constriction was comparable between untreated control and diabetic animals at every level of the arteriolar tree. Also, the diameter decrease after AngII infusion in the AG-treated diabetic animals was not different from the diameter change in their untreated littermates, yet the AG-treated control animals showed a higher arteriolar constriction compared with the untreated control animals. This tendency towards hyperconstriction in AG-treated control animals was clear within all three arteriolar classes but reached statistical significance in A1 only after $0.3 \mu \mathrm{g} \mathrm{kg}^{-1} \cdot \mathrm{min}^{-1}$ AngII $(-16 \pm 2 \%$ vs. $-7 \pm 2 \%$ in control animals, $P<0.01)$ and in $\mathrm{A} 2$ only after $0.1 \mu \mathrm{g} \cdot \mathrm{kg}^{-1} \cdot \mathrm{min}^{-1}$ AngII $(-10 \pm 2 \%$ vs. $-2 \pm 2 \%$ in control animals, $P<0.05$ ). Infusion of increasing dosages of NA caused dosagedependent decreases in internal diameters that were comparable in treated and untreated diabetic and control animals (Figure 2.2).


Figure 2.2 Influence of noradrenaline infusion $\left(0.2,0.6\right.$ and $2 \mu \mathrm{g} \cdot \mathrm{kg}^{-1} \cdot \mathrm{min}^{-1} \mathrm{i} . \mathrm{v}$ ) on arteriolar diameters in the cutaneous maximus muscle of conscious rats. Open bars represent mean percentage decrease in diameter for untreated control rats, filled bars for untreated diabetic rats, hatched bars for aminoguanidine treated control rats and cross-hatched bars tor aminoguanidine treated diabetic rats.

ACh dilated the striated muscle arterioles of untreated and $\mathrm{AG}$-treated control rats, whereas it had almost no effect or caused a small constriction in untreated and $A G$ treated diabetic rats (Figure 2.3). The highest ACh dose $\left(30 \mu \mathrm{g} \cdot \mathrm{kg}^{-1} \cdot \mathrm{min}^{-1}\right)$ evoked a dilatation in $A 1$ arterioles of $13 \pm 3 \%$ in untreated control animals and $12 \pm 3 \%$ in AG-treated control animals, whereas the responses in the untreated and AG-treated diabetic animals were $1 \pm 3 \%$ and $-1 \pm 3 \%$ respectively. In $A 3$ arterioles, the same 
trend was observed. Although the difference between untreated diabetic and controll animals was not statistically significant $(6 \pm 3$ in C vs. $-2 \pm 3 \%$, NS), there was again a significant difference between the AG-treated control and diabetic animals

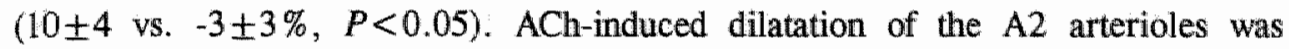
attenuated not only in the untreated and $A G$-treated diabetic groups $(1 \pm 7$ and $-4 \pm 4 \%$, respectively) but also in the $A G$-treated control animals $(2 \pm 3 \%$ vs. $19 \pm 7 \%$ in untreated control animals, $P<0.05$ ). A bolus injection of $30 \mu \mathrm{g} / \mathrm{kg} \mathrm{LC}$ caused a marked dilatory response. At all arteriolar levels, this response was attenuated in the untreated diabetic rats compared with the untreated controll animals $(-3 \pm 2$ vs. $15 \pm 3 \%$ in $\mathrm{A} 1[P<0.05], 7 \pm 3$ vs. $34 \pm 8 \%$ in $\mathrm{A} 2[P<0.01]$, and $14 \pm 5 \%$ vs. $38 \pm 7 \%$ in $A 3[P<0.05]$ ) (Figure 2.4 ). After LC injection, the arteriolar response of the AG-treated diabetic animals was comparable with that of the untreated diabetic animals $(-1 \pm 3$ in $\mathrm{A} 1,2 \pm 5$ in $\mathrm{A} 2$ and $16 \pm 8 \%$ in A3). LC induced the same amount of vasodilatation in AG-treated and untreated control rats in the $A 1$ and $A 3$ arterioles $(13 \pm 5$ and $27 \pm 5 \%$ respectively), whereas the response was attenuated in $\mathrm{A} 2$ vessels (15 \pm 6 [AG-treated control animals] vs. $34 \pm 8 \%$ [untreated control animals]; $P<0.05)$.
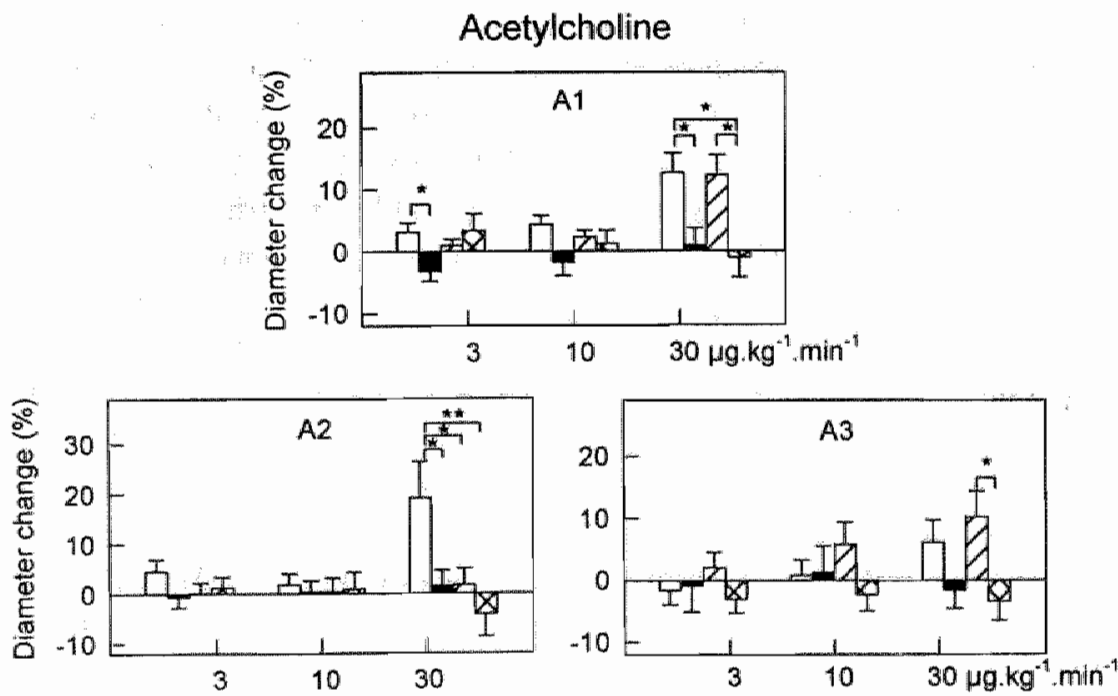

Figure 2.3 Infiuence of acetylcholine infusion (2, 10 and $\left.30 \mu \mathrm{g.kg} \cdot \mathrm{min}^{-1 /} \mathrm{i} . \mathrm{w}^{-}\right)$on arteriolar diameters in the cutaneous maximus muscle of conscious rats. Open bars represent mean percentage decrease in diameter for untreated control rats, filled bars for untreated diabetic rats, hatched bars for aminoguanidine treated control rats and cross-hatched bars for aminoguanidine treated diabetic rats. " $P<0.05,{ }^{*} " P<0.01$ 


\section{Levcromakalim}

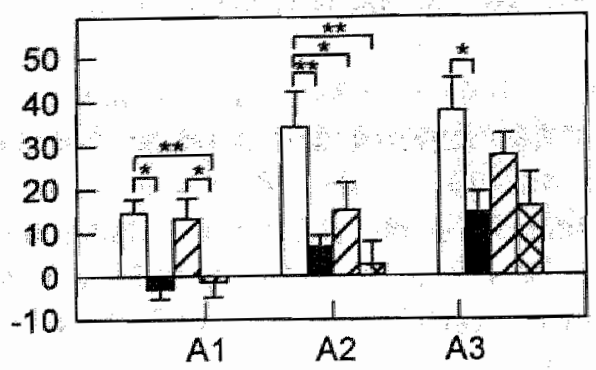

Figure 2.4 Influence of a bolus injection leveromakalim $\left(30 \mu \mathrm{g} \cdot \mathrm{kg}^{-1} \cdot \mathrm{min}^{-4}\right.$ i.v.) on arteriolar diameters in the cutaneous maximus muscle of conscious rats. Open bars represent mean percentage change in diameter for untreated control rats, filled bars for untreated diabetic rats, hatched bars for aminoguanidine treated control rats and cross-hatched bars for aminoguanidine treated diabetic rats. $*<0.05, * * P<0,01$

\section{Discussion}

This study showed that after 6 weeks of STZ-induced diabetes, arteriolar vasodilatory responses to infusions of the vasodilators $\mathrm{ACh}$ and $\mathrm{LC}$ were impaired in conscious rats, whereas reactivity to the vasoconstrictors AngII and NA remains unaffected. Furthermore, we demonstrated that 6 weeks of AG treatment-whether in dosages of $50 \mathrm{mg} \cdot \mathrm{kg}^{-1}$. day ${ }^{-1}$ s.c. or $250 \mathrm{mg} / 1$ added to drinking water-did not prevent the development of microvascular dilatory disturbances in diabetic rats. Moreover, AG treatment of nondiabetic animals results in a hyperconstriction to AngII in large- and intermediate-size arterioles, and less vasodilatation to $\mathrm{ACh}$ and LC in intermediate-size arterioles.

Until this study, no data were available on arteriolar responsiveness to vasoactive agents in conscious diabetic animals. Anesthesia can influence microcirculatory responses ${ }^{6}$, because it was unknown whether the effects of anesthesia were the same in diabetic and control animals, it was important to study diabetes-related microvascular changes in conscious animals. We therefore used the dorsal microcirculatory chamber model, which allowed intravital microscopy in awake animals; the animals used in this study were also unstressed due to prior extensive training. In the preparation, three different classes of arterioles were distinguished according to branching order and internal diameter at baseline. They showed anatomical differences and differences in sensitivity to pharmacological tools ${ }^{16-18}$. Although systemic blood pressure is influenced in this model by infusing drugs intravenously, Struijker Boudier et al. ${ }^{19}$ showed that the diameter changes in the arterioles of the cutaneous maximus muscle are mainly determined by the local 
effect of the infused drug. In that study, the nonpharmacologically hemorrhageinduced effect on microvascular diameter was seen only at a much higher degree of blood pressure decrease as compared with the effects caused by ACh or LC in the present study.

AG treatment resulted in a slight but not significant increase in MAP, indicating that no acute nitric oxide synthase inhibitory effect could be observed after chronic AG treatment. The changes in MAP due to drug infusions tended to be smaller in both diabetic groups compared with in the control groups (Table 2.2). This agrees with the studies of $\mathrm{Yu}$ and $\mathrm{McNeill{ } ^ { 2 0 }}$ and Jackson and Carrier ${ }^{21}$. One might speculate that the infused dosage in the diabetic animals is lower because of their hyperglycaemia-induced lower body weight. However, this is probably not the case, as blood volume per unit of body weight was comparable in control and diabetic rats 6 weeks after diabetes induction (data not shown).

Bucala et al. ${ }^{9}$ suggested that the impaired blood pressure response to vasodilators was due to the formation of AGEs in the vascular wall, since $A G$ treatment prevented this disturbance. Nevertheless, the present study demonstrated that $A G$ treatment had no influence on the diminished pressure response to $\mathrm{ACh}$ in diabetic animals and even lowered the pressure increase to vasoconstrictors. The fact that Bucala et all. ${ }^{9}$ studied their animals during anesthesia and used much higher dosages of $A C h$ and $A G$ could explain this discrepancy. Our study therefore did not support the suggestion that AGE-formation is responsible for the observed impaired pressure response to $\mathrm{ACh}$ in diabetes. Nevertheless, we cannot exclude the possibility that treatment during a more prolonged period or with higher dosages of AG would show an improvement of blood pressure responses in diabetes.

The arteriolar constriction due to infusion of AngII or NA was comparable between untreated control and diabetic rats (Figures 2.1 and 2.2). These results conflict with the hyperconstriction found in arterioles of the cremaster muscle of anesthetized STZ-induced diabetic rats in response to topically applied $\mathrm{NA}^{4}$ and AngII ${ }^{5}$. However, in patients with uncomplicated type 1 diabetes, no changes occurred in forearm blood flow in response to vasoconstrictors ${ }^{22-24}$. Although $A G$ treatment had no effect on agonist-induced constriction in diabetes, AngIl infusion resulted in hyperconstriction in the arterioles of treated versus untreated control rats. This may indicate that the arterioles studied in control animals are subjected more to the nitric oxide synthase-inhibitor capacities of $A G$ than the proximally located resistance arteries. However, no differences in baseline diameter were observed and no significant changes were seen after vasoconstriction with NA.

Endothellium-dependent vasodilatation was markedly impaired in arterioles of untreated diabetic rats compared with normal control rats (Figure 2.3). This finding supported the in vivo experimental studies of the endothelium-dependent relaxation in the microcirculation ${ }^{1,2}$. Studies in the forearm of patients with uncomplicated IDDM, however, have reported both normal and impaired responses to 
endothelium-dependent vasodilators ${ }^{25,26}$. It is possible that the degree of metabolic control accounts for this controversion. In the study of Johnstone et al. ${ }^{26}$, who reported impaired endothelial function, glycated hemoglobin levels were higher $(11.9 \pm 0.6 \%)$ than those reported by Smitset al. $(9.2 \pm 0.9 \%)^{25}$. In the experimental conditions used in the present study, the diabetic rats were also markedly hyperglycemic. Hill and $\mathrm{Ege}^{3}$ recently demonstrated that, although $\mathrm{AG}$ treatment normalized arteriolar mechanical properties, it did not improve the $\mathrm{ACh}$ dilator response $^{3}$. This suggests that the favorable effects of $\mathrm{AG}$ on diabetes-related microvascular complications involve extracellular matrix-associated mechanical properties rather than endothelium-dependent mechanisms of vascular smooth musele cell reactivity. In addition to the disturbances in endothelium-dependent vasodilatation in diabetes, arteriolar responses to the ATP-sensitive potassiumchannel opener LC are significantly impaired as well. LC preferentially dilates small arterioles in normotensive and spontaneously hypertensive rats ${ }^{16}$. This preferential sensitivity of small arterioles for LC was also found in this study on diabetic rats, and therefore confirms a general higher sensitivity of small arterioles for potassium-channel opening. Mayhan and colleagues ${ }^{27.28}$ reported that STZinduced diabetes attenuated the relaxation of basilar arteries and pial arterioles to activators of ATP-sensitive potassium channels. The disturbances in endotheliumindependent relaxation to $\mathrm{LC}$ combined with the diminished response to $\mathrm{ACh}$ may indicate that vasodilatation of the arterioles in the cutaneous maximus muscle is impaired in diabetes in a nonspecific manner. Nevertheless, part of the vasodilator action of $\mathrm{ACh}$ is mediated through the release of an unidentified endotheliumderived hyperpolarising factor (EDHF). Because this factor is suggested to be an activator of potassium channels ${ }^{29,30}$, an impaired release or action of EDHF may play a role in the attenuated relaxation of arterioles in diabetes. Although Endo et $\mathrm{al}^{31}$ reported that EDHF does not contribute to the decrease in endotheliumdependent relaxation in the aorta of STZ-induced diabetic rats, Hwa et al. ${ }^{32}$ showed that relaxation in large arteries is largelly due to nitric oxide, whereas EDHF plays a more important role in smaller resistance arteries.

In summary, this study is the first to show that relaxation of striated muscle arterioles is impaired in conscious rats with STZ-induced diabetes of 6 weeks' duration. Both endothelium-dependent relaxation and -independent relaxation are reduced. The mechanism involved in this disturbance is not affected by AG treatment, and needs further research to be clarified. 


\section{References}

1. Lash JM, Bohlen HG. Structural and functional origins of suppressed acetylcholine vasodilation in diabetic rat intestinal arterioles. Circ Res 1991;69:1259-68.

2. Mayhan WG, Simmons LK, Sharpe GM. Mechanism of impaired responses of cerebral arterioles during diabetes mellitus. Am J Physiol 1991;260:H319-26.

3. Hill MA, Ege EA. Active and passive mechanical properties of isolated arterioles from STZ-induced diabetic rats. Effect of aminoguanidine treatment. Diabetes $1994 ; 43: 1450-56$.

4. Morff RJ. Microvascular reactivity to norepinephrime at different arteriolar levels and durations of streptozocin-induced diabetes. Diabetes 1990;39:354-60.

5. Hill MA, Larkins RG. Altered microwascular reactivity in streptozotocin-induced diabetes in rats. Am J Physiol 1989;257:H1438-45.

6. Le Noble JL, Struijker Boudier HAJ, Smits JFM. Differential effects of general anesthetics on regional vasoconstrictor responses in the rat. Arch Int Pharmacodyn Ther $1987 ; 289: 82-92$.

7. Gilbert $\mathrm{M}$, Roberts SL, Mori M, Blomberg R, Tinker JH. Comparative coronary vascular reactivity and hemodynamics during halothane and isoflurane anesthesia in swine. Anesthesiology 1988;68:243-53.

8. Kiff RJ, Gardiner SM, Compton AM, Bennett $T$. Selective impairment of hindquarters vasodilator responses to bradykinin in conscious Wistar rats with streptozotocin-induced diabetes mellitus. Br J Pharmacol 1991;103:1357-62.

9. Bucala R, Tracey KJ, Cerami A. Adwanced glycosylation products quench nitric oxide and mediate defective endothelium-dependent vasodilatation in experimental diabetes. J Clin Invest 1991;87:432-38.

10. Corbett IA, Tilton RG, Chang K, Hasan KS, Ido $\mathrm{Y}$, Wang JL, Sweetland MA, Lancaster JR, Williamson JR, McDaniel ML. Aminoguanidine, a novel inhibitor of nitric oxide formation, prevents diabetic vascular dysfunction. Diabetes 1992;41: 552-56.

11. Huijberts MSP, Wolffenbuttel BHR, Struijker Boudier HAJ, Crijns FRL, Nieuwenhuijzen Kruseman $\mathrm{AC}_{\text {s }}$ Poitevin $\mathrm{P}$, Lévy Bl. Aminoguanidine treatment increases elasticity and decreases fluid filtration of large arteries from diabetic rats. $\mathrm{J}$ Clin Invest 1993;92:1407-11.

12. Hammes HP, Martin S, Federlin $K$, Geisen K, Brownlee M. Aminoguanidine treatment inhibits the development of experimental diabetic retinopathy. Proc Natl Acad Sci USA 1991;88:11555-58.

13. Tilton RG, Chang K, Hasan KS, Smith SR, Petrash IM, Misko TP, Moore WM, Currie MG, Corbett JA, McDaniel ML, Williamson JR. Prevention of diabetic vascular dysfunction by guanidines. Inhibition of nitric oxide synthase versus advanced glycation end-product formation. Diabetes 1993;42:221-32.

14. Smith TL, Osborne SW, Hutchins PM. Long-term micro- and macro-circulatory measurements in conscious rats. Microwasc Res 1985;29:360-70. 
15. Le Noble IL, Smith TL, Hutchins PM, Struijker Boudier HAJ. Microvascular alterations in adult conscious spontaneously hypertensive rats. Hypertension $1990 ; 15: 415-19$.

16. Struijker Boudier HAJ, Messing MW, van Essen H. Preferential small arteriolar vasodilatation by the potassium channel opener, BRL 38227 , in conscious spontaneously hypertensive rats. Eur J Pharmacol 1992;218:191-93.

17. Messing $M$, Van Essen $H$, Smith TL, Smits JFM, Struijker-Boudier HAJ. Microvascular actions of calcium channel antagonists. Eur J Pharmacol 1991;198: 189.95.

18. Messing MWJ, van Essen H, Struijker Boudier HAJ. Effects of alfa-adrenoceptor antagonists on striated muscle microcirculation of conscious rats. Drugs $1990 ; 40$ (suppl. 4):31-33.

19. Struijker Boudier HAJ, Messing MWJ, van Essen H. Alpha-adrenergic reactivity of the microcirculation in conscious spontaneously hypertensive rats. Mol Cell Biochem 1996;157:239-44.

20. Yu $\mathrm{Z}, \mathrm{McNeill} \mathrm{JH}$. Blood pressure and heart rate response to vasoactive agents in conscious diabetic rats. Can J Physiol Pharmacol 1992;70:1542-48.

21. Jackson $C V$, Carrier GO. Influence of short-term experimental diabetes on blood pressure and heart rate in response to norepinephrine and angiotensin II in the conscious rat. J Cardiovasc Pharmacol 1983;5:260-65.

22. Calver $\mathbf{A}$, Collier $\mathbf{J}$, Vallence $\mathbf{P}$. Inhibition and stimulation of nitric oxide synthesis in the human forearm arterial bed of patients with insulin-dependent diabetes. $J$ Clin Invest 1992;90:2548-54.

23. Halkin A, Benjamin N, Doktor HS, Todd SD, Viberti G, Ritter JM. Vascular responsiveness and cation exchange in insulin-dependent diabetes. Clin Sci 1991;81: 223-32.

24. Huvers FC, de Haan CHA, Houben AJHM, de Leeuw PW, Schaper NC. The elevated blood pressure in insulin-dependent diabetes mellitus patients with microalbuminuria is not caused by changes in adrenoceptor activity (Abstract). Neth J Med 1996;48:A74.


vascular relaxation in patients with type I diabetes. Diabetes 1993;42:148-53.

26. Johnstone MT, Creager SJ, Scales KM, Cusco JA, Lee BK, Creager MA. Impaired endothelium-dependent vasodilation in patients with insulin-dependent diabetesmellitus. Circulation 1993;88:2510-16.

27. Mayhan WG. Effect of diabetes mellitus on response of the basilar artery to activation of ATP-sensitive potassium channels. Brain Research 1994;636:35-39.

28. Mayhan WG, Faraci FM. Responses of cerebral arterioles in diabetic rats to activation of ATP-sensitive potassium channels. Am J Physiol 1993;265:H152-57.

29. Standen NB, Quale JM, Davis NW, Brayden JE, Huang $Y$, Nelson TM. Hyperpolarizing vasodilators activate ATP-sensitive $\mathrm{K}$ +channels in arterial smooth muscle. Science 1989;245:177-80. 
30. Bauersachs J, Hecker M, Busse R. Display of the characteristics of endotheliumderived hyperpolarizing factor by a cytochrome P450-derived arachidonic acid metabolite in the coronary microcirculation. Br J Pharmacol 1994;113:1548-53.

31. Endo $K$, Abiru $T$, Machida $H$, Kasua $Y$, Kamata $K$. Endothelium-derived hyperpolarizing factor does not contribute to the decrease in endothelium-dependent relaxation in the aora of streptozotocin-induced diabetic rats. General Pharmacology $1995 ; 26: 149-53$.

32. Hwa JJ, Ghibaudi L, Williams $\mathbb{P}$, Chatterjee M. Comparison of acetylcholinedependemt relaxation in large and small arteries of rat mesenteric vascular beds. Am J Physiol 1994;266:H952-58. 


\section{Chapter 3}

\section{Mechanical properties of mesenteric arteries in diabetic rats: consequences of outward remodeling}

FRL Crijns, BHR Wolffenbuttel, JGR de Mey, HAJ Struijker Boudier

Am J Physiol 1999;276:HI672-H1677 


\section{Abstract}

Diabetes induces hemodynamic and biochemical changes which can influence mechanical properties of arteries. Structure and mechanics of mesenteric small arteries were investigated in rats with streptozotocin-induced diabetes (duration 7-9 weeks). The external diameter of mesenteric artery branches was measured in control $(\mathrm{n}=9)$ and diabetic $(\mathrm{n}=7)$ Wistar $\mathrm{Rp}$ rats, at baseline and during pressurization in situ $(0-150 \mathrm{mmHg})$ under normal and passive smooth muscle conditions: Mean arterial pressure and mesenteric artery pressure were not significanly different. Baseline mesenteric artery diameter was larger in the diabetes group ( $439 \pm 12$ vs. $388 \pm 18 \mu \mathrm{m}, P<0.05$ ). Media cross-sectional area of arteries from diabetic rats was not significantly increased $(0.0149 \pm 0.0015$ vs. $\left.0.0122 \pm 0.0007 \mathrm{~mm}^{2}\right)$. Cross-sectional compliance was significantly increased in diabetic rats at intraluminal pressures ranging from $25-75 \mathrm{mmHg}(P<0.005)$, whereas cross-sectional distensibility was not modified. Wall tension and circumferential wall stress were increased in diabetes. These results indicate that mesenteric small arteries of diabetic rats display eutrophic outward remodeling, associated with increased wall tension and circumferential wall stress. 


\section{Introduction}

Diabetes mellitus is associated with hemodynamic changes and alterations in the regional distribution of cardiac output ${ }^{1}$. In rats with streptozotocin (STZ)-induced diabetes, blood flow to the small intestine is markedly increased, while skin and skeletal muscle blood flow are significantly reduced ${ }^{1}$. Changes in flow and/or pressure can modify structural and mechanical properties of vascular beds and individual vascular segments ${ }^{2}$. Arteries respond to changes in blood flow with acute vasomotor responses and with changes in wall structure when flow changes persist $^{3}$. Pourageaud and $\mathrm{De} \mathrm{Mey}^{4}$ demonstrated that chronic elevation of blood flow in mesenteric small arteries resulted in an increase in lumen diameter and media cross-sectional area which normalize wall shear rate and circumferential wall stress. Sustained elevation of transmural pressure, as in chronic hypertension, is in many cases associated with an increase in the arterial wall mass to lumen ratio as a result of media hypertrophy or reduction of arterial lumen diameter ${ }^{5}$. These chronic alterations in vascular structure are collectively referred to as remodeling and may have important effects on the mechanical properties of vessels such as compliance and distensibility ${ }^{6}$. Arterial compliance is defined as the change in lumen volume for a given change in pressure, expressing the buffering capacities of the arterial system $^{7}$. It depends on the size of the vascular lumen and on the elastic properties of the vascular wall. Distensibility is compliance corrected for the size of the vascular lumen and depends on the mass and intrinsic elastic properties of the vascular wall ${ }^{7}$.

In diabetes, in addition to flow-induced changes, hyperglycaemia by itself can lead to structural and functional vascular changes. High concentrations of D-glucose stimulate smooth muscle cell proliferation and growth ${ }^{8}$. Furthermore, formation of advanced glycation end products (AGEs), as a consequence of chronic hyperglycaemia, can influence vascular properties. These products accumulate on tissue proteins with slow degradation rates and have been implicated in many complications associated with diabetes. Increased AGEs cause a diminished vascular elasticity and greater permeability of the vascular wall in diabetes". Moreover, glycated collagen has been proven to abolish the inhibitory effect of collagen on smooth muscle cell proliferation and may thus induce an increase in vascular wall mass ${ }^{10}$.

The present study was performed to investigate to what degree the diabetes-induced hemodynamic and biochemical changes affect mechanical and morphological properties of mesenteric small arteries in rats, using an in situ model ${ }^{11}$ to assess these properties. 


\section{Research design and methods}

\section{Animals}

Sixteen male Wistar Rp rats (TNO-Repgo, Rijswijk, The Netherlands) were housed individually in temperature controlled rooms and had free access to standard rat chow and water. At an average body weight of $250 \mathrm{~g}$ (approximate age of 2 months) diabetes was induced in seven animals (D) by i.p. injection of $70 \mathrm{mg.kg}$ steptozotocin (Sigma, St. Louis, MO, USA) in citrate buffer ( $\mathrm{pH}$ 4.5). The remaining rats (C) received the vehicle. The experimental procedures were performed according to institutional guidelines and were approved by the Ethical Committee for the Use of Experimental Animals of the Maastricht University (The Netherlands), Between 7 and 9 weeks after diabetes induction, mesenteric artery experiments were performed.

\section{Mesenteric artery preparation}

The experimental set-up of the in situ mesenteric artery is an adaptation from a previlously described method ${ }^{11}$. Animals were anesthetized by an i.p. injection of sodium pentobarbital $\left(50 \mathrm{mg} \cdot \mathrm{kg}^{-1}\right)$. An arterial catheter connected to a pressure transducer (CP-01, Century Technology Company, Inglewood, CA, USA) was introduced into the left femoral artery in order to measure mean arterial blood pressure. A second catheter was introduced into the left femoral vein for continuous infusion of sodium pentobarbital $\left(30 \mathrm{mg} \cdot \mathrm{kg}^{-1} \cdot \mathrm{h}^{-1}\right)$ in order to maintain constant anesthesia during the whole experiment. A blood sample of the non-fasted rats was taken via the arterial catheter to measure levels of glucose and glycated hemoglobin $\left(\mathrm{HbA}_{10}\right)$, by a hexokinase method and HPLC respectively. $\mathrm{HbA}_{1 \mathrm{c}}$ levels reflect the amount of adducts of glucose to hemoglobin and estimate the long-term glycemic control.

A median laparotomy was performed and the most distal loop of small intestine was exteriorized. It was exposed and irrigated with a buffered Tyrode's solution $\left(\mathrm{pH} \mathrm{7.4)}\right.$ maintained at $38^{\circ} \mathrm{C}$. The mesenteric arteries and arcades were neither fixed nor stretched. The preparation was trans-illuminated. A short segment of mesenteric artery (approximately $3 \mathrm{~mm}$ ) of a second generation branch (diameter $300-500 \mu \mathrm{m}$ ) was gently freed of surrounding tissue under a binocular lens. (Wild M5A, Heerbrugg, Switzerland). A video camera (CCD, Sony, the Netherlands) was mounted on the binocular lens. The final magnification was $\times 100$. All arterial branches downstream of the exposed arterial segment, except one, were ligated. A removable microclamp was placed on the mesenteric artery upstream of the isolated segment. A polyethylene catheter, filled with Tyrode's solution containing albumin $(4 \%)$, was introduced into the unligated branch for local mesenteric artery pressure measurements, using a micro switch pressure transducer (150 PC Flow-Thru 
pressure sensor, Honeywell, USA). The same catheter was connected via a threeway tap to a manometer with adjustable pressure levels. After putting a removable micro-clamp proximally on the observed segment, the mesenteric artery was exposed to different pressure levels, while external diameter was measured with an image shearing monitor (Model 908, IPM, San Diego, Cal., USA). The artery was exposed to pressure steps of $25 \mathrm{mmHg}$ from 0 to $150: \mathrm{mmHg}$ at $2 \mathrm{~min}$ intervals. Video recordings of the last 20 seconds of each pressure step were used for the diameter measurements.

\section{Study protocol}

After the arterial segment was exposed to atmospheric pressure for 30 minutes, mean arterial pressure, mean mesenteric artery pressure and external diameter of the mesenteric artery were measured. Mesenteric arterial pressure-diameter relationships were obtained during superfusion with normal Tyrode's solution (control conditions). Subsequently, the mesenteric artery was flushed and superfused with Tyrode's solution containing potassium cyanide (KCN $100 \mathrm{mg} / \mathrm{l}$ ). An incubation period of $30 \mathrm{~min}$ was sufficient to poison the smooth muscle and totally abolish smooth muscle tone without a significant effect on vessel wall morphology ${ }^{12}$. The mesenteric arterial diameter-pressure relation was then determined in this fully relaxed state.

At the end of the experiment, the mesenteric artery was flushed and filled with formaldehyde $(4 \%)$. The vessel was maintained for 20 min under these conditions at its individual baseline mesenteric artery pressure. The fixed vessel was then excised and processed for morphometrical analysis. Media cross-sectional area (CSA), defined as the area enclosed by the internal and external elastic laminae, and media thickness $(\mathrm{Mt})$ were determined by semi-automated morphometry (JAVA 1.21, Jandel Scientific, Corte Madera, CA, USA) on $4 \mu \mathrm{m}$ sections stained with Lawson's solution, a classic elastin stain. Media-to-lumen ratio $(\mathrm{m} / \mathrm{l})$ was calculated as 2 times Mt divided by the lumen diameter.

\section{Data calculation}

Using the measured values of the 'in situ' arterial external diameter $\left(\mathrm{D}_{e}, \mu \mathrm{m}\right)$ over the pressure range of 0 to $150 \mathrm{mmHg}$ and the media cross-sectional area (CSA, $\mu \mathrm{m}^{2}$ ) measured after the experiment, the following parameters were calculated, using S.I. units:

* wall thickness $(h, \mu m)$ as: $h=D_{e} / 2-\left(D_{e}{ }^{2} / 4-C S A / \pi\right)^{1 / 2}$ on the basis of the assumption of a non-compressible arterial wall

* internal diameter $\left(D_{i}, \mu \mathrm{m}\right)$ as: $D_{i}=D_{e}-2 h$

* lumen area $\left(A_{i}, \mu \mathrm{m}^{2}\right)$ as: $A_{i}=\pi \cdot D_{i}^{2} / 4$ 
* cross-sectional compliance (Comp, $\mathrm{mm}^{2} \cdot \mathrm{kPa}^{-1}$ ) as: $\mathrm{Comp}=\Delta \mathrm{A} \cdot \Delta \mathrm{P}^{-1}$, in which $\Delta \mathrm{A}$ is the change in lumen area induced by a pressure change $(\Delta \mathrm{P})$

* cross-sectional distensibility (Dist, $\mathrm{kPa}^{-1}$ ) as: Dist $=$ Comp $\cdot \mathrm{A}_{\mathrm{i}}^{-1}$

* wall tension (WT, N.m.1. ) as: WT $=P \cdot D_{i} / 2$ on the basis of Laplace's law

* circumferential wall stress (WS, $\mathrm{kPa}$ ) as: WS $=\mathrm{WT}: \mathrm{h}^{-1}$

The various parameters were determined for each pressure applied.

\section{Statistical analysis}

Results are expressed as mean \pm SEM. Statistical significance of differences was evaluated by Students' $t$-test or two-way ANOVA followed by the StudentNewman-Keuls post-hoc test for multiple comparisons. $P$-values $<0.05$ were considered statistically significant.

\section{Results}

Table 3.1 summarizes the general characteristics of the control and diabetic animals. Glucose levels were significantly elevated in the diabetes group compared to the control group, while body weight was significantly lower $(P<0.001$; t-test). The increased $\mathrm{HbA}_{1 \mathrm{c}}$ levels in the diabetic rats $(P<0.01 ; \mathrm{t}$-test $)$ reflect long-term exposure to high blood glucose levels. Mean aortic and mesenteric artery pressure were slightly but not significantly lower in the diabetes group compared to the controls. External diameter of mesenteric arteries at baseline was larger in the diabetes group $(P<0.05, t$ test). Morphological properties of the mesenteric arteries, measured on cross-sections of formaldehyde fixed vessels, are shown in table 3.2. Media cross-sectional area was not significantly increased in the diabetic rats $(P=0.09$, t-test $)$. Media thickness and media-to-lumen ratio were comparable in both groups.

Table 3.1 Genteral characteristics of the study groups

\begin{tabular}{lcc}
\hline & Control $(\mathrm{n}=9)$ & Diabetes $(\mathrm{n}=7)$ \\
\hline Body weight $(\mathrm{g})$ & $297 \pm 137$ & $204 \pm 10^{* * *}$ \\
Glucose (mmol/l) & $7.3 \pm 0.7$ & $22.3 \pm 2.2^{* * *}$ \\
HbA $_{10}($ \%) & $1.3 \pm 0.1$ & $5.2 \pm 0.7^{* *}$ \\
MAP (mmHg) & $105 \pm 5$ & $96 \pm 7$ \\
MMAP (mmHg) & $100 \pm 4$ & $85 \pm 8$ \\
Dofpm) & $388 \pm 18$ & $439 \pm 12^{*}$ \\
\hline
\end{tabular}

Values are means \pm SEM, $" P<0.05, " P<0.01,{ }^{* * *} P<0.001$ versus control MAP, mean aortic pressure; MMAP, mean mesenteric artery pressure; $D_{k}$, baseline external diameter mesenteric artery. 
Table 3.2 Morphological properties of the mesenteric artery cross sections after formaldehyde fixation at operating pressures

\begin{tabular}{lcc}
\hline & Control $(\mathbf{n}=9)$ & Diabetes $(\mathrm{n}=7)$ \\
\hline CSA $\left(\mathrm{mm}_{2}\right)$ & $0.0122 \pm 0.0007$ & $0.0149 \pm 0.0015$ \\
Mt $(\mathrm{mm})$ & $0.0129 \pm 0.0010$ & $0.0145 \pm 0.0010$ \\
$\mathrm{~m} / \mathrm{l}$ & $0.091 \pm 0.006$ & $0.094 \pm 0.003$ \\
\hline
\end{tabular}

Values are means \pm SEM. CSA, media cross-sectional area mesenteric artery; Mt, media thickness; $\mathrm{m} / \mathrm{l}$, media-to-lumen ratio.
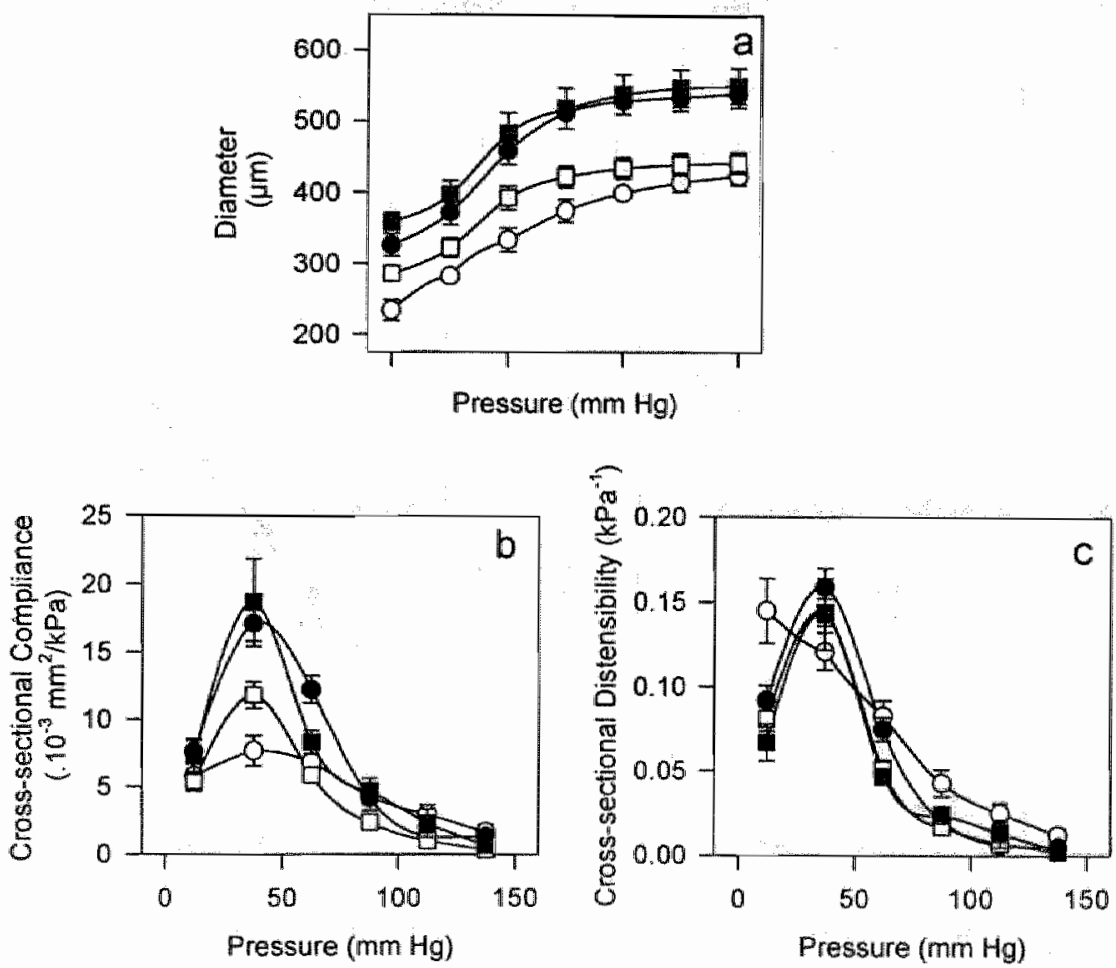

Figure 3.1 Pressure diameter (a), pressure-compliance (b) and pressure-distensibility (c) relationships in mesenteric arteries abtained by stepwise increasing the intraluminal pressure of in situ exposed second order mesenteric arteries. Open circles: control rats; closed circles: diabetis rats; open squares: control rats following smooth miscle poisoning by $\mathrm{KCN}$; closed squares: diabetic rats following smooth miscle poisoning by $\mathrm{KCN}$.

Figure 3.1a shows the pressure-diameter relationships under basal conditions and after inactivation of the smooth muscle. At all pressure levels, and under both basal and passive smooth muscle conditions, the diabetic animals exhibited a larger external arterial diameter than their non-diabetic littermates $(P<0.001$; two-way 
ANONA). Although smooth muscle poisoning seemed to have more effect in the control than in the diabetic rats, two-way ANOVA showed no statistically significant difference between basal and passive diameters within each group. Cross-sectional compliance and distensibility reached in both groups their highest level in the pressure range of 25 to $75 \mathrm{mmHg}$ (Figure $3.1 \mathrm{~b}$ and $3.1 \mathrm{c}$ ). In this range, compliance was significantly larger in the diabetes group than in the control group ( $P<0.005$, t-test), whereas distensibility was comparable between groups. In the lower pressure range $(25-75 \mathrm{mmHg})$ in control animals, cross-sectional compliance was higher under passive conditions compared to basal, whereas in the higher pressure range opposite effects were obtained. Comparable to the effect on external diameter, smooth muscle poisoning had only minor effects on compliance of arteries of diabetic rats. Pressure-wall tension and pressure-circumferential wall stress relationships (Figure 3.2) were steeper for diabetic rats compared to controls $(P<0.001$; two-way ANOVA). Similar findings were obtained in the presence of $\mathrm{KCN}$ (not shown).
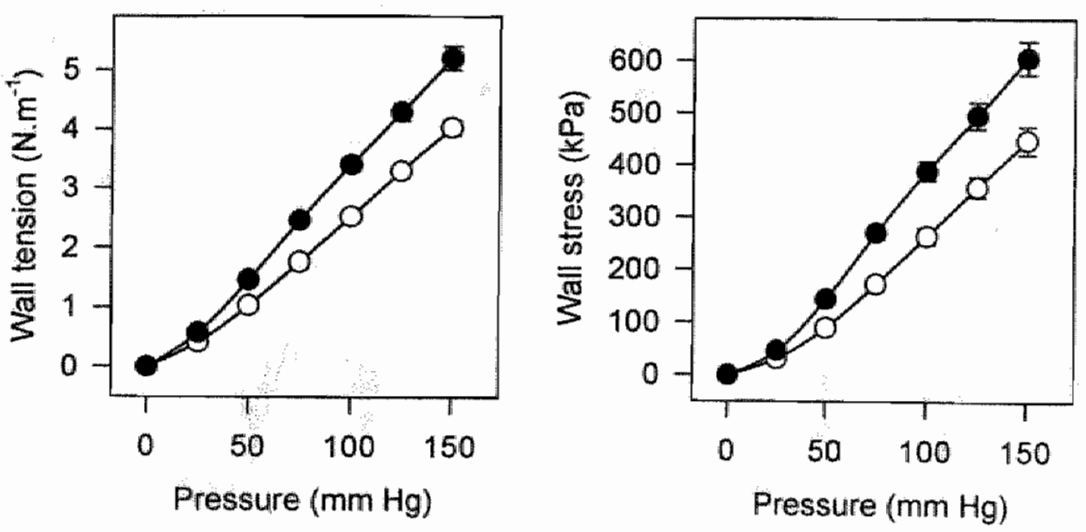

Figure 3.2 Pressure-wall tension curves (left panel) and pressure-wall stress curves of mesenteric arteries of control (open circles) and diabetic (closed circles) rats under basal conditions.

\section{Discussion}

The present study shows that mesenteric small arteries of streptozotocin-induced diabetic rats display an increased diameter. This outward remodeling is observed over a broad range of intraluminal pressures and persists after abolition of smooth muscle tone. Mesenteric artery compliance is increased at low pressure levels in diabetic rats, whereas distensibility is not modified. On the other hand, wall tension 
and circumferential wall stress in diabetic mesenteric arteries are enhanced compared to arteries of non-diabetic control rats.

The streptozotocin-induced diabetic rat is a widely-used model for type 1 diabetes. Numerous studies are performed with this model, proving is usefullness in studieing diabetic complications. Histological studies and studies using insulintreated diabetic rats have clearly demonstrated that STZ is selectively toxic to the pancreatic $\beta$-cells ${ }^{13}$.

Most studies of arterial mechanics in diabetes have been performed in large vessels, such as aorta and carotid arteries. They describe increased arterial stiffness, indicated by reduced distensibility ${ }^{14,15}$. Few reports demonstrate that the mechanical properties of small arteries and arterioles are affected as well ${ }^{16,17}$.

Arterial mechanical properties can be influenced by humoral and metabolic factors on the one hand, and hemodynamic forces and structural factors on the other hand. In diabetes, accumulation of AGEs in the vascular wall is a major feature, which can contribute to a diminished elasticity of arteries, as demonstrated by Huijberts et al. ${ }^{9}$ who studied carotid artery properties of aminoguanidine treated rats. Rumble et al. ${ }^{18}$ showed that AGE formation is present in the mesenteric vascular bed of streptozotocin-induced diabetic rats as well. Nevertheless, we demonstrate here that in mesenteric small arteries of diabetic rats no change in distensibility occurs, whereas compliance is even increased at low pressure levels. The latter is in contradiction with earlier reports on arterial mechanical properties in diabetes. A reduced arterial compliance and distensibility is found by several authors who studied mechanical properties of arteries or arterioles in diabetes ${ }^{14-17}$. However, none of these studies investigated mechanical properties in mesenteric arteries. The enhanced compliance, as described in our study, results from changes in mesenteric artery dimensions that occur in experimental diabetes. We observed larger external mesenteric artery diameters of diabetic rats at baseline and at imposed pressures ranging from 0 to $150 \mathrm{mmHg}$. The enhanced mesenteric artery diameter at baseline can be caused by several factors. Korthuis et al. ${ }^{19}$ demonstrated that blood-borne or humoral agents which are associated with diabetes mellitus, e.g. hyperosmolarity, hyperglycaemia and elevated plasma glucagon, induce vasodilatation of the intestinal vascular bed. Furthermore, insulin is known to induce vasoconstriction in mesenteric arteries ${ }^{20}$. Because the insulin concentration is extremely low in STZdiabetic rats, these arteries may be dilated compared to mesenteric arteries of control rats. Our observation that the enhanced diameter in diabetic arteries persists after perfusion of the arteries with Tyrode's solution and under passive smooth muscle conditions, indicates, however, that diameter changes in the mesenteric arterial bed following long-term diabetes involve other processes than vasomotor mechanisms. An increased flow to the small intestine of diabetic rats due to marked hyperphagia $^{1,22}$, is a plausible stimulus for the outward remodeling that occurs in mesenteric arteries of diabetic rats. An increase in flow or wall shear stress has 
been shown to lead to an acute vasodilatation involving endothelium-derived $\mathrm{NO}$ and prostacyclin ${ }^{22}$. Fujii et al.$^{23}$ demonstrated that flow-induced dilatation is, unlike acetylcholine-induced endothelium-dependent relaxation, well preserved in the basilar artery of diabetic rats. Our study suggests that chronic flow-induced outward remodeling, which has been demonstrated to depend on the endothelium in certain settings ${ }^{24}$, is preserved in mesenteric arteries of diabetic rats as well.

In addition to outward remodeling, chronic increases in blood flow are accompanied by wall hypertrophy, in order to normalize circumferential wall stress that increases during the expansion of the vessels ${ }^{4}$. However, in the present study we could not detect a statistically significant hypertrophy of small mesenteric arteries. This is in contrast with earlier finding ${ }^{25,25}$. Nevertheless, these studies were performed in Sprague-Dawley rats, on arteries and arterioles of different sizes than those used in our study, and the diabetes duration of the rats was different ( 3 weeks and 6 month). This might explain why these authors observed a significant hypertrophy and we did not. Although the exact mechanism of vascular wall hypertrophy accompanying hyperperfusion is not yet elucidated, an upregulation of growth factor genes in response to elevated shear stress has been demonstrated ${ }^{27}$. In hyperglycemic circumstances, the mitogenic activity of bFGF is markedly reduced due to cytosolic protein modification by $\mathrm{AGEs}^{28}$. It may be speculated that in diabetes, intracellular AGEs interfere in this way with the wall hypertrophy that normally accompanies flow-induced remodeling. One possibility to test this hypothesis would be to study vascular wall hypertrophy in aminoguanidine (AG)treated diabetic rats, for $A G$ is known to inhibit AGE-formation. We performed morphological measurements on mesenteric arteries of rats, that were diabetic for 8 weeks and chronically treated with AG (250 mg/l in drinking water). This group of rats supported our hypothesis that glycation products interfere with the hypertrophic response to flow. Mesenteric arteries of AG-treated rats showed indeed a significantly enhanced hyperthophy of the media, compared to non-diabetic control rats $\left(\mathrm{CSA}=0.0174 \pm 0.0015 \mathrm{~mm}^{2}\right.$ in $\mathrm{AG}$ treated diabetic rats vs. $0.0122 \pm 0.0071$ $\mathrm{mm}^{2}$ in control rats; $P<0.05$ ). However, $\mathrm{AG}$ is also known to act as an NOsynthase inhibitor ${ }^{29}$. Because NO has antimitogenic effects ${ }^{30}$, reduction of NO production by $\mathrm{AG}$ treatment might increase vascular smooth muscle growth. Therefore, the AG data cannot be used as a definite proof of our hypothesis. We have to await the availability of newly developped drugs, acting specifically on the formation or degradation of glycation products, to obtain a definite answer to the question whether flow-induced hypertrophy is inhibited by AGE-formation in diabetes or not.

As a result of the outward remodeling of the mesenteric small arteries without significant wall hypertrophy, wall tension as well as circumferential wall stress were elevated in the diabetic rats. Apparently, the structural response of the arteries of diabetic rats was insufficient to normalize circumferential wall stress. 
This is in contrast with earlier findings in hypertension where the pressure-related hypertrophy of the vascular wall results in a normalization of the arterial circumferential wall stress ${ }^{11,31}$. The elevated circumferential wall stress in mesenteric arteries of diabetic rats can therefore be deleterious for the functional integrity of the vascular wall ${ }^{2}$ and may contribute to enhanced permeability of blood vessels in diabetes ${ }^{9,32}$.

In the first years after diabetes onset in humans, blood flow has been found to be increased in several organs and tissues e.g. in the kidney and retina. Taking into account the experimental findings of the present study, outward remodeling of arteries may lead to an elvated wall tension and circumferential wall stress and may affect these tissues in a similar way, and contribute to the typical complications such as diabetic retinopathy and nephropathy.

In conclusion, this study demonstrates that in STZ-induced diabetic rats, mesenteric small arteries display eutrophic outward remodeling. Despite these structural changes, which could develop as a consequence of increases in blood flow to the small intestine, mesenteric arteries show an elevated circumferential wall stress. We hypothesize that advanced glycosylation of proteins that are involved in normal control of arterial wall structure interferes with the hypertrophic response normally seen in situations of elevated blood flow. 


\section{References}

1. Hill MA, Larkins RG. Alterations in distribution of cardiac output in experimental diabetes in rats. Am J Physiol 1989;257:H571-80.

2. Glagow $\mathrm{S}$, Vito $\mathrm{R}$, Giddens DP, Zarins CK. Micro-architecture and composition of artery walls: relationship to location, diameter and the distribution of mechanical stress; J Hypertens 1992;10 (supp: 6):S101-04.

3. Langille BL. Remodeling of developing and mature arteries. endothelium, smooth muscle, and matrix. J Cardiovasc Pharmacol 1993;21 (suppl. 1):S11-17.

4. Pourageaud F, De Mey JGR. Structural properties of rat mesenteric small arteries after 4-wk exposure to elevated or reduced blood flow. Am I Physiol 1997;273: 11699-706.

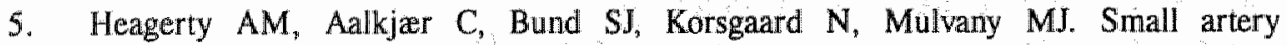
structure in hypertension. Duall processes of remodeling and growth. Hypertension $1993 ; 21: 391-97$.

6. Levy BI, Curmi P, Poitevin P. Safar ME. Modifications of the arterial mechanical properties of normotensive and hypertensive rats without arterial pressure changes. I Cardiovasc Pharmacol 1989;14:253-59.

7. Yin FCP, Ting CT. Compliance changes in physiological and pathological states. J Hypertens 1992;10 (suppl 6):S31-33.

8. Graier WF, Grubenthal $I$, Dittrich $P$, Wascher TC, Kostner GM. Intracellular mechanism of high D-glucose modulation of vascullar cell proliferation. Eur J Pharmacol 1995;294:221-29.

9. Huijberts MSP, Wolffenbuttel BHR, Struijker Boudier HAJ, Crijns FRL, Nieuwenhuijzen Kruseman AC; Poitevin P, Lévy BI. Aminoguanidine treatment increases elasticity and decreases fluid filtration of large arteries from diabetic rats. J Clin Invest 1993;92:1407-11.

10. lino $K$, Yoshinari $M$, Yamamoto $M$, Kaku $K$, Doi $Y$, Ichikawa $K$, Iwase $M$, Fujichima $M$. Effect of glycated collagen on proliferation of human smooth muscle cells in vitro. Diabetologia 1996;39:800-06.

1. Qui HY, Valtier B, Struijker Boudier HAJ, Lévy BI. Mechanical and contractile properties of in situ localized mesenteric artery in normotensive and spontaneously hypertensive rats. J Pharmacol Toxicol Methods 1995;33:159-70.

12. Dobrin PB, Rovick AA. Influence of vascular smooth muscle on contractile mechanics and elasticity of arteries. Am J Physiol 1969;217:1644-51.

13. Tomlinson $\mathrm{KC}$, Gardiner $\mathrm{SM}$, Hebden $\mathrm{RA}$, Bennet $\mathrm{T}$. Functional concequences of streptozotocin-induced diabetes mellitus, with particular reference to the cardiovascular system. Pharm Rev 1992;44:103-50.

14. Kool MJ, Lambert J, Stehouwer CD, Hoeks AP, Struijker Boudier HAJ, Van Bortel LM. Vessel wall properties of large arteries in uncomplicated insulindependent diabetes mellitus (IDDM). Diabetes Care 1995;18:618-24.

15. Oxlund H, Rasmussen LM, Andreassen TT, Heickendorff L. Increased aortic stiffness in patients with type $\mathbb{1}$ (insulin-dependent) diabetes mellitus. Diabetologia $1989 ; 32: 748-52$. 
16. Hill MA, Ege EA. Active and passive mechanical properties of isolated arterioles from STZ-induced diabetic rats. Effect of aminoguanidine treatment. Diabetes $1994 ; 43: 1450-56$.

17. Kastrup J, Norgaard T, Parving HH, Lassen NA. Decreased distensibility of resistance vessels of the skin in type 1 (insulin-dependent) diabetic patient with microangiopathy. Clin Sci 1987;72:123-30.

18. Rumble JR, Cooper ME, Soulis $T$, Cox A, Wu L, Youssef S, Jasik M, Jerums G, Gilbert RE. Vascular hypertrophy in experimental diabetes. Role of advanced glycation end products. J Clin Invest 1997;99:1016-27.

19. Korthuis RJ, Benoit IN, Kvietys PR, Laughlin MH, Taylor AE, Granger DN. Intestinal hyperemia in experimental diabetes mellitus. Am J Physiol 1987;253: Gi26-32.

20. Wu $H$, Jeng $Y$, Yue $C$, Chyu $K$, Hsueh WA, Chan TM. Endothelial-dependent vascular effects of insulin and insulin-like growth factor $I$ in the perfused rat mesenteric artery and aortic ring. Diabetes 1994;43:1027-32.

21. Friedman MI, Ramirez I. Food intake in diabetic rats: relationship to metabolic effects of insulin treatment. Physiology and Behaviour 1994;56:373-78.

22. Pohl U, Holtz $J$, Busse $R$, Bassenge $E$. Crucial role of endothelium in the vasodilatator response to increased flow in vivo. Hypertension $1986 ; 8: 37-44$.

23. Fujii K, Heistad DD, Faraci FM. Effect of diabetes mellitus on flow-mediated and endothelium-dependent dilatation of the rat basilar artery. Stroke 1992;23:1494-98.

24. Tronc F, Wassef M, Esposito B, Henrion D, Glagov S, Tedgui A. Role of NO in flow-induced remodeling of the rabbit common carotid artery. Arterioscler Throtib Vasc Biol 1996;16:1256-62.

25. Vranes $\mathrm{D}$, Cooper $\mathrm{ME}$, Dilley $\mathrm{RJ}$. Angiotensin-converting enzyme inhibition reduces diabetes-induced vascular hypertrophy: morphometric studies. I Vasc Res 1995;32:183-89.

26. Connors BA, Bohlen HG, Evan AP. Vascular endothelium and smooth muscle remodeling accompanies hypertrophy of intestinal arterioles in streptozotocin diabetic rats. Microvasc Res 1995;49:340-49.

27. Malek AM, Gibbons GH, Dzau VJ, lzumo S. Fluid shear stress differentially modulates expression of genes encoding basic fibroblast growth factor and plateletderived growth factor B chain in vascular endothelium. J Clin Invest 1993;92: 2013-21.

28. Giardino I, Edelstein D, Brownlee M. Nonenzymatic glycosylation im vitro and in bovine endothelial cells alters basic fibroblast growth factor activity. J Clin Invest 1994;94:110-17.

29. Laszlo F, Evans SM, Whittle BJR. Aminoguanidine inhibits both constitutive and inducible nitric oxide synthase isoforms in rat intestinal microvasculature in viwo. Eur J Pharmacol 1995;272:169-75.

30. Scott-Burden T, Vanhoutte PM. The endothelium as a regulator of vascular smoothmuscle proliferation. Circulation 1993;87:51-55. 
31. Struijker Boudier HA, van Essen H, Fazzi G, De Mey IGR, Qiu HY, Lévy BI. Disproportional arterial hypertrophy in hypertensive mRen-2 transgenic rats. Hypertension 1996;28:779-84.

32. Huijberts MSP, Wolffenbuttel BHR, Crijns FRL, Nieuwenhuijzen Kruseman AC, Bemelmans MHA, Struijker Boudier HAJ. Aminoguanidine reduces regional albumin clearance but not urinary albumin excretion in streptozotocin-diabetic rats. Diabetologia 1994;37:10-14. 


\section{Chapter 4}

\section{Altered cyclic GMP production in carotid arteries of streptozotocin-induced diabetic rats}

FRL Crijns, BHR Wolffenbuttel, PMH Schiffers, HAJ Struijker Boudier, J de Vente, JGR De Mey 


\section{Abstract}

Impaired endothelium-dependent and endothelium-independent relaxation may play a role in development of vascular complications in diabetes mellitus. In experimental diabetes, aminoguanidine (AG) treatment prevents or reduces several of these complications, possibly through interference with NO-dependent vascular mechanisms. The aim of this study was to investigate disturbances in NO-dependent cyclic GMP (cGMP) production in diabetes. Basal and stimulated cGMP concentrations were measured in intact and denuded carotid arteries of control and streptozotocin diabetic rats, untreated or treated with $\mathrm{AG}$ (50 mg/kg s.c.) or insulin for 10-12 weeks. Carotid artery segments were incubated for $10 \mathrm{~min}$ in Krebs Henseleit Buffer plus 3-isobutyl-1-methylxanthine, with or without addition of acetylcholine (ACh), sodium-nitroprusside (SNP) or S-nitroso-N-acetylpenicillamine (SNAP) during the last 2 min. Vessel segments were then processed for determination of cGMP and protein content.

In intact carotid arteries, basal cGMP content was comparable in all groups and higher than in denuded preparations. ACh as well as SNP and SNAP caused a marked increase of cGMP in intact segments which was comparable for control and diabetic rats. In denuded arteries, a reduced sensitivity for stimulation with SNP and SNAP was present in the diabetic animals compared to non-treated controls. Insullin, but not AG treatment could prevent this reduced response. We conclude that the presence of an intact endothelium provides normal basal or stimulated cGMP responses in experimental diabetes. Endothelial dysfunction, however, leads to a reduced sensitivity to NO-donors. This implies that in diabetes, loss of endothelial integrity has more severe consequences on vascular function than in non-diabetic subjects. 


\section{Introduction}

Subjects with type 1 diabetes mellitus display a high risk for the development of micro- and macrovascular complications. Early manifestations of vessel abnormalities are alterations in reactivity to vasoactive substances. Several authors have described decreased endothelium-dependent vasodilatation in diabetes, whereas endothelium-independent relaxation was unaffected ${ }^{14}$. Others, however, reported no differences in either endothelium-dependent or endotheliumindependent vascular relaxation ${ }^{\text {s-7. }}$.

The formation of advanced glycation end products (AGEs) may be involved in the development of many (vascular) complications in diabetes. Vlassara and co-workers demonstrated that administration of AGEs in non-diabetic animals evoked vessel disturbances and an increase in vascular permeability similar to those found in diabetes ${ }^{8}$. Previously, our group reported that treatment with aminoguanidine (AG), an inhibitor of AGE-formation, increased elasticity of carotid arteries of diabetic rats and decreased vascular albumin permeation in the eye, ileum, skin and skeletal muscle $^{9,10}$. Some authors, however, suggest that the NO-synthase inhibitor properties of AG, rather than the reduced AGE-formation, are responsible for the beneficial effects of this compound on vascular complications in diabetes ${ }^{11}$.

Nitric oxide, produced by the endothelium or generated by nitrovasodilators, activates soluble guanylate cyclase (sGC) to produce $3^{\prime}, 5^{\prime}$-cyclic guanosine monophosphate (cGMP), which induces relaxation of arterial smooth muscle by protein phosphorylation ${ }^{12}$. The purpose of the present study was to investigate the possible development of disturbances in NO-mediated cGMP production in diabetes by measuring basal and stimulated carotid artery cGMP content. This artery was chosen because diabetes-related vascular complications were previously documented for this vessel $1^{9,13,14}$. To examine the contributory role of endothelium and vascular smooth muscle, intact arterial segments as well as de-endothelialized vessels were studied. Using immunohistological staining we were able to localise cGMP in carotid arteries. Furthermore, we evaluated the effects of chronic treatment with insulin or aminoguanidine on cGMP levels.

\section{Research design and methods}

\section{Animals}

Inbred male Wistar Rp rats (Central Animal Services, University Maastricht), weighing approximately $200 \mathrm{~g}$, were divided into five groups: an untreated control group $(C, n=30)$, an untreated diabetic group $(D, n=31)$, a control group treated with aminoguanidine $(C+A G, n=8)$, a diabetic group treated with aminoguanidine 
$(D+A G, n=8)$ and a diabetic group treated with insulin $(D+I, n=9)$. Diabetes was induced by i.p. injection of $70 \mathrm{mg} / \mathrm{kg}$ STZ dissolved in citrate buffer, $\mathrm{pH} 4.5$ (Sigma). Control animals received vehicle only. Aminoguanidine-hemisulphate (Sigma) was administered daily by s.c. injections $(50 \mathrm{mg} / \mathrm{kg} /$ day). Insulin treatment was established by subcutaneously implanted sustained release implants (Linplant, Møillegaard, Denmark), releasing 1-2 $U$ insulin per day. Treatment was started as soon as diabetes was established (i.e. within $48 \mathrm{~h}$ ), indicated by blood glucose $>15$ mM measured by Haemo-gluco-testkit (Bohringer Mannheim). Ten to twelve weeks later, animals were anesthetized with pentobarbital $(60 \mathrm{mg} / \mathrm{kg}$, i.p.). One $\mathrm{ml}$ of blood was withdrawn to measure blood glucose (hexokinase method). From each rat; both common carotid arteries were isolated. The experimental procedures were performed according to institutional guidelines and approved by the Ethical Committee for the Use of Experimental Animals of the Maastricht University (the Netherlands).

\section{Carotid artery preparation}

The arteries were placed in freshly-prepared Krebs-Henseleit buffer (KHB) aerated with $95 \% \mathrm{O}_{2}$ and $5 \% \mathrm{CO}_{2}$. The $\mathrm{KHB}$ consisted of $4.8 \mathrm{mM} \mathrm{KCl}, 2.0 \mathrm{mM} \mathrm{CaCl}$, $1.2 \mathrm{mM} \mathrm{KH}_{2} \mathrm{PO}_{4}, 1.2 \mathrm{mM} \mathrm{MgSO}, 118 \mathrm{mM} \mathrm{NaCl}, 25 \mathrm{mM} \mathrm{NaHCO}_{3}$ and 7 or 20 mM D-glucose. $\mathrm{pH}$ was 7.4. The D-glucose concentration in the buffer was chosen to approximate the in vivo situation, since pilot experiments in aortic tissue revealed that the glucose concentration of the incubation medium can influence cGMP content. Thus, the incubation media for arteries of non-diabetic rats and insulin-treated diabetic rats contained $7 \mathrm{mM}$ of D-glucose, whereas $20 \mathrm{mM} \mathrm{D}$ glucose was added to the media of arteries from non-treated and AG-treated diabetic rats. From each artery, surrounding tissue was gently removed. The endothelium of one carotid artery from each rat was removed by passing a stainless steel wire $(\varnothing 0.7 \mathrm{~mm})$ through the lumen of the artery. In a pilot study, histologic examination of cross-sections showed that the endothelium was removed in this manner, without damage to the smooth muscle or elastic laminae. Intact and denuded arteries were then cut into segments of 3-4 mm.

\section{Incubations for cGMP production}

All segments were pre-incubated for one hour in $1 \mathrm{ml}$ oxygenated $\mathrm{KHB}\left(95 \% \mathrm{O}_{2}\right.$ $5 \% \mathrm{CO}_{2}$ ) at $37^{\circ} \mathrm{C}$. The bathing fluid was replaced with fresh $\mathrm{KHB}$ every $20 \mathrm{~min}$. The following $10 \mathrm{~min}$ the incubation took place in the presence of $1 \mathrm{mM} \mathrm{3-}$ isobutyl-1-methyl-xanthine (IBMX, Sigma), a non-selective phosphodiesterase inhibitor, which inhibits break-down of cGMP. Arterial segments were either studied under baseline conditions, or stimulated with different agonists: acetylcholine (ACh), sodium-nitroprusside (SNP) or S-nitroso-N-acetyl- 
penicillamine (SNAP) during the last 2 min of the incubation. ACh stimulates the release of endothelial NO which subsequently stimulates $\mathrm{SGC}$ to produce cGMP (endothelium-dependent CGMP production). SNP and SNAP act as endotheliumindependent NO donors (endothelium-independent CGMP production). The incubations were terminated by freezing the vessel segments in liquid nitrogen after which they were stored at $-20^{\circ} \mathrm{C}$ until further analysis.

\section{Biochemical analyses}

Arterial segments were powdered with a pestle and mortar that were previously cooled in liquid nitrogen. The powder was incubated in $1 \mathrm{ml}$ of $6 \%$ cold trichloroacetic acid (TCA) for $30 \mathrm{~min}$ at $4^{\circ} \mathrm{C}$ and further homogenized by ultra-turrax. After centrifugation (10 min at $3000 \mathrm{~g}$ ) the pellet was used to determine protein content as described by Bradford ${ }^{15}$. The supernatant was extracted 4 times with 3 volumes water saturated diethylether. The aqueous phase was dried under a stream of nitrogen at $40^{\circ} \mathrm{C}$. The residue was dissolved in phosphate buffer just before cGMP analysis. The cGMP content of the residues was measured with a commercial radioimmunoassay kit (Immuno Biological Laboratories, Hamburg, Germany). Intra- and inter-assay coefficients of variation were $4.3 \%(n=10)$ and $8.6 \%(\mathrm{n}=8)$ respectively.

\section{Immunohistochemical staining}

After incubation of the arterial segments (see above), carotid artery segments of non-treated control $(n=6)$ and diabetic rats $(n=6)$ were fixed overnight in $4 \%$ formaldehyde in $0.1 \mathrm{M}$ phosphate buffer. Transverse sections (20 $\mu \mathrm{m}$ thick) were cut on a cryostat at $-20^{\circ} \mathrm{C}$ and thawed onto chrome alum gelatine-coated slides. The method for immunohistochemical staining of cGMP was adapted from an earlier described method by de Vente et al..$^{15,17}$. Tissue sections were pretreated with $0.3 \% \mathrm{H}_{2} \mathrm{O}_{2}$ in methanol, washed in PBS and incubated overnight at $4{ }^{\circ} \mathrm{C}$ with rabbit antiserum against formaldehyde-conjugated cGMP (diluted 1:600 in PBS containing $0.2 \%$ Triton X-100 (PBS-T)). The sections were then incubated at room temperature for $1 \mathrm{~h}$ with biotinylated swine anti-rabbit immunoglobulin $\mathrm{G}$ (diluted 1:100 in PBS-T) (Dako A/S, Denmark) and for $30 \mathrm{~min}$ with a preformed Avidin and biotinylated horseradish peroxidase macromolecular complex (Vectastain ABC kit, Vector Laboratories, Burlingame, CA, USA). After washing, the cGMP immunoreactivity was visualized by diaminobenzidine (Sigma, St. Louis, USA). Cell nuclei were stained with haematoxiline. The sections were then dehydrated and covered with a coverslip using Entellan (Merck, Darmstadt, Germany). Photographs were taken on a Zeiss Axioskop microscope and camera, and a Kodak tri-X film (400 ASA). This staining allows no quantitative measurements, only localization of cGMP is obtained. 


\section{Statistical analysis}

The results of CGMP measurements were normalized to the protein content of the individual vessel segments. All results are expressed as means \pm SEM. Differences between groups were tested by an unpaired Student's $t$ test or ANOVA with Student-Newman-Keuls correction for multiple comparisons. $P$-values $<0.05$ were considered statistically significant.

\section{Results}

Blood glucose levels were markedly increased in the non-treated and aminoguanidine treated diabetes groups compared to the control groups $(24.0 \pm 0.5$ in $D$ and $23.4 \pm 1.1$ in $D+A G$ vs. $7.0 \pm 0.3$ in $C$ and $7.3 \pm 0.5 \mathrm{mM}$ in $C+A G$; $P<0.001$ ). Insulin treatment of diabetic rats lowered glucose levels significantly, but normoglycaemia was not achieved by the insulin dose used in this experiment $(13.2 \pm 5.1 \mathrm{mM} ; P<0.001$ vs. $C$ and $D)$.

Basal cGMP content was comparable in the intact carotid arteries of the five groups studied (Table 4.1). De-endothelialization markedly decreased basal cGMP content in all groups.

Table 4.1 cGMP content (fmol/mg protein) in isolated carotid arteries of rats in the absense of exogenous stimuli.

\begin{tabular}{lcc}
\hline & Intact & De-endotheliazed \\
\hline C-L $(\mathrm{n}=10-11)$ & $22 \pm 6$ & $2 \pm 1$ \\
$\mathrm{D}-\mathrm{H}(\mathrm{n}=10-1,1)$ & $23 \pm 3$ & $2 \pm 1$ \\
$\mathrm{D}+\mathrm{I}-\mathrm{L}(\mathrm{n}=5-7)$ & $31 \pm 5$ & $7 \pm 1$ \\
C $+\mathrm{AG}-\mathrm{L}(\mathrm{n}=6-7)$ & $21 \pm 6$ & $3 \pm 1$ \\
$\mathrm{D}+\mathrm{AG}-\mathrm{H}(\mathrm{n}=8)$ & $34 \pm 8$ & $4 \pm 1$ \\
\hline
\end{tabular}

Data are expressed as means \pm SEM. C-L, segments of control rats incubated in low glucose medium (7mM); D-H, segments of diabetic rats incubates in high glucose medium $(20 \mathrm{mM})$; $\mathrm{D}=\mathrm{J}-\mathrm{L}$, segments of insulin treated diabetic rats incubated in low glucose medium; $\mathrm{C}+\mathrm{AG}-\mathrm{L}$, segments of $A G$ treated control rats incubates in low glucose medium; D $+A G-H$, segments of $A G$ treated diabetic rats incubated in high glucose medium.

Exposure of the intact carotid artery segments to the endothelium-dependent vasodilator $\mathrm{ACh}$ and the NO-donors SNP and SNAP led to a dose dependent increase in cGMP content (Figure 4.1). Although there was a tendency towards higher cGMP levels in control vs. diabetic carotid artery segments, no statistical significance was observed. As expected, ACh did not increase cGMP levels in deendothelialized artery segments (data not shown). Stimulation of denuded segments with SNP or SNAP, which act independently from the endothelium, increased cGMP levels in both groups (Figure 4.2). However, in concentrations of $10^{-6}$ and 
$10^{-5} \mathrm{M}$ SNP, significantly lower cGMP levels were found in denuded arteries from diabetic rats compared to controls. The response of diabetic and control segments was comparable in the presence of a high concentration of SNP $\left(10^{-4} \mathrm{M}\right)$. The same results were obtained following stimulation with SNAP (Figure 4.2). The lowest concentration of SNAP $\left(10^{-6} \mathrm{M}\right)$, led to significantly lower cGMP levels in diabetic arteries compared to controls. In the presence of $10^{-5}$ and $10^{-4} \mathrm{M} S \mathrm{NAP}$, the arteries from control as well as diabetic rats were maximally stimulated to produce cGMP.

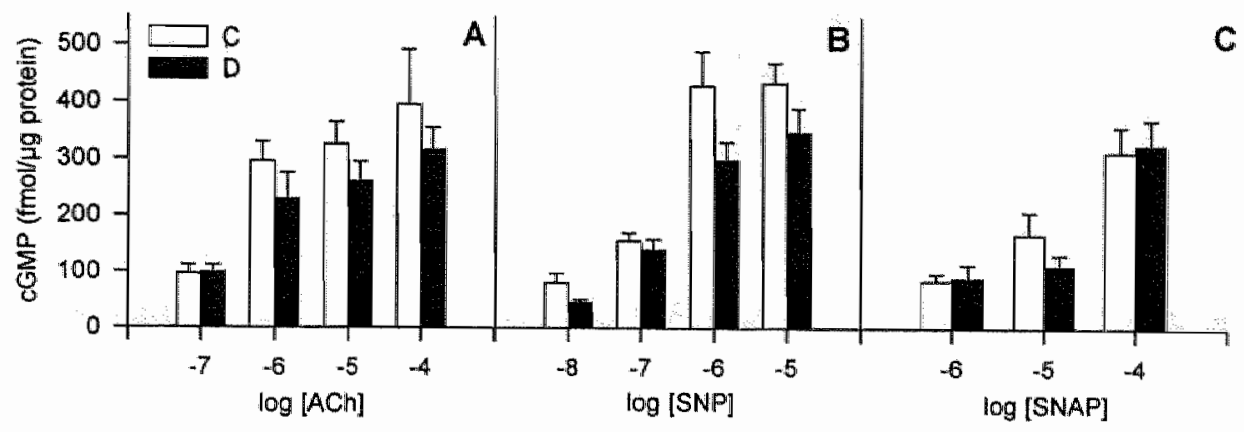

Figure 4.1 cGMP content in carotid artery segments of control $(n=7-10)$ and diabetic rats $(\mathrm{n}=6-10)$, following incubation for $10 \mathrm{~min}$ in the presence of $\mathrm{IBMX}$ with 2 min stimulation with ACh. (A), SNP (B) or SNAP (C). Blank bars: segments of control rats incubated in low glucose medium $(7 \mathrm{mM})$; filled bars: segments of diabetic rats incubated in high glucose medium $(20 \mathrm{mM})$.

\section{Effects of aminoguanidine and insulin treatment}

AG treatment of rats had no influence on the SNP stimulated cGMP response in intact carotid artery segments of control as well as diabetic animals (Figure 4.3). As shown before, removal of the endothelium significantly reduced SNP-induced cGMP levels in diabetic rats. AG treatment of diabetic rats did not influence this impaired response, whereas CGMP levels of AG-treated control rats were significantly reduced as well. Insulin treatment of diabetic rats led to higher cGMP levels of intact arteries following SNP stimulation and restored the cGMP response in denuded carotid arteries (Figure 4.3).

\section{Immunohistochemical staining}

The immunoreactive staining of cGMP in carotid arteries is shown in Figure 4.4ad. In tissues incubated in the absence of exogenous stimuli (Figure $4.4 \mathrm{a}, 4.4 \mathrm{~b}$ ), besides the endothelium only smooth muscle cells close to the endothelial layer are stained, which is in line with basal NO-production by the endothelium. In artery 
segments that were incubated in the presence of SNP $\left(10^{-6} \mathrm{M}\right)$ the staining is clearly enhanced and distributed throughout the entire medial smooth muscle layer (Figure $4.4 c, 4.4 d$ ). No differences could be observed in localization of cGMP between tissue of control and diabetic rats.

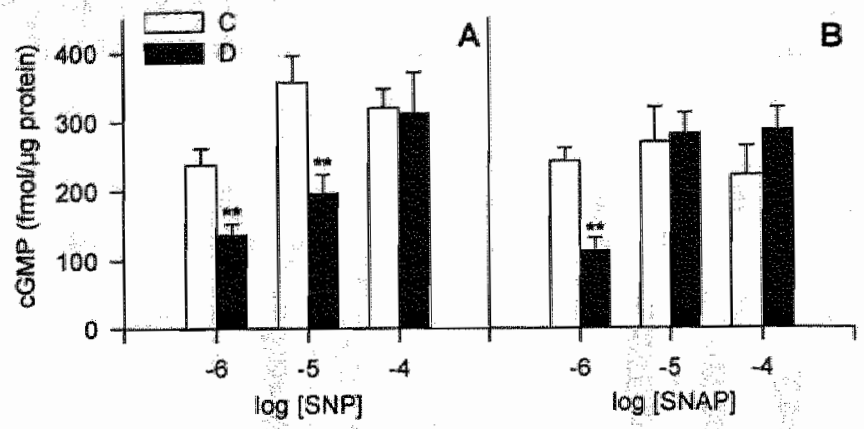

Figure 4.2 cGMP content in de-endothelialized carotid artery segments of control $(n=7-10)$ and diabetic rats $(n=6-9)$, following incubation for $10 \mathrm{~min}$ in the presence of IBMX with 2 min stimulation with SNP (A) or SNAP (B). Blank bars: segments of control rats incubated in low glucose medium $(7 \mathrm{mM})$; filled bars: segments of diabetic rats incubated in high glucose medium $(20 \mathrm{mM}) * * P<0.01 \mathrm{vs.} \mathrm{control} \mathrm{segments.}$

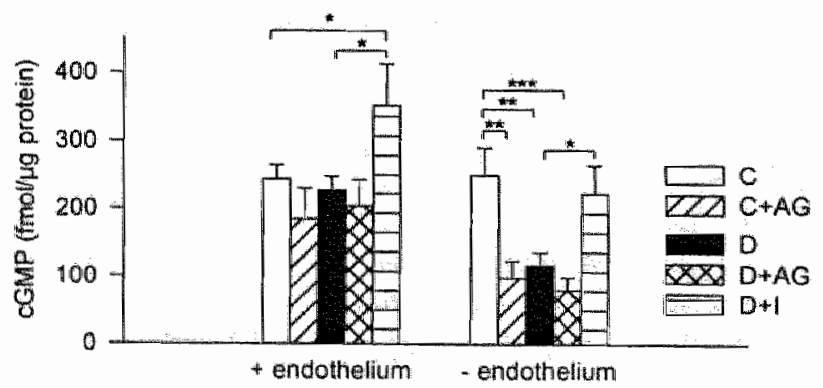

Figure 4.3 cGMP content in intact (left) or de-endothelialized (right) carotid artery segments following incubation for 10 min in the presence of IBMX with 2 min stimulation with SNP $\left(10^{-6} \mathrm{M}\right)$. Blank bars: segments of control rats incubated in low glucose medium $(7 \mathrm{mM})(\mathrm{n}=9)$, hatched bars: segments of $\mathrm{AG}$ treated control rats incubated in low glucose medium $(n=6-7)$; filled bars: segments of diabetic rats incubated in high glucose medium (20 $\mathrm{mM})(\mathrm{n}=11-12)$; cross-hatched bars: segments of $\mathrm{AG}$ treated diabetic rats incubated in high glucose medium $(n=8)$; striped bars: segments of insulin treated diabetic rats incubated in low glucose medium $(\mathrm{n}=7) . * P<0.05$, $* * P<0.01$, *** $P<0.001$ 



Figure 4.4 CGMP immunostaining in rat carotid artery segments incubated in witro.

a. Basal cGMP immunostaining in non-treated control rats.

b. Basal cGMP immunostaining in non-treated diabetic rats. 

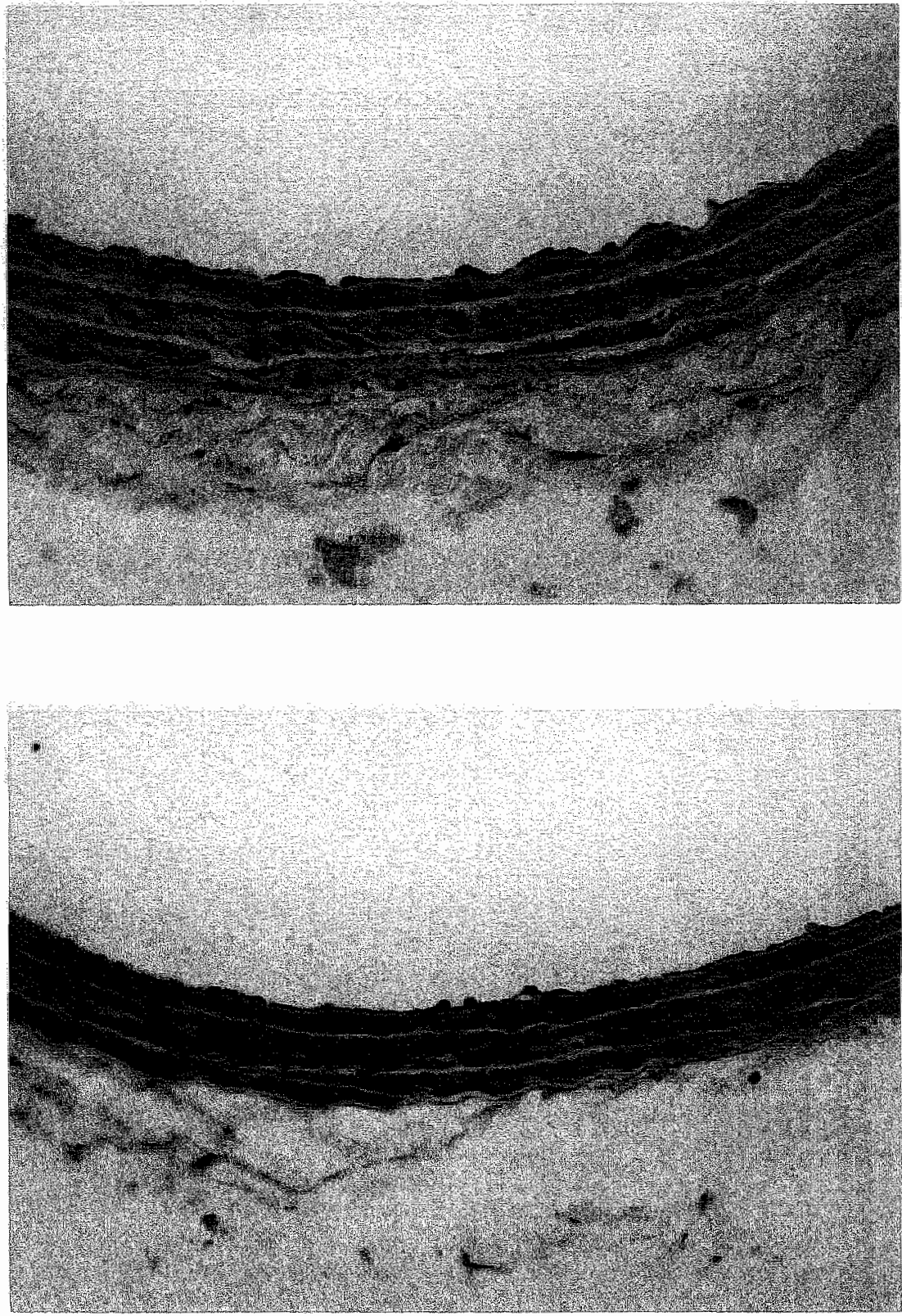

c. cGMP immunostaining in non-treated control rats after incubation of carotid artery segment in the presence of $10^{-6} \mathrm{M} \mathrm{SNP}$.

d. cGMP immunostaining in non-treated diabetic rats after incubation of carotid artery segment in the presence of $10^{6} \mathrm{M}$ SNP.

Photographs are representative for 6 animals per experimental group. 


\section{Discussion}

In this study, we examined cGMP production in carotid arteries of control and STZ-diabetic rats, untreated or treated with either aminoguanidine or insulin. We demonstrated that cGMP production in de-endothelialized carotid arteries of diabetic rats was markedly impaired during stimulation with SNP or SNAP. Chronic AG treatment of diabetic rats did not reverse this effect, whereas insulin treatment did. Moreover, control animals treated with AG showed the same defect in cGMP production as diabetic rats.

In intact carotid arteries, basal cGMP production was comparable in control and diabetic rats. This confirms the results of Harris and MacLeod in the aorta of STZ induced diabetic rats ${ }^{18}$. Nonetheless, Kamata et al. found significantly lower cGMP levels in the aorta of 8 weeks STZ-induced diabetic rats ${ }^{2}$. However, both studies were performed with buffer glucose concentrations of $11 \mathrm{mM}$, which is unphysiologic for control as well as diabetic animals. Removal of the endothelium reduced basal cGMP levels to the same extent in diabetic and control carotid arteries. This indicates that the spontaneous release of NO from the endothelium is not lower in the diabetes groups compared to the controls. Stimulation with $\mathrm{ACh}$ increased the carotid artery cGMP production in the intact vessel segments. Although the non-treated diabetes group shows a slightly lower cGMP content in intact ACh-stimulated arteries, there were no statistically significant differences. This indicates that the ability of the endothelium to respond to this agonist with an increase in NO, followed by enhanced cGMP production in the vessel wall, is hardly influenced by diabetes. Similar findings were obtained by Harris and MacLeod $^{18}$, but other reports ${ }^{2,4.19}$ demonstrate that in the aorta of STZ-induced diabetic rats, the ACh stimulated cGMP response is attenuated. Possibly the regional heterogeneity between aorta and carotid artery and/or strain differences can explain the contradictory results. Our finding that diabetes does not influence ACh-induced CGMP content fits with the unchanged endothelium-dependent relaxation of large arteries reported by several authors ${ }^{5,6,18}$. Nevertheless, many papers suggest the opposite ${ }^{2,4,19,20}$. Possibly, a diabetes-related enhanced response to the constrictor agent, added to preconstrict the vessels before ACh-induced dilatations, may influence the degree of relaxation ${ }^{21}$. Less contradiction exists concerning endothelium-independent relaxation. Most studies indicate that vasodilatation during exogenous $\mathrm{NO}$ supplementation is preserved in diabetes ${ }^{\mathrm{In}}$. Our data on SNP- and SNAP-induced cGMP formation in the intact carotid arteries confirm these functional studies.

In de-endothelialized arteries, however, an impaired production of CGMP in response to SNP or SNAP was observed. Thus, although SNP and SNAP are generally considered as endothelium-independent vasodilators, removal of the endothelium attenuated the agonist-stimulated cGMP production in the smooth 
muscle of diabetic rats. One might hypothesize that cGMP production in diabetic rats is shifted from arterial smooth muscle to the endothelium. This would be in agreement with the enhanced bradykinin-induced NO-formation in cultured endothelial cells exposed to high glucose $\mathrm{e}^{22}$. However, the localization of cGMP production performed by immunohistochemistry is in contradiction with this hypothesis. Alternatively, we hypothesize that an increased production of oxygen free radicals in diabetes could interfere with the amount of NO that reaches the vascular smooth muscle cells ${ }^{23}$. The presence of an intact endothelium may protect against degradation of NO by free radicals, since it has been suggested that in diabetes endothelial cells increase their level of anti-oxidants ${ }^{24}$. However, to verify this hypothesis an extensive study is required to find out whether vessels of diabetic and control rats, with and without endothelium and incubated in the presence of several anti-oxidants, respond differently upon stimulation with NO-donors.

AG treatment of diabetic animals did not affect cGMP responses to SNP or SNAP in denuded artery segments. Thus, despite the beneficial effects of $A G$ on vascular mechanical properties ${ }^{9.25}$ and vascular permeability ${ }^{10}$ in diabetes, stimulated cGMP production by smooth muscle cells did not improve. Since AG treatment does not reduce enhanced free radicals in diabetes, as measured by conjugated dienes ${ }^{26}$, the same suggestions concerning this impaired cGMP response can be made as in untreated diabetic vessels. Insulin treatment, on the other hand, amelioreted the disturbed cGMP response. A reduction in oxidative stress, in vivo as well as in the in vitro condition ${ }^{27}$, could account for this normalization of the CGMP response.

Remarkably, we found that control animals treated with $A G$ also show a diminished stimulated endothelium-independent cGMP production in denuded carotid artery segments. Apparently, AG induces the same endothelial disturbance in control animals as diabetes does. The mechanism behind this remains unclear.

Our study suggests that in diabetic subjects, vascular responses to endotheliumdependent and endothelium-independent vasodilators are normal when the endothelium is still intact. The disturbance in vascular relaxation occurs when the endothelium is somehow damaged or dysfunctional. Clinical studies support these findings. Smits et al. ${ }^{5}$ showed that in patients with insulin-dependent diabetes without vascular complications, responses to nitroprusside and methacholine were not altered. Elliott and co-workers, however, showed that in diabetic patients with microalbuminuria, which can be considered as a marker for endothelial dysfunction, impaired responses to NO-donors were present ${ }^{28}$. Our study also suggests that treatment of diabetic patients with aminoguanidine to prevent or decrease complications, should start before endothelial damage occurs.

In conclusion, our results demonstrate that de-endothelialized carotid arteries of diabetic rats show a reduced sensitivity towards endothelium-independent stimulators, as measured by CGMP production. Chronic insulin treatment, but not AG treatment reversed this disturbance, whereas $A G$ treated control rats show the 
same defect as the hyperglycemic rats. Further research is required to elucidate whether an enhanced endothelial anti-oxidant production in diabetes may account for the normal cGMP response in intact vessels and a reduced cGMP production when the endothelium is removed. 


\section{References}

1. Johnstone MT, Creager SJ, Scales KM, Cusco IA, Lee BK, Creager MA. Impaired endothelium-dependent vasodilation in patients with insulin-dependent diabetesmellitus. Circulation 1993;88:2510-16.

2. Kamata K, Miyata N, Kasuya $Y$. Impairment of endothelium-dependent relaxation and changes in levels of cyclic GMP in aorta from streptozotocin-induced diabetic rats. Br J Pharmacol 1989;97:614-18.

3. Durante W, Sen AK, Sunahara FA. Impairment of endothelium-dependent relaxation in aortae from spontaneously diabetic rats. $\mathrm{Br} J$ Pharmacol 1988;94: 463-68.

4. Pieper GM, Siebeneich W, Dondlinger LA. Short-term oral administration of Larginine reverses defective endothelium-dependent relaxation and cGMP generation in diabetes. Eur J Pharmacol 1996;317:317-20.

5. Smits P, Kapma JA, Jacobs MC, Lutterman J, Thien T. Endothelium-dependent vascular relaxation in patients with type I diabetes. Diabetes 1993;42:148-53.

6. Chang KS, Stevens WC. Endothelium-dependent increase in vascular sensitivity to phenylephrine in long-term streptozotocin diabetic rat aorta. $\mathrm{Br} J$ Pharmacol 1992;107:983-90.

7. Mulhern M, Docherty JR. Effects of experimental diabetes on the responsiveness of rat aorta. Br J Pharmacol 1989;97:1007-12.

8. Vlassara H, Fuh H, Makita Z, Krungkrai S, Cerami A, Bucala R. Exogenous advanced glycosylation end products induce complex vascular dysfunction in normal animals: a model for diabetic and aging complications. Proc Natl Acad Sci USA 1992;89:12043-47.

9. Huijberts MSP, Wolffenbuttel BHR, Struijker Boudier HAJ, Crijns FRL, Nieuwenhuijzen Krusernan AC, Poitevin P, Lévy BI. Aminoguanidine treatment increases elasticity and decreases fluid filtration of large arteries from diabetic rats. $J$ Clin Invest 1993;92:1407-11.

10. Huijberts MSP, Wolffenbuttel BHR, Crijns FRL, Nieuwenhuijzen Kruseman AC, Bemelmans MHA, Struijker Boudier HAJ. Aminoguanidine reduces regional albumin clearance but not urinary albumin excretion in streptozotocin-diabetic rats. Diabetologia 1994:37:10-14.

11. Tilton RG, Chang K, Hasan KS, Smith SR, Petrash JM, Misko TP, Moore WM, Currie MG, Corbett JA, McDaniel ML, Williamson JR. Prevention of diabetic vascular dysfunction by guanidines. Inhibition of nitric oxide synthase versus advanced glycation end-product formation. Diabetes 1993;42:221-32.

12. Walter U. Physiological role of cGMP and cGMP-dependent protein kinase in the cardiovascular system. Rev Physiol Biochem Pharmacol 1989;113:41-88.

13. Yamasaki $Y$, Kawamori $R$, Nishizawa $H$, Kodama $M$, Kajimoto $Y$, Morishima $T$, Kamada $T$. Atherosclerosis in carotid artery of young IDDM patients monitored by ultrasound high-resolution B-mode imaging. Diabetes 1994;43:634-39. 
14. Jensen-Urstad KJ, Reichard PG, Rosfors IS, Lindblad LEL, Jensen-Urstad MT: Early atherosclerosis is retarded by improved long-term blood glucose control in patients with IDDM. Diabetes 1996;45:1253-58.

15. Bradford MM. A rapid and sensitive method for quantitation of microgram quantities of protein utilizing the principle of protein-dye binding. Anal Biochem $1976 ; 72: 248$.

16. de Vente J, Schipper J, Steinbusch HWM. Formaldehyde fixation of cGMP in distinct cellular pools and their recognition by different cGMP-antisera. An immunocytochemical study into the problem of serum specificity. Histochemistry 1989;91:401-12.

17. Berkelmans HS, Schipper J, Hudson L, Steinbusch HWM, de Vente J. cGMP immunocytochemistry in aorta, kidney, retina and brain tissues of the rat after perfusion with nitroprusside. Histochemistry 1989;93:143-48.

18. Harris KH, MacLeod KM. Influence of the endothelium on contractile responses of arteries from diabetic rats. Eur J Pharmacol 1988;153:55-64.

19. Miller MAW, Morgan RJ, Thompson CS, Mikhailidis DP, Jeremy JY. Adenylate and guanylate cyclase activity in the penis and aorta of the diabetic rat: an in vitro study. $\mathrm{Br} \rrbracket$ Urol 1994;74:106-11.

20. Endo K, Abiru T, Machida H, Kasua Y, Kamata K. Endothelium-derived hyperpolarizing factor does not contribute to the decrease in endolhelium-dependent relaxation in the aorta of streptozotocin-induced diabetic rats. General Pharmacology $1995 ; 26: 149-53$.

21. Furchgott RF. Role of endothelium in responses of vascular smooth muscle. Circ Res $1983 ; 53: 557-72$.

22. Graier WF, Simecek S, Kukovetz WR, Kostner GM. High-D-glucose-induced changes in endothelial Ca2+/EDRF signaling is due to generation of superoxide anions. Diabetes 1996;45:1386-95.

23. Rubanyi GM, Vanhoutte PM. Superoxide anions and hyperoxia inactivate endothelium-derived relaxing factor. Am. J Physiol 1986;250:H822-27.

24. Ceriello $A$, dello Russo $P$, Amstad $P$, Cerutti $P$. High glucose induces antioxidant enzymes in human endothelial cells in culture. Evidence linking hyperglycemia and oxidative stress. Diabetes 1996;45:471-77.

25. Hill MA, Ege EA. Active and passive mechanical properties of isolated arterioles from STZ-induced diabetic rats. Effect of aminoguanidine treatment. Diabetes $1994 ; 43: 1450-56$.

26. Kihara M, Schmelzer JD, Poduslo JF, Curran GL, Nickander KK. Aminoguanidine effects on nerve blood flow, vascular permeability, ellectrophysiology, and oxygen free radicals. Proc Natl Acad Sci USA 1991;88:6107-11.

27. Young IS, Tate S, Lightbody JH, McMaster D, Trimble ER. The effects of desferrioxamine and ascorbate on oxidative stress in the streptozotocin diabetic rat. Free radical biology and medicine $1995 ; 18: 833-40$. 


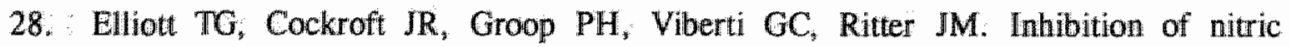
oxide synthesis in forearm vasculature of insulin-dependent diabetic patients: blunted vasoconstriction in patients with microalbuminuria. Clin Sci Colch 1993;85: $687-93$. 


\section{Chapter 5}

\section{Hemodynamics in conscious}

streptozotocin-induced diabetic rats: influence on vascular morpholopgy

FRL Crijns, BHR Wolffenbuttel, JGR De Mey, JFM Smits, HAJ Struijker Boudier 


\begin{abstract}
Diabetes mellitus induces hemodynamic changes that may influence structural vascular properties. In conscious male streptozotocin-induced diabetic Wistar rats $(\mathrm{n}=11$; duration 12-13 weeks) and age-matched control rats $(\mathrm{n}=10)$ hemodynamic parameters were measured, using a chronically implanted arterial catheter and an electromagnetic flow probe placed around the aorta. One day later, following perfusion-fixation, several arteries were excised, embedded in paraffin and prepared for morphometric analyses.

Diabetic rats were hyperglycemic (blood glucose: $23 \pm 1$ vs. $8 \pm 1 \mathrm{mmol} / \mathrm{l}, P<0.001$ ) and had lower body weights and body surface areas after 3 months of diabetes, compared to age-matched control rats $(P<0.001)$. Mean arterial pressure was significantly reduced in diabetic rats $(92 \pm 2$ vs. $101 \pm 3 \mathrm{mmHg}$ ), whereas heart rate was comparable. Severe cardiac dysfunction was present after 3 months of diabetes, evidenced by reductions in cardiac output $(66 \pm 4$ vs. $109 \pm 4 \mathrm{ml} / \mathrm{min}, P<0.001)$, cardiac index $(0.214 \pm 0.014$ vs. $0.259 \pm 0.009$

$\left.\mathrm{ml} \cdot \mathrm{min}^{-1} . \mathrm{cm}^{-2}, P<0.05\right)$, stroke volume index $\left(0.60 \pm 0.03\right.$ vs. $0.72 \pm 0.03 \mu \mathrm{l} / \mathrm{cm}^{2}$, $P<0.05)$ and maximal flow acceleration $\left(246 \pm 14\right.$ vs. $\left.433 \pm 17 \mathrm{ml} / \mathrm{s}^{2}, P<0.001\right)$.

A hypotrophic inward remodeling, without a change in media-to-lumen ratio was observed in the abdominal aorta, the renal and femoral artery of diabetic rats. However, in the thoracic aorta no significant morphometric changes were observed, whereas small mesenteric arteries displayed a hypertrophic outward remodeling.

These results indicate that after 12 weeks of experimental diabetes, severe cardiac dysfunction and hemodynamic changes have developed. These changes were accompanied by heterogenous morphological adaptations of large and small arteries, depending on the anatomical location of the artery.
\end{abstract}




\section{Introduction}

Diabetes mellitus is an important risk factor for the development of cardiovascular diseases. In patients with diabetes, cardiac problems such as a reduction in stroke volume, cardiac index and ejection fraction, and an increase in left ventricular end diastolic pressure occur ${ }^{1,2}$. The presence of atherosclerosis often contributes to the development of cardiovascular diseases in diabetes ${ }^{3}$. But even in the absence of coronary vascular complications, heart failure develops in a considerable number of diabetic patients ${ }^{2,4}$. In rat models of type 1 diabetes, atherosclerotic lesions are practically absent, although blood glucose levels are chronically much more elevated than in patients ${ }^{s}$. Using the streptozotocin (STZ)-induced diabetic rat makes it therefore possible to study intrinsic hemodynamic changes independently of atherosclerotic complications. The presence of cardiovascular complications in experimental diabetes has been previously described. In perfused hearts of diabetic rats, a significant reduction in cardiac output, contractility and maximal relaxation rate were observed ${ }^{6-8}$. Nevertheless, conflicting results exist on hemodynamic studies in vivo. Hill and Larkins ${ }^{9}$ reported that after 8 weeks of STZ-induced diabetes, cardiac output was significantly reduced compared with age-matched control rats, whereas cardiac index was comparable. No significant changes occured after 4 weeks of diabetes. Litwin et al. ${ }^{10}$ showed that cardiac index and stroke volume index were significantly increased after 4 weeks of STZ-induced diabetes. However, these studies were performed in anesthetized animals, with or without open-chest. It is well-known that anesthesia may induce vasodilatation and hypotension ${ }^{11}$. Because small changes in blood pressure can have a large impact on overall hemodynamics, and because it is unlikely that diabetic and control rats respond with quantitatively comparable vasodepressant effects to the anesthetics used $^{12,13}$, it is important to study hemodynamic properties in conscious rats. Carbonell et al. ${ }^{14}$ studied hemodynamic alterations in conscious diabetic rats, using a thermodilution method. They found that after 12 weeks of STZ-induced diabetes, cardiac index and stroke volume index were increased and total peripheral resistance was reduced compared with control rats of similar body weights.

Changes in hemodynamic properties can have marked influences on peripheral vascular morphology ${ }^{15}$. Langille and $O^{\prime}$ Donnell ${ }^{16}$ reported that chronic decreases in blood flow of rabbit carotid arteries caused an endothelium-dependent reduction in diameter of this vessel. Chronic elevation of local blood flow, on the contrary, resulted in an increase in lumen diameter and media cross-sectional area of small mesenteric arteries ${ }^{17}$. These alterations in vascular structure, as a consequence of chronic changes in flow and/or pressure are collectively referred to as remodeling ${ }^{18}$. Only limited information is available on regional changes in vascular structure consequent on hemodynamic alterations in diabetes ${ }^{19,20}$.

The purpose of the present study was, therefore, to investigate the hemodynamic 
properties in conscious unrestrained rats following 3 months of STZ-induced diabetes and to evaluate the arterial morphological alterations in several elastic and muscular arteries, which may be linked to the hemodynamic changes.

\section{Research design and methods}

\section{Animals}

Male Wistar rats $(n=21$; Iffa Credo, Someren, The Netherlands) were housed under standard conditions $\left(20^{\circ} \mathrm{C}, 12 \mathrm{~h}\right.$ light/dark cycle) and given free acces to standard rat diet (Hope Farms, The Netherlands) and tap water. Diabetes was induced in 11 rats, weighing $200-250 \mathrm{~g}$, by an i.p. injection of streptozotocin ( 70 $\mathrm{mg} / \mathrm{kg})$. Control rats $(n=10)$ received vehicle only.

Hemodynamic measurements were performed 12-13 weeks after diabetes induction.

\section{Hemodynamic measurements}

\section{Instrumentation}

One week before the measurements, all animals were equipped with an electromagnetic flow probe $(2.7 \mathrm{~mm}$ diameter; Skalar, Delft, The Netherlands) on the ascending aorta, according to previously described methods ${ }^{21,22}$. Briefly, rats were anesthetized with sodium pentobarbital $(60 \mathrm{mg} / \mathrm{kg}$ i.p.). After endotracheal intubation and after positive pressure respiration was started, the thorax was opened in the third right intercostal space and the ascending aorta was dissected from surrounding tissue. The electromagnetic flow probe was placed around the aorta at 1-2 $\mathrm{mm}$ above the outlet of the heart. The thorax was closed in layers, the cable was fixed to the ribs, and the connector was exteriorized in the neck, where it was sutured to the skin.

Five days later, animals were again anesthetized with sodium pentobarbital and provided with an arterial and venous catheter. The arterial catheter (PE-10; Portex, Hythe, Kent, England) was implanted in the abdominal aorta through a femoral artery to measure arterial blood pressure. The venous catheter (PE-10) was implanted into the abdominal vena cava for bolus injections. Both catheters were exteriorized in the neck.

\section{Measurements and protocol}

Two to three days after catheter-implantations experiments were performed. The electromagnetic flow probe was connected to a sine-wave flowmeter (model MDL 401, Skalar, Delft, The Netherlands) to measure blood flow through the ascending aorta. Although this flow comprises cardiac output (CO) minus coronary blood flow, we refer to it as $\mathrm{CO}$. The baseline was established by taking the late diastolic 
biood flow as zero. The arterial catheter was connected to a low-volume displacement pressure transducer ( $\mathrm{CPO1}$; Century Technology, Inglewood, $\mathrm{CA}$, USA). All signals were fed into a computer, sampling all signals at $1000 \mathrm{~Hz}$ each. Mean values for arterial blood pressure (MAP) were obtained by digital integration. Heart rate (HR) was obtained from the flow signal. Stroke volume (SV) was calculated from the flow signal by integration of each beat. Total peripheral resistance (TPR) was calculated as MAP/CO. All derivations were made on-line and stored on disk for later processing.

After acclimatization of the animals, baseline recordings were made for $15 \mathrm{~min}$.

\section{Structural vascular properties}

\section{Tissue processing}

One day after hemodynamic measurements, rats were anesthetized with pentobarbital $(60 \mathrm{mg} / \mathrm{kg}$ i.p.). Blood was withdrawn via abdominal aortic puncture and was used for glucose and $\mathrm{HbA}_{\mathrm{lc}}$ measurements, using a hexokinase and a HPLC method respectively. Then, the animals were perfused retrogradely with PBS followed by perfusion with $2.5 \%$ phosphate-buffered formaldehyde at a pressure of $100 \mathrm{mmHg}$, via a catheter in the abdominal aorta. Sodium-nitroprusside (1 g/1; Sigma Chemical Co, St Louis, Mo, USA) was added to both perfusion solutions to ensure maximal vasodilatation. Segments of thoracic and abdominal aorta , carotid artery, renal artery, superior mesenteric artery and a mesenteric resistance artery were carefully excised. Anatomical landmarks were used to ensure that segments from exactly the same location were taken in every animal. All tissues were fixed overnight in $5 \%$ phosphate-buffered formaldehyde. Fixed tissues were then dehydrated and embedded in paraffin. Media cross-sectional area (CSA), defined as the area enclosed by the internal and external elastic laminae, and media thickness (Mt) were determined by semi-automated morphometry (JAVA 1.21, Jandel Scientific, Germany) on $4 \mu \mathrm{m}$ sections stained with Lawson's solution, a classic elastin stain. Lumen radius was calculated from the lumen area, assuming that this has a circular shape. Media-to-lumen ratio $(\mathrm{m} / \mathrm{l})$ was calculated as $\mathrm{Mt}$ divided by the lumen radius.

\section{Data analysis}

Results are expressed as mean $\pm \mathrm{SE}$. The hemodynamic properties $\mathrm{CO}, \mathrm{SV}$ and TPR were normalised for body surface area (BSA) using previously published methods $^{23}$. The formula used to calculate BSA from body weight takes into account the relatively starved state of the diabetic rats compared to control rats: BSA $\left(\mathrm{cm}^{2}\right)=k \cdot B W^{2 / 3}$ (BW = body weight in $\mathrm{g}$; $\mathrm{k}=7.47$ for control rats and $\mathrm{k}=7.64$ for starved rats).

Statistical significance of differences was evaluated by Students* $t$-test. A $P$-value 
$<0.05$ was considered statistically significant.

\section{Results}

\section{General characteristics of the study groups}

After 12 weeks of diabetes, body weight and BSA were significantly lower compared with age-matched control rats (Table 5.1). Diabetic rats were markedly hyperglycemic. $\mathrm{HbA}_{1 \mathrm{c}}$ levels were significantly elevated, indicating long-term hyperglycaemia.

Table 1.1 General characteristics of the study groups after 12 weeks of diabetes or age-matched controls.

\begin{tabular}{lcc}
\hline & Control rats & Diabetic rats \\
\hline Body weight $(\mathrm{g})$ & $420 \pm 6$ & $258 \pm 10^{*}$ \\
Body surface area $\left(\mathrm{cm}^{2}\right)$ & $419 \pm 6$ & $309 \pm 10^{*}$ \\
Blood glucose $(\mathrm{mM})$ & $8 \pm 1$ & $23 \pm 1^{*}$ \\
HbA $_{1 \mathrm{c}}(\%)$ & $1.4 \pm 0.1$ & $3.9 \pm 0.2^{*}$ \\
\hline
\end{tabular}

Data are means $\pm \mathrm{SE} . * P<0.001$

\section{Hemodynamic properties}

In table 5.2 the hemodynamic properties of conscious diabetic and age-matched control rats are shown. The diabetic animals showed a significant reduction in MAP $(P<0.05)$ compared with control animals, whereas heart rate was not influenced by the diabetic state. Cardiac output, as well as cardiac index, were significantly lower in the diabetic rats. Thus, even when the smaller BSA of the diabetic rats was taken into account, significantly smaller aortic flows were measured. Also peak flow was substantially reduced in diabetic rats $(P<0.001)$. Stroke volume, as an absolute value as well as indexed for BSA, was considerably. lower in the hyperglycemic animals compared with normoglycemic controls $(P<$ 0.01 and 0.05 respectively). In contrast, TPR was markedly increased in the diabetic rats $(P<0.01)$. Indexed for BSA, differences in TPR showed the same trend, but did not reach statistical significance.

The systolic phase was prolonged after 12 weeks of diabetes, as indicated by an enhanced left ventricular ejection time $(P<0.01)$. Maximal aortic flow acceleration and deceleration were significantly reduced in the diabetic rats compared with normoglycemic controls $(P<0.001)$. 


\section{Vascular morphology}

In table 5.3, morphologic properties of large and small arteries are summarized. Diabetes-induced changes in vascular morphology appeared to be regionally selective. In the thoracic aorta, no significant differences could be observed between diabetic and control rats. However, in the carotid and superior mesenteric artery, a significantly smaller media mass, accompanied by comparable lumen dimensions, led to a strong reduction in media-to-lumen ratio in the diabetic group compared with the control group $(P<0.01)$. On the contrary, a reduction in media mass together with a smaller lumen radius, led to a comparable media-to-lumen ratio in the renal and femoral artery, as well as in the abdominal aorta of diabetic rats. In mesenteric small arteries, a significant increase in CSA and lumen radius was observed $(P<0.05$ and 0.01 respectively), with no change in media-to-lumen ratio.

Table 5.2 Hemodynamic measurements in conscious rats.

\begin{tabular}{|c|c|c|}
\hline & Control rats & Diabetic rats \\
\hline MAP $(\mathrm{mmHg})$ & $101 \pm 3$ & $92 \pm 2$ \\
\hline HR (beats-per-min) & $362 \pm 4$ & $361 \pm 14$ \\
\hline Cardiac output (mi/min) & $109 \pm 4$ & $66 \pm 4 *$ \\
\hline Cardiac index $\left(\mathrm{ml} \cdot \mathrm{min}^{-1} \cdot \mathrm{cm}^{-2}\right)$ & $0.259 \pm 0.009$ & $0.214 \pm 0.014^{*}$ \\
\hline SV $(\mu \mathrm{l})$ & $301 \pm 11$ & $185 \pm 10 \neq$ \\
\hline$S V$ index $\left(\mu l / \mathrm{cm}^{2}\right)$ & $0.72 \pm 0.03$ & $0.60 \pm 0.03 *$ \\
\hline TPR (mmHg.min/ml) & $0.94 \pm 0.04$ & $1.45 \pm 0.11+$ \\
\hline TPR index $\left(\mathrm{mmHg} \cdot \mathrm{min} \cdot \mathrm{ml}^{-1} \cdot \mathrm{cm}^{2}\right)$ & $393 \pm 19$ & $446 \pm 32$ \\
\hline Peak flow (ml/min) & $436 \pm 16$ & $251 \pm 14 *$ \\
\hline Left ventricular ejection time (ms) & $63 \pm 1$ & $68 \pm 21$ \\
\hline$+\mathrm{d} \mathrm{F} / \mathrm{dt}_{\max }\left(\mathrm{ml} / \mathrm{s}^{2}\right)$ & $433 \pm 17$ & $246 \pm 14 *$ \\
\hline$-\mathrm{dF}^{2} / \mathrm{dt}_{\text {intare }}\left(\mathrm{ml} / \mathrm{s}^{2}\right)$ & $220 \pm 9$ & $93 \pm 9 *$ \\
\hline
\end{tabular}

Data are means \pm SE. $* P<0.05, \uparrow P<0.01, \pm P<0.001$. 
Table 5.3 Morphometric measuremenis of maximally dilated arteries from pressure perfusionfixed animals.

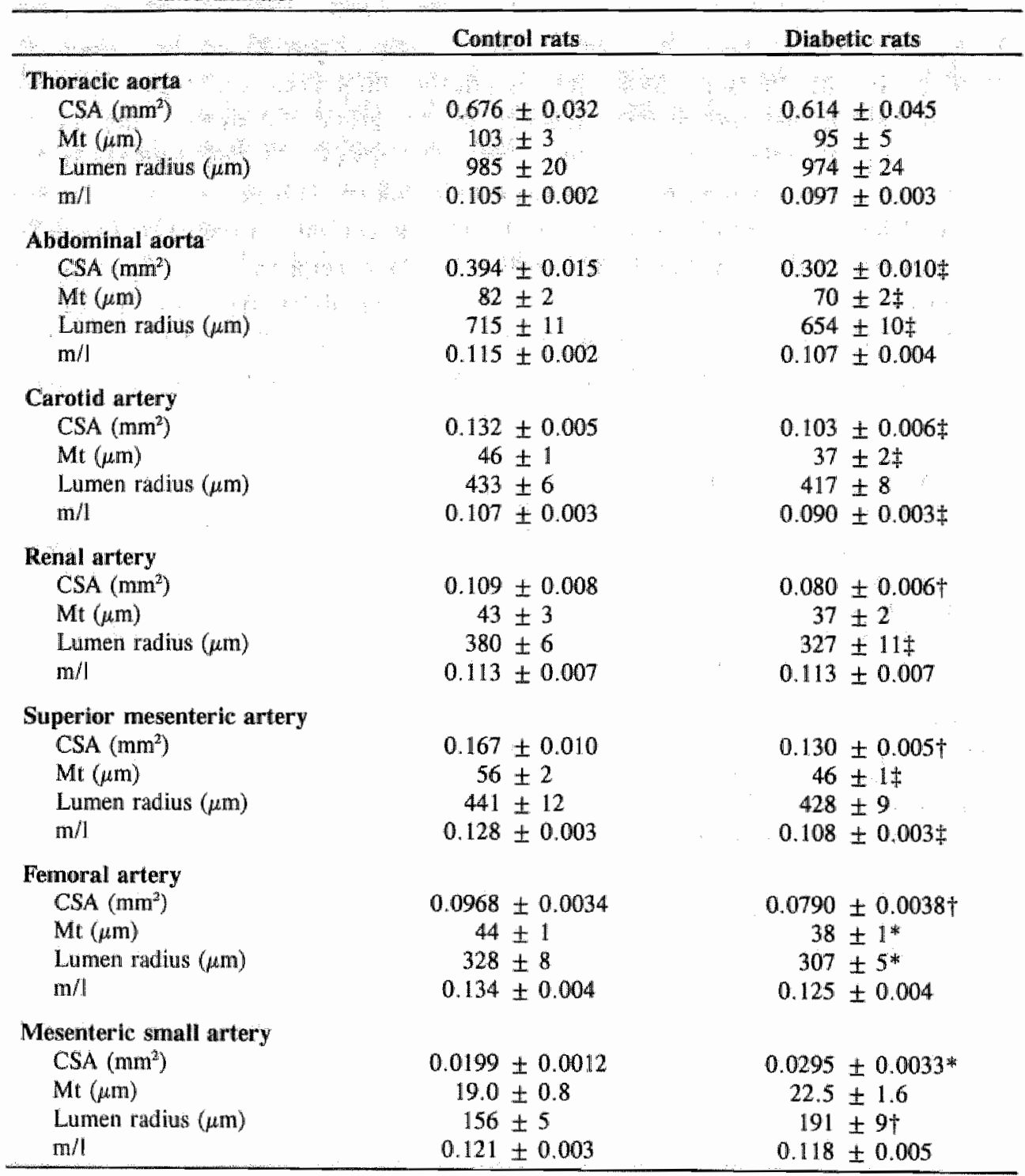

Datat are means \pm SE. $* P<0.05,+P<0.01, \ddagger P<0.001$. 


\section{Discussion}

The present study shows that considerable cardiovascular complications develop in rats during 3 months of STZ-induced diabetes. This was demonstrated by means of significant reductions of indicators of cardiac function in conscious diabetic rats. Furthermore, heterogeneous structural changes occurred in arteries of diabetic rats in a regionally specific manner.

After 3 months of STZ-induced diabetes, MAP was significantly lower in the diabetic rats compared with age-matched controls. Similar results were obtained by Jackson and Carrier ${ }^{24}$ and Kusaka et al. ${ }^{25}$ in conscious rats, even after shorter diabetes-duration. A reduction in cardiac index, without a change in indexed TPR, accounts for the observed reduction in MAP.

Heart rates were comparable in control and diabetic rats, but are often reported to be reduced ${ }^{13,24}$. The shorter diabetes duration in these studies (4-5 weeks) may contribute to the discrepancy with our study. Also the stress-state of the animals has an impact on heart rate. In the study of Jackson and Carrier ${ }^{24}$ rats were restrained during the measurements, and thus probably more stressed. Stresshormones induce tachycardia to a greater extent in control rats than in diabetic animals ${ }^{24}$. The chronic reduction in MAP can cause an increase in left ventricular ejection time without a change in heart rate, as observed in our diabetic animal ${ }^{26}$. Cardiac output and index, as well as stroke volume (index) and peak flow were significantly reduced in rats after 12 weeks of diabetes. Hill and Larkins ${ }^{9}$ reported that the $\mathrm{CO}$ was reduced after 8 weeks of STZ-induced diabetes, whereas cardiac index, expressed as $\mathrm{CO}$ per body weight, was unchanged in anesthetized rats. Carbonell et al. ${ }^{14}$ described an increase in cardiac index $(\mathrm{CO} /$ body weight) and stroke volume index (SV/body weight) in conscious 12 weeks diabetic rats, compared with weight-matched control animals ${ }^{14}$. Important in the interpretation of these data, is the correction that was made for the large differences in body weight. Diabetes inevitably leads to lower weight gain, which is partly due to the loss of fat mass, that is relatively under-perfused and does not play an important role in $\mathrm{CO}$ distribution. In contrast, some organs such as the kidney ${ }^{27}$ and the small intestine ${ }^{28}$ have an increased weight in experimental diabetes. This suggests that a simple correction for body weight might not be correct. We therefore corrected our data for body surface area instead of body weight, using a formula with different constant values for normal and starved rats.

We observed significant reductions in maximal flow acceleration and deceleration rates in the diabetic rats. This indicates that 12 weeks of STZ-induced diabetes causes severe cardiac dysfunction, comparable to the human situation ${ }^{2,4}$. This may be due to defects in contractile properties of the heart in diabetes, consequent on changes in the regulation of contractile proteins ${ }^{29}$ and intracellular $\mathrm{Ca}^{2+}$ handling ${ }^{30}$. 
We hypothesized that the marked reduction in $\mathrm{CO}$ and alterations in $\mathrm{CO}$ distribution ${ }^{9}$ in diabetes would influence morphology of large and small arteries, analogous to the described structural adaptations of arteries to altered blood flow ${ }^{\text {is }}$. Indeed, we noticed a hypotrophic inward remodeling ${ }^{\text {18 }}$ in the abdominal aorta and the renal and femoral artery of diabetic rats, leading to an unchanged $\mathrm{m} / \mathrm{l}$ ratio, presumably in response to the reduction in aortic flow. Similar structural responses were seen in rat mesenteric arteries, that were exposed to a reduced blood flow for 4 weeks $^{17}$. However, although flow through the thoracic aorta, the superior mesenteric artery and the carotid artery is also reduced in diabetic rats; these arteries have responded differently to the flow-changes from what was expected. The thoracic aorta of diabetic rats displayed no significant morphological changes in comparison with control vessels. Possibly, the lack of changes in dimensions of the thoracic aorta in diabetic rats, depends on an increased stiffness of this elastic artery in diabetic rats ${ }^{31}$.

In the carotid and superior mesenteric artery of diabetic rats, a significant reduction in $\mathrm{m} / \mathrm{l}$ ratio was observed, due to a reduction in wall mass, without a significant change in lumen radius. This hypothrophic remodeling may occur in response to a reduced flow and pressure in these arteries. However, since this is again an elastic artery, which is also subjected to hyperglycaemia-induced stiffening ${ }^{32}$, lumen radius remains relatively large. In mesenteric small arteries of diabetic rats, we observed a hypertrophic outward remodeling. This means that wall mass as well as lumen radius were increased, in this case leading to an unchanged $\mathrm{m} / \mathrm{l}$ ratio. This is in agreement with earlier findings in mesenteric arteries and arterioles after 3 weeks and 6 months of diabetes ${ }^{19,33}$. In an earlier study of our group ${ }^{20}$, outward remodeling without a statistically significant increase in wall mass was found in mesenteric arteries with a shorter diabetes duration (7-9 weeks). On that occasion, we hypothesized that an increased flow to the small intestine of diabetic rats, due to marked hyperphagia ${ }^{9,34}$, is a plausible stimulus for the outward remodeling in mesenteric arteries. In addition to the outward remodeling, chronic increases in blood flow are associated with wall hypertrophy, which normalizes circumferential wall stress, that increases during the expansion of the vessel ${ }^{17,35}$. However, this is in contradiction with the finding of a hypotrophic remodeling in the superior mesenteric artery. Possibly the difference in wall composition of the larger elastic arteries, such as the superior mesenteric artery, and the smaller mesenteric arteries, which are predominantly composed of smooth muscle cells with less extracellular matrix, makes them respond differently to mechanical and chemical changes. Furthermore, the small resistance arteries are much more innervated than large arteries, which might possibly influence structural responses. More research is needed to further elucidate the heterogeneous structural changes in diabetes.

In conclusion, this study demonstrates that after 12 weeks of experimental diabetes, in the absence of atherosclerosis, severe cardiac dysfunction has develloped. In 
conscious rats, significant reductions in cardiac output and index, peak flow, stroke volume and maximal aortic flow acceleration and deceleration were observed. These hemodynamic alterations were associated with marked changes in morphology of large and small arteries. Depending on the localization of the artery, hypotrophic (inward) remodeling as well as hypertrophic outward remodeling and absence of morphological changes were observed. The nature of the remodeling depended upon the type of blood vessel. 


\section{References}

1. Rodrigues B, McNeill JH. The diabetic heart: metabolic causes for the development of a cardiomyopathy. Cardiovasc Res 1992;26:913-22.


1974;229:1749-54.

3. Van Hoeven $\mathrm{KH}$, Factor SM. Diabetic heart disease. I. The clinical and pathological spectrum. Clin Cardiol 1989;12:600-604.

4. D'Elia JA, Weinrauch LA, Healy RW, Libertino JA, Bradley RF, Leland OS. Myocardial dysfunction without coronary artery disease in diabetic renal failure. Am J Cardiol 1979;43:193-99.

5. Reaven P, Merat S, Casanada F, Sutphin M, Palinski W. Effect of streptozotocininduced hyperglycemia on lipid profiles, formation of advanced glycation endproducts in lesions, and extent of atherosclerosis in LDL receptor-deficient mice. Arterioscler Thromb Vasc Biol 1997;17:2250-56.

6. Smith JM, Paulson DJ, Romano FD. Inhibition of nitric oxide synthase by LNAME improves ventricular performance in streptozotocin-diabetic rats. J Mol Cell Cardiol 1997;29:2393-2402.

7. Penpargkul S, Schaible T, Yipintsoi T, Scheuer J. The effect of diabetes on performance and metabolism of rat hearts. Circ Res 1980;47:911-21.

8. Rodrigues $\mathrm{B}, \mathrm{McNeill} \mathrm{JH}$. Cardiac dysfunction in isolated perfused hearts from spontaneously diabetic BB rats. Can J Physiol Pharmacol 1990;68:514-18.

9. Hill MA, Larkins RG. Alterations in distribution of cardiac output in experimental diabetes in rats. Am J Physiol 1989;257:H571-80.

10. Litwin SE, Raya TE, Daugherty S, Goldman S. Peripheral control of cardiac output in diabetic rats. Am J Physiol 1991;261:H836-42.

11. Altura BM, Altura BT, Carella A, Turlapaty PDMV, Weinberg J. Vascular smooth muscle and general anesthetics. Fed Proc 1980;39:1584-91.

12. Crijns FRL, Struijker Boudier HAJ, Wolffenbuttel BHR. Arteriolar reactivity in conscious diabetic rats. Influence of aminoguanidine treatment. Diabetes 1998;47: 918-23.

13. Yu Z, McNeill JH. Blood pressure and heart rate response to vasoactive agents in conscious diabetic rats. Can J Physiol Pharmacol 1992;70:1542-48.

14. Carbonell LF, Salom MG, Garcia-Estan J, Salazar FJ, Ubedo M, Qesada T. Hemodynamic alterations in chronically conscious unrestrained diabetic rats. Am J Plyysiol 1987;252:H900-H05.

15. Langille BL. Arterial remodeling: relation to hemodynamics. Can J Physiol Pharmacol 1996;74:834-41.

16. Langille $\mathrm{BL}$, O'Donnell $\mathrm{F}$. Reductions in arterial diameter produced by chronic decreases in blood flow are endothelium-dependent. Science 1986;231:405-7.

17. Pourageaud $F_{n}$ De Mey JGR. Structural properties of rat mesenteric small arteries after 4-wk exposure to elevated or reduced blood flow. Am J Physiol 1997;273: H1699-706. 
18. Mulvany MJ, Baumbach GL, Aalkjaer C, Haegerty AM. Vascular remodeling. Hypertension 1996;28:505-6.

19. Connors BA, Bohlen HG, Evan AP. Vascular endothelium and smooth muscle remodeling accompanies hypertrophy of intestinal arterioles in streptozotocin diabetic rats. Microvasc Res 1995;49:340-49.

20. Crijns FRL, Wolffenbuttel BHR, De Mey JGR, Struijker Boudier HAJ. Mechanical properties of mesenteric arteries in diabetic rats: consequences of outward remodeling. Am J Physiol 1999;276:H1672-77.

21. Schoemaker RG, Debets JJM, Struijker Boudier HAJ, Smits JFM. Delayed but not immediate captopril therapy improves cardiac function in conscious rats, following myocardial infarction. J Mol Cell Cardiol 1991;23:187-97.

22. Smits JFM, Coleman TG, Smith TL, Kasbergen CM, van Essen H, Struijker Boudier HAJ. Antihypertensive effect of propranolol in conscious spontaneously hypertensive rats: central hemodynamics, plasma volume, and renal function during beta-blockade with propranolol. J Cardiovasc Pharmacol 1982;4:903-14.

23. Petty C. Miscellaneous. In: Research techniques in the rat. Charles C Thomas, Springfield, Illinois 1982;271-306.

24. Jackson CV, Carrier GO. Influence of short-term experimental diabetes on blood pressure and heart rate in response to norepinephrine and angiotensin II in the conscious rat. I Cardiovase Pharmacol 1983;5:260-65.

25. Kusaka M, Kishi K, Sokabe H. Does so-called streptozotocin hypertension exists in rats? Hypertension 1987;10:517-21.

26. De Scalzi M, De Leonardis. V, Citi S, Cinelli P. Relationship between systolic time intervals and arterial blood pressure. Clin Cardiol 1986;9:545-49.

27. Seyer-Hansen K. Renal hypertrophy in experimental diabetes. Kidney Int 1983;23: 643-46.

28. Unthank JL, Bohlen HG. Intestinal microvascular growth during maturation in diabetic juvenile rats. Circ Res 1988;63:429-36.

29. Malhotra A, Sanghi V. Regulation of contractile proteins in diabetic heart. Cardiovasc Res 1997;34:34-40.

30. Pierce GN, Russell JC. Regulation of intracellular $\mathrm{Ca}_{2}+$ in the heart during diabetes. Cardiovasc Res 1997;34:41-47.

31. Wolffenbuttel BHR, Boulanger CM, Crijns FRL, Huijberts MSP, Poitevin P, Swennen GNM, Vasan S, Egan JJ, Ulrich P, Cerami A, Lévy BI. Breakers of advanced glycation end products restore large artery properties in experimental diabetes. Proc Natl Acad Sci USA 1998;95:4630-34.

32. Huijberts MSP, Wolffenbuttel BHR, Struijker Boudier HAJ, Crijns FRL, Nieuwenhuijzen Kruseman AC, Poitevin P, Lévy BI. Aminoguanidine treatment increases elasticity and decreases fluid filtration of large arteries from diabetic rats. J Clin Invest 1993;92:1407-11.

33. Vranes $D$, Cooper ME, Dilley $\mathbb{R}$. Angiotensin-converting enzyme inhibition reduces diabetes-induced vascular hypertrophy: morphometric studies. IJ Vasc Res 1995;32:183-89. 
34. Friedman $\mathrm{MI}_{\text {; }}$ Ramirez I. Food intake in diabetic rats: relationship to metabolic effects of insulin treatment. Physiology and Behaviour 1994;56:373 78 .

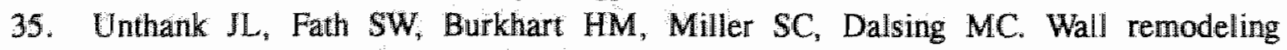
during luminal expansion of mesenteric arterial collaterals in the rat. Circ Res $1996 ; 79: 1015-23$. 


\section{Chapter 6}

\section{Breakers of advanced glycation end products restore large artery properties in experimental diabetes}

BHR Wolffenbuttel, CM Boulanger, FRL Crijns, MSP Huijberts, P Poitevin, GNM Swennen, S Vasan, JJ Egan, P Ulrich, A Cerami, BI Lévy

Proc Natl Acad Sci 1998; 95: 4630-4634 


\begin{abstract}
Glucose and other reducing sugars react with proteins by a nonenzymatic, posttranslational modification process called nonenzymatic glycation. The formation of advanced glycation end products (AGEs) on connective tissue and matrix components accounts largely for the increase in collagen cross-linking that accompanies normal aging and which occurs at an accelerated rate in diabetes, leading to an increase in arterial stiffness. A new class of AGE crosslink 'breakers' reacts with and cleaves these covalent, AGE-derived protein crosslinks. Treatment of rats with streptozotocin-induced diabetes with the AGE-breaker ALT-711 for 1-3 weeks reversed the diabetes-induced increase of large artery stiffness as measured by systemic arterial compliance, aortic impedance and carotid artery compliance and distensibility. These findings will have considerable implications for the treatment of patients with diabetes-related complications and aging.
\end{abstract}




\section{Introduction}

Altered arterial wall properties that develop in diabetes may influence important determinants of circulatory function, such as peripheral resistance, neural control mechanisms, and cardiac work ${ }^{1}$. In comparison to the small quantitative alterations $^{2-5}$, qualitative collagen changes may be of more importance: formation of advanced glycation end products (AGEs) plays a crucial role in the etiology of diabetic complications ${ }^{6}$. Glucose-derived crosslinks on collagen are formed under hyperglycemic conditions, and these crosslinks drastically alter the structure and function of this protein ${ }^{7-10}$. Increased arterial stiffness was observed in patients with diabetes, and showed a strong correlation with blood glucose levels ${ }^{11}$ and increased aorta and myocardial collagen advanced glycation ${ }^{12}$.

Previously, our group has shown that arterial wall stiffness was increased in diabetic rats: characteristic input impedance of the ascending aorta, determined from phasic recordings of pressure and flow, was higher and carotid artery compliance lower in diabetic rats than in controls ${ }^{13}$. Treatment of these diabetic rats with aminoguanidine, an inhibitor of AGE formation, significantly increased carotid artery compliance and decreased aortic impedance ${ }^{14}$. Normalization of blood glucose levels reduced the amount of glycation products on collagen ${ }^{15}$. These results suggested that the disturbances of vascular mechanical properties in experimentall diabetes are caused by AGE accumulation ${ }^{14}$.

To further substantiate this concept, we evaluated the effects of a newly developed AGE breaker compound ALT-711 on functional arterial wall properties in diabetic rats. ALT-711 is the stable 4,5-dimethylthiazolium derivative of the prototype compound $\mathrm{N}$-phenacylthiazolium bromide ${ }^{16}$, which has been shown to break AGEs in vitro and in vivo. Treatment of rats with streptozotocin-induced diabetes with ALT-711 for 1-3 weeks reversed the diabetes-induced increase of large artery stiffness as measured by systemic arterial compliance and characteristic aortic input impedance, and by carotid artery compliance and distensibility assessed in vivo and in vitro. These findings will have significant impact on the future treatment of patients with diabetes-related complications and aging.

\section{Research design and methods}

\section{Animals}

Male Wistar rats were made diabetic at the age of $9-10$ weeks by intraperitoneal injection of $70 \mathrm{mg} / \mathrm{kg}$ of streptozotocin. Only animals that developed blood glucose levels $>15 \mathrm{mmol} / \mathrm{l}$ were used. After 9 weeks of diabetes, the animals were divided into three groups: one group was studied to assess the exact hemodynamic changes 
that were caused by the diabetic state $(n=13)$, and two groups received ALT-711 (1.0 mg/kg/day i.p.) for a period of 1 or 3 weeks ( $n=8-10$ animals in each group) to assess possible reversal of the diabetes-induced cardiovascular abnormalities by treatment with this compound. Studies were carried out in a fixed scheme, allowing comparable exposure to hyperglycaemia in all animals before therapy. Diabetes duration was $62 \pm 5$ days in untreated animals, $65 \pm 2$ days in the animals that subsequently were treated for 1 week (total diabetes duration $72 \pm 2$ days), and $60 \pm 3$ days in the animals treated for 3 weeks (total diabetes duration $80 \pm 3$ days).

\section{Hemodynamic measurements}

Details regarding the surgical procedure and hemodynamic measurements have been described elsewhere ${ }^{17}$. In summary, animals were anesthetized with $50 \mathrm{mg} / \mathrm{kg}$ of pentobarbital i.p., and placed on a heating pad, intubated, and ventilated with a rodent respirator (Harvard Bioscience model 683, South Natick, MA, USA). After midsternal thoracotomy, an adapted. Doppler probe was placed around the ascending aorta to measure mean (cardiac output minus coronary blood flow) and phasic aortic blood flow ${ }^{17}$. A 2F Millar Instruments (Houston, TX, USA) catheter tip pressure transducer was advanced into the ascending aorta. After stabilization for 10 minutes, aortic blood flow and pressure were recorded on a beat-to-beat basis for $30 \mathrm{sec}$, averaged, and processed by a microcomputer system with analogdigital converter. In this way, systolic, diastolic and mean arterial blood pressure (BP), mean cardiac output, and heart rate were determined.

The elasticity assessment of the arterial system is based on the concept that mechanically- the arterial system can be regarded as a simple elastic system, which discharges during diastole into a single resistance representing the total peripheral resistance. Systemic arterial compliance (SAC) can be regarded as a global parameter, representing the mechanical properties of the whole aorta ${ }^{18}$. The stiffer the arterial wall is, the lower the compliance. Liu et al. ${ }^{19}$ have proposed a modification of this method, which is based on the measurement of the surfaces under the systolic and diastolic parts of the aortic pressure curve; this method is less dependent on actual bllood pressure. Pulsatile aortic pressure and flow signals were subjected to Fourier analysis and impedance modulus and phase-determined from the harmonic components. Corrections were made for the delay of the pressure transducer and flowmeter, which was linear $(6.6 / \mathrm{Hz})$ in the frequency range $0-50 \mathrm{~Hz}$. Characteristic aortic input impedance $(\mathrm{Zc})$ mainly represents the elastic modulus of the ascending thoracic aorta ${ }^{20}$, and was taken as the average value of the modulus of impedance for high frequencies (4th to 10th harmonic) ${ }^{20}$. This parameter is independent of the reflection waves and is higher when the aorta is stiffer. The impedance modulus at 0 frequency represents total peripheral resistance (TPR). Cardiac output and TPR have been corrected for body surface area (BSA). 


\section{Carotid artery compliance}

Both common carotid arteries were dissected free. Pressure was measured in the right carotid artery with a $2 \mathrm{~F}$ Millar catheter tip pressure transducer. The diameter and change in diameter of the left carotid artery during the cardiac cycle were assessed by using a vessel wall echotracking system (Asulab S.A., Neuchâtel; Switzerland) using a $10 \mathrm{MHz}$ probe $\mathrm{e}^{21}$, and converted to lumen areas and changes thereof ( $A$ and $\triangle A$ ), assuming a circular cross-section of the vessel. Carotid artery cross-sectional compliance (CSC) was determined by computing the ratio of lumen area $(\triangle A)$ and phasic pressure oscillations $(\Delta P)$ as $\operatorname{CSC}=\Delta A / \Delta P$.

\section{In vitro carotid artery compliance and distensibility}

The distal end of the left carotid artery was first ligated and then catheterized with a 9-gauge catheter and connected via a three-way stopcock to a reservoir filled with Tyrode's solution containing albumin $(4 \%)$ at $130 \mathrm{~mm} \mathrm{H}_{2} \mathrm{O}$, as described previously $^{22}$. The presence of albumin in incubating and flushing solutions maintained a physiological osmotic pressure gradient across the arterial wall and preserved the endothelial integrity and functions. A second catheter closed with a three-way stopcock pointing distally was then inserted into the proximal ligated end of the carotid artery. By this procedure, a pressure of $130 \mathrm{~cm} \mathrm{H} \mathrm{H}_{2} \mathrm{O}$ (approximately $100 \mathrm{~mm} \mathrm{Hg}$ ) was continuously maintained within an isolated segment of carotid artery (20-23 mm long). The two catheters were then clamped into a crossbar that maintained the artery at its in vivo length and prevented shortening on excision. Removed carotid artery segments were immersed in a bath containing a modified Krebs-Ringer bicarbonate solution (pH 7.4, $95 \% \mathrm{O}_{2}, 5 \% \mathrm{CO}_{2}, 38^{\circ} \mathrm{C}, 10 \mathrm{mM}$ HEPES, $4 \%$ albumin, $25 \mathrm{mM}$ glucose). A glass tube $30 \mathrm{~cm}$ long and $0.5 \mathrm{~cm}$ in diameter was filled with alburnin-Tyrode's solution and connected to a manometer pressurized to $100 \mathrm{~mm} \mathrm{Hg}$ and to the still-pressurized artery via a three-way stopcock: The artery was then perfused discontinuously for 30 seconds every 20 minutes. Changes in the carotid artery diameter were determined with an ultrasonic microdimensiometer (Application Electronique, Montreuil, France), which allowed continuous measurement of the arterial diameter (with an accuracy of measurement better than $10 \mu \mathrm{m})$. During step-wise increase in pressure $(75-150 \mathrm{mmHg}$ ), diameter and lumen area changes were assessed in response to pressure (elasticity). The protocol was repeated after incubating the vessel with $\mathrm{KCN}$ to abolish smooth muscle cell function (passive elasticity). Carotid artery cross-sectional compliance (CSC) was calculated by the ratio of lumen area $(\triangle A)$ and pressure $(\triangle P)$ as $\operatorname{CSC}=\triangle A / \triangle P$; carotid artery distensibility was calculated as compliance divided by baseline cross-sectional lumen area: $(\triangle \mathrm{A} / \mathrm{A}) / \Delta \mathrm{P}$. 


\section{Collagen cross-linking}

Because it is likely that the observed improvements result from a reduced crosslinking of arterial wall extracellular matrix proteins, we assessed the effects of ALT-711 on collagen cross-linking. For this purpose, tails were removed and the tail collagen was dissected from the tendon sheet by gentle pulling. The tendons were cleaned free of debris and fat in NaCl $0.9 \%$ over ice, rolled into a ball, patted dry on paper towels, lyophylized and transferred to capped polypropylene tubes. Samples were stored at $-70^{\circ} \mathrm{C}$ until use. Collagen solubility was assessed by treating tail tendon collagen with pepsin $(5.0 \mu \mathrm{g} / \mathrm{ml})$ for $45 \mathrm{~min}$, according to previously described methods ${ }^{23,24}$.

\section{Red blood cell-IgG assay}

Another biochemical marker of the effects of ALT-711 is its capacity to break crosslinks of $\mathrm{IgG}$ to red blood cells ( $\mathrm{RBCs})^{16}$. In a separate series of experiments, the biochemical effects of ALT-711 treatment were studied in STZ-diabetic male Lewis rats. After 3 months of diabetes, treatment with vehicle or ALT-711 administered orally by gavage in a dose of $10 \mathrm{mg} / \mathrm{kg}$ was initiated, and blood samples were collected after $1,2,5$ and 10 weeks of treatment for erythrocyte-cellsurface IgG determinations using an anti-IgG ELISA adapted for use with celluloseester-membrane-sealed 96-well microtitre plates (Multiscreen-HA, Millipore). Also, a separate series of diabetic rats were treated for 8 days with ALT-711 in doses varying from 0.01 to $10 \mathrm{mg} / \mathrm{kg}$. Heparinized blood was washed three times with PBS; the packed RBCs were diluted 1:250-1:500 in PBS. Membrane-containing wells first were blocked with $0.3 \mathrm{ml}$ of Superblock (Pierce), then washed with 0.3 $\mathrm{ml} \mathrm{PBS} / 0.05 \%$ Tween, followed by $0.1 \mathrm{ml}$ PBS. RBCs were gently vortexed and $50-\mu \mathrm{l}$ aliquots pipetted into wells. Cells then were washed, and $50 \mu 1$ of a polyclonal rabbit anti-rat IgG (Sigma, diluted 1:25,000) was added. After incubation at room temperature for $2 \mathrm{hr}$, the cells were washed 3 times with PBS, once with Tris-buffered saline, and $0.1 \mathrm{ml}$ of $\mathrm{p}$-nitrophenyl phosphate substrate was added $(1 \mathrm{mg} / \mathrm{ml}$ in $0.1 \mathrm{M}$ diethanolamine buffer, $\mathrm{pH} \mathrm{9.5).} \mathrm{By} \mathrm{this} \mathrm{technique,} \mathrm{the}$ A410 of non-diabetic red cells was $0.10 \pm 0.02$ and the A410 of diabetic red cells was $0.57 \pm 0.06(\mathrm{n}=4 ; P<0.001)$.

\section{Statistical analysis}

All results are reported as mean $\pm \mathrm{SD}$, unless stated otherwise. Differences between groups were evaluated by using a one-way analysis of variance (ANOVA) with Student-Newman-Keuls correction for multiple comparisons, and linear-trend analysis for treatment effects. A two-tail $P$ value of $<0.05$ was considered as statistically significant. 


\section{Results}

\section{Hemodynamic measurements}

Body weight of the animals at randomization was $255 \pm 15 \mathrm{~g}$ and comparable between the groups; ALT-711 treatment did not result in significant weight changes. Also, blood glucose levels were not different. Table 6.1 provides details on the metabolic and hemodynamic data, as well as results of hemodynamic measurements obtained in nondiabetic animals of comparable age. Between the three groups of diabetic animals, systolic, diastolic and mean arterial BP were not different. In comparison with nondiabetic age-matched control animals, body weight of the diabetic animals was lower, while BP and cardiac output were slightly higher. However, SAC was lower, and $\mathrm{Zc}$ was considerably higher, indicating significant alterations of vascular wall properties. Treatment with ALT711 resulted in an increase in cardiac output, a reduction of total and indexed peripheral resistance, an increase of $\mathrm{SAC}$, and a reduction of $\mathrm{Zc}$, with increasing duration of treatment (Table 6.1).

Table 6.1 Glycemic and hemodynamic measurements performed in diabetic animals and diabetic animals treated with ALT-711 for 11 or 3 weeks

\begin{tabular}{|c|c|c|c|c|}
\hline Treatment & $\begin{array}{l}\text { Non-diabetic } \\
\text { controls }\end{array}$ & $\begin{array}{l}\text { 9-weeks } \\
\text { diabetes }\end{array}$ & $\begin{array}{l}\text { Diabetes + } \\
1 \text { week }\end{array}$ & $\begin{array}{l}\text { ALT-711 for: } \\
3 \text { weeks }\end{array}$ \\
\hline Blood glucose (mmol/l) & $6.0 \pm 2.0$ & $24.5 \pm 3.2^{*}$ & $23.3 \pm 2.9$ & $24.0 \pm 3.5$ \\
\hline $\mathrm{HbAlc}(\%)$ & $1.3 \pm 0.3$ & $4.7 \pm 0.4^{*}$ & $4.6 \pm 0.5$ & $4.6 \pm 0.5$ \\
\hline Body weight $(\mathrm{g})$ & $354 \pm 29$ & $258 \pm 14^{*}$ & $255 \pm 16$ & $251 \pm 15$ \\
\hline Systolic BP (mmHg) & $126 \pm 11$ & $111 \pm 12^{*}$ & $108 \pm 11$ & $109 \pm 13$ \\
\hline Diastolic BP ( $\mathrm{mmHg}$ ) & $98 \pm 8$ & $87 \pm 15$ & $83 \pm 10$ & $85 \pm 16$ \\
\hline Mean BP (mmHg) & $111 \pm 10$ & $98 \pm 15$ & $95 \pm 10$ & $96 \pm 16$ \\
\hline Heart rate (/min) & $412 \pm 66$ & $321 \pm 32^{*}$ & $296 \pm 25$ & $320 \pm 34$ \\
\hline Cardiac output $(\mathrm{m} / \mathrm{min})$ & $69 \pm 6$ & $59 \pm 15$ & $62 \pm 10$ & $75 \pm 18 H$ \\
\hline Cardiac index $\left(\mathrm{ml} / \mathrm{min} / \mathrm{cm}^{2}\right)$ & $0.19 \pm 0.02$ & $0.19 \pm 0.05$ & $0.21 \pm 0.03$ & $0.25 \pm 0.07 H$ \\
\hline TPR $\left(10^{3}\right.$ dyrie sec/ $\left./ \mathrm{cm}^{5}\right)$ & $128 \pm 17$ & $141 \pm 46$ & $126 \pm 31$ & $107 \pm 348$ \\
\hline TPR-index (dyne $\left.\mathrm{sec} / \mathrm{cm}^{3}\right)$ & $359 \pm 35$ & $463 \pm 170$ & $429 \pm 106$ & $357 \pm 1238$ \\
\hline $\mathrm{SAC}\left(10^{-3} \mathrm{~mL} / \mathrm{mm} \mathrm{Hg}\right)$ & $6.9 \pm 0.6$ & $5.6 \pm 1.8^{*}$ & $6.4 \pm 1.6$ & $7.3 \pm 3.3 n$ \\
\hline $\mathrm{Zc}\left(10^{3}\right.$. dyne. $\left.\mathrm{sec} / \mathrm{m}^{3}\right)$ & $8.7 \pm 3.1$ & $13.3 \pm 4.6^{*}$ & $11.7 \pm 4.2$ & $8.6 \pm 3.8 \#$ \\
\hline
\end{tabular}

Values are mean $\pm \mathrm{SD} ; ", P<0.05$ vs. non-diabetic control animals; " $P<0.05$ and,$P=0.075$ by ANONA vs. 9-week diabetic animals.

\section{Carotid artery compliance and distensibility in vivo}

Both systolic and diastolic carotid artery lumen diameter were significantly larger in animals treated 1 and 3 weeks. The change of vessel cross-sectional lumen area during the cardiac cycle was larger for both groups of ALT-711 treated animals, whereas the pressure changes were not different. Hence, the cross-sectional 
compliance of the carotid artery, which reflects the buffering capacities of the vessel, was significantly increased by $40 \%$ as a cause of the AGE-breaker treatment (Figure 6.1).

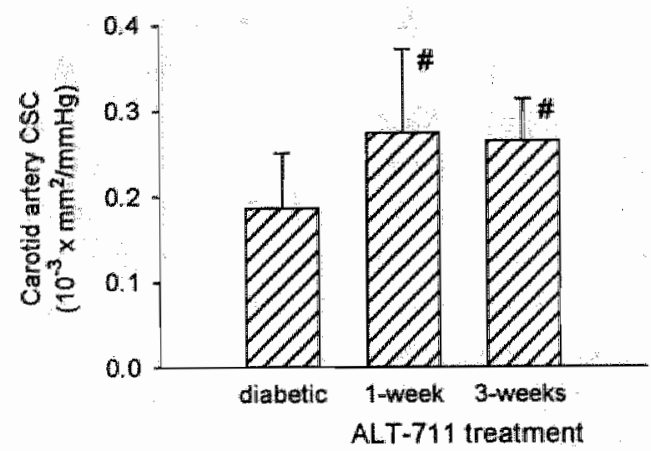

Figure 6.1 ALT-711 significantly increases in wivo carotid artery cross-sectional compliance (CSC) as assessed by ultrasound in diabetic animals, and animals treated with ALT711 for 1 or 3 weeks. \# refiects $P=0.017$ (by ANOVA) for animals treated for week, and $P=0.012$ for those treated for 3 weeks.

\section{In vitro carotid artery distensibility}

Basal carotid artery diameter in vitro was $1.09 \pm 0.17 \mathrm{~mm}$ in the untreated animals. In contrast, carotid artery diameter was $14-15 \%$ higher in the animals that were treated with ALT-711 for 1 week and 3 weeks, respectively. Under no flow conditions, the intraluminal pressure was increased from 75 to $150 \mathrm{mmHg}$ by 25 mmHg increments; in the untreated animals, diameter increased to a limited extent, from $1.09 \pm 0.12 \mathrm{~mm}$ at $75 \mathrm{mmHg}$ to $1.21 \pm 0.16 \mathrm{~mm}$ at $150 \mathrm{mmHg}$. In the animals that were treated with ALT-711, this increase in diameter during increasing pressure levels was significantly higher (from $1.22 \pm 0.13$ to $1.38 \pm 0.09 \mathrm{~mm}$ in those treated for 1 week, and from $1.24 \pm 0.15$ to $1.49 \pm 0.08 \mathrm{~mm}$ in those treated for 3 weeks, both $P<0.05$ vs. untreated). This finding implies that both carotid artery compliance and distensibility were markedly improved by treatment with ALT-711 (Figure 6.2). After incubation of the vessels with KCN to abolish smooth muscle tone, a significant difference between the diameters of arteries obtained from untreated diabetic animals and those from 1- and 3-week-treated animals remained, indicating that the diabetes-induced increase of passive stiffness was reverted in the treated animals. 

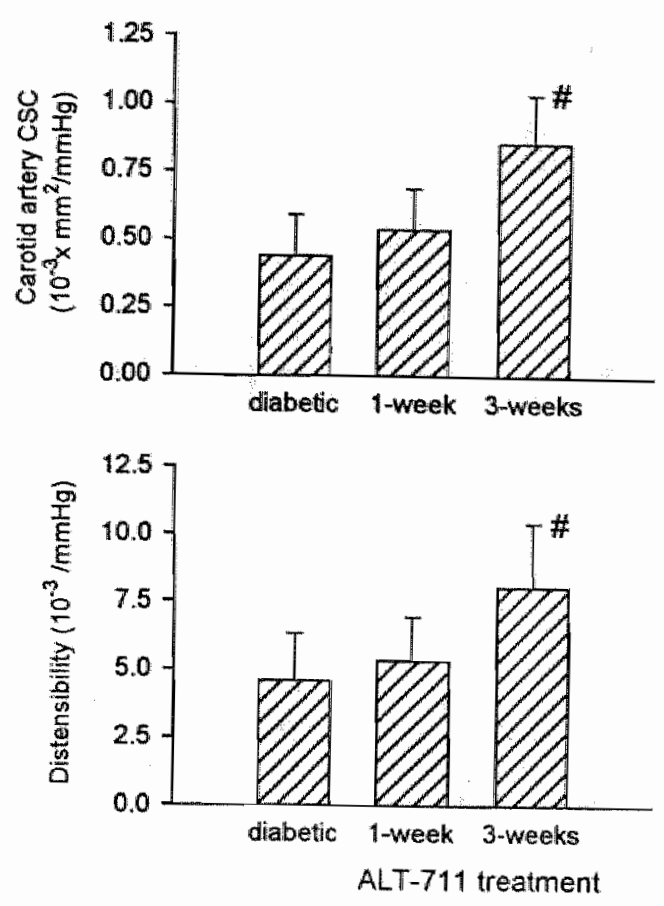

Figure 6.2 ALT-711 improves in vitro carotid artery cross-sectional compliance (CSC) and distensibility with increasing duration of treatment. Compliance and distensibility were calculated based on the increase of diameter and subsequent lumen area when pressure was increased from 75 to $125 \mathrm{mmHg}$ under no flow conditions. $\#, P<$ 0.05 by ANOVA compared with diabetic animals.

\section{Biochemical markers of protein cross-linking}

The increase in collagen crosslinking as a consequence of diabetes-induced AGE accumulation resulted in a marked decrease in the susceptibility of tail tendon collagen to pepsin digestion, as found in earlier studies ${ }^{5,23}$. By contrast, pepsin solubility of collagen, which was obtained from the animals which had been treated with ALT-711, was not different from that observed in nondiabetic controls (Figure 6.3).

When compared with the control group, ALT-711 treatment decreased cell-surface IgG content by $90 \%$ after one week, which remained at this level during the subsequent weeks, whereas this parameter increased slightly further in the vehicietreated animals (Figure 6.4A). The reduction of cell-surface $\mathrm{IgG}$ content proved to be dose-dependent (Figure 6.4B), and the $\mathrm{EC}_{50}$ for breaking $\mathrm{RBC}-\mathrm{IgG}$ crosslinks, calculated by the INPLOT program, was $0.06 \mathrm{mg} / \mathrm{kg}$. 


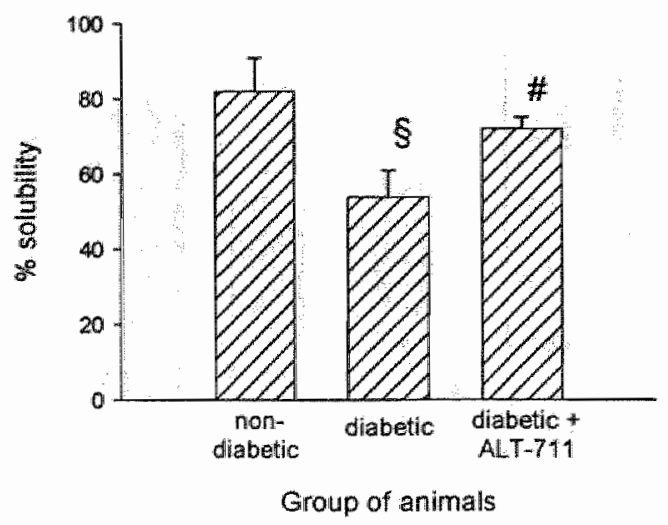

Figure 6.3 Chronic treatment with ALT-711 increases pepsin-induced tail tendon collagen solubility in diabetic rats. $\$, P<0.05$ vs. age-matched nondiabetic control animals, \#, $P<0.05$ vs. diabetic animalls. The ALT-711 group reflects animals that were treated for 3 weeks ( $1 \mathrm{mg} / \mathrm{kg}$ daily by i.p. injection).

\section{Discussion}

The different approaches used in these studies consistently show the beneficial effects of treatment with the AGE breaker ALT-711 on arterial elasticity. In vivo, treatment increased systemic arterial compliance (SAC) and reduced characteristic input impedance of the aorta $(\mathrm{Zc})$. There was a decrease of carotid artery stiffness, by assessment with ultrasound in vivo and in vitro. These effects seemed to be related to the duration of the treatment, with stronger effects after 3 weeks than after 1 week of treatment. The finding of the marked increase of compliance and decrease of impedance can not be attributed to differences in blood pressure, which did not change during treatment; therefore it reflects intrinsic modifications of the mechanical properties of the arterial wall. The increase of SAC and decrease of $\mathrm{Zc}$ indicate that because of treatment with ALT-711 the stiffness of the aorta was reduced by $25 \%(\mathrm{SAC})$ to $35 \%(\mathrm{Zc})$ to levels comparable to those observed in nondiabetic animals. This improvement was comparable to our results achieved with preventive treatment with aminoguanidine in diabetic rats ${ }^{14}$. 



Figure 6.4 ALT-711 decreases IgG crosslinked to the red blood cell (RBC) surface.

(A) Chronic treatment decreases $\mathrm{RBC}-\operatorname{IgG}$ already after 1 week of chronic dosing. Values are means $\pm S D$ of the percent change with respect to day 0 . All time points $P<0.01$ vs. predose and vs. vehicle.

(B) RBC-IgG levels decrease dose-dependently after 8 days of oral dosing with ALT-711.

Diabetic rats were treated for 8 days with ALT-711 in doses varying from 0.01 to $10 \mathrm{mg} / \mathrm{kg}$. All doses in the range $0.03-10.0$ are $P<0.01 \mathrm{ws}$. predose values.

The augmented stiffness of the arterial wall in diabetes could be attributed to changes in intrinsic mechanical wall properties caused by histological differences, especially in the ratio of elastin to collagen content. However, it has been demonstrated that the absolute and relative concentrations of elastin and collagen in the vessel wall are unaltered in rats with streptozotocin-induced diabetes and in diabetic patients $s^{3}$. Therefore, it is more likely that glucose-derived crosslinking of extracellular matrix proteins causes the increase in stiffness, and that the observed improvements after ALT-711 treatment result from a reduced crosslinking of these matrix proteins. Collagen obtained from tail tendons is the best accessible to evaluate the magnitude of this effect, since the hyperglycaemia-induced changes in 
collagen will not differ between the locations of this protein. We found that there indeed was an increase in collagen crosslinking in diabetic rats as evidenced by a marked decrease in the susceptibility of tail tendon collagen to pepsin digestion; this has also been shown in earlier studies ${ }^{5,23}$. By contrast, pepsin solubility of collagen that was obtained from the animals that had been treated with ALT-711 was considerably improved, and not different from that observed in nondiabetic control rats. A related biochemical marker of diabetes-induced crosslinking is the increase of erythrocyte cell surface-bound $\mathrm{IgG}^{16}$. It was shown that treatment with ALT-711 resulted in a reduction of red-cell-surface $\mathrm{IgG}$ content in diabetic rats, which proved to be dose-dependent.

Functional abnormalities and disturbed elastic properties of the aorta may precede structural changes in the aortic wall ${ }^{25}$. The process of AGE formation on arterial wall matrix proteins may be related to the development of atherosclerosis in many different ways. It is supposed that reactive free radicals are formed during the glycation process, and these free radicals may interact with various arterial wall constituents. It has been demonstrated that AGEs inhibit a normal network formation by collagen ${ }^{26}$. Also, glycation of collagen abolished the inhibitory effect of this matrix protein on human smooth muscle cell proliferation in vitro ${ }^{27}$ and increased the adhesion of monocytes ${ }^{28}$. Furthermore, the resulting abnormal elastic properties of the aorta constitute a greater work load for the heart, which can result in the development of hypertension and left ventricular hypertrophy.

The hallmark Diabetes Control and Complications Trial (DCCT) showed that nearnormalization of blood glucose control by intensive insulin therapy reduced the risk of development of diabetic complications ${ }^{29}$. However, intensive insulin therapy does not prevent nor cure complications, and this intensive therapy carries a high risk of side effects, especially occurrence of severe hypoglycaemia. Thus, a large number of people still are prone to develop vascular complications, and additional pharmacological approaches to prevent these complications are warranted. Both inhibitors of AGE formation, like aminoguanidine, and AGE breakers like ALT$71 \Perp$, may have a beneficial effect in this respect. Clinical studies with aminoguanidine are now ongoing. In our earlier studies in diabetic rats, a 30-35\% lower arterial stiffness was observed in diabetic rats treated long-term with aminoguanidine compared with vehicle-treated animals, whereas cardiac output corrected for body surface area and total peripheral resistance did not differ ${ }^{14}$. The latter effect may have been because of the (weak) effects of aminoguanidine as an inhibitor of the endotheliall constitutive nitric oxide synthase. It must be reminded that aminoguanidine was given in our earlier studies as a preventive treatment, i.e. treatment started directly after the induction of diabetes. In contrast, in the current studies ALT-711 was given as a curative treatment, i.e. treatment started after 
diabetes had already existed for more than 2 months. Thus, both aninoguanidine and ALT-711 beneficially influenced arterial stiffness as assessed by aortic impedance, carotid artery compliance and distensibility. The increase of cardiac output corrected for body surface area and reduction of peripheral resistance observed with ALT-711 in the absence of any effects on blood pressure suggests that these breaker compounds by directly reducing vascular AGE-accumulation have an additional beneficial influence on the hemodynamic system.

As pointed out earlier, glucose-induced damage is not unique to diabetic patients. Even at normal levels of blood glucose there will be some degree of glycation and accumulation of AGE-related products over time ${ }^{30}$. Increased accumulation of AGEs has indeed been demonstrated in the mesenteric artery tissue specimens obtained from humans, and was clearly associated with aging ${ }^{31}$; the changes in the aorta that occur with aging are characterized by a progressive increase in aortic stiffness. Our findings therefore may have significant therapeutic potential in the future treatment of conditions characterized by increased AGE accumulation and protein crosslinking, such as diabetes-related complications, systolic hypertension, and aging. 


\section{References}

1. Cox RH, Bagshaw RJ. Effects of hypertension and its reversal on canine arterial wall properties. Hypertension 1988;12:301-309.

2. Andreassen TT, Oxlund $\mathrm{H}$. Changes im collagen and elastin of rat aorta induced by experimental diabetes and food restriction. Acta Endocrinol (Copenh) 1987;115: 345-352.

3. Rasmussen LM, Ledet T. Aortic collagen alterations in human diabetes mellitus. Changes in basement membrane collagen content and in the susceptibility of total collagen to cyanogen bromide solubilisation. Diabetologia $1993 ; 36: 445-453$.

4. Spanheimer RG, Umpierrez GE, Stumpf V. Decreased collagen production in diabetic rats. Diabetes 1988;37:371-376.

5. Reddi AS. Collagen metabolism in the myocardium of normal and diabetic rats. Exp Mol Pathol 1988;48:236-243.

6. Brownlee M, Cerami A, Vlassara H. Advanced glycosylation end products in tissue and the biochemical basis of diabetic complications. $N$ Engl J Med 1988;318: 1315-21.

7. Kennedy L, Baynes JW. Non-enzymatic glycosylation and the chronic complications of diabetes: an overview. Diabetologia $1984 ; 26: 93-98$.

6. Brownlee $\mathrm{M}$, Cerami A, Vlassara H. Advanced glycosylation end products in tissue and the biochemical basis of diabetic complications. N Engl J Med 1988;318: 1315-1321

7. Raabe HM, Molsen H, Mlinaric SM, Acil Y, Sinnecker GHG, Notbohm H, Kruse $\mathrm{K}$, Muller PK. Biochemical alterations in collagen IV induced by in vitro glycation. Biochem J 1996;319:699-704.

8. Winlove $\mathrm{CP}$, Parker $\mathrm{KH}$, Avery $\mathrm{NC}$, Bailey AJ. Interactions of elastin and aorta with sugars in vitro and their effects on biochemical and physical properties. Diabetologia 1996;39:1131-1139.

9. Brownlee $M$, Vlassara $H$, Kooney A, Ulrich $P$, Cerami A. Aminoguanidine prevents diabetes induced arterial wall protein cross-linking. Sci 1986;232: 1629.1632 .

10. Meng J, Sakata $N$, Takebayashi $S_{n}$ Asano $T$, Futata $T$, Araki $N$, Horiuchi $S$. Advanced glycation end products of the Maillard reaction in aortic pepsin-insoluble and pepsin-soluble collagen from diabetic rats. Diabetes 1996;45:1037-43.

11. Lo CS, Relf IRN, Myers KA, Wahlquist ML. Doppler ultrasound recognition of preclinical changes in arterial wall in diabetic subjects: compliance and pulse-wave damping. Diabetes Care 1986;9:27-31.

12. Airaksinen KEJ, Salmela PI, Linnaluoto MK, Ikaheimo MJ, Ahola K, Ryhanen LJ. Diminished arterial elasticity in diabetes: association with fluorescent advanced glycosylation end products in collagen Cardiovasc Res 1993;27:942-45.

13. Huijberts MSP. Vascular dysfunction in experimental diabetes. PhD thesis, University Maastricht, The Netherlands 1994. 
14. Huijberts MSP, Wolffenbuttel BHR, Struijker Boudier HAJ Crijns FRL, Nieuwenhuijzen Kruseman AC, Poitevin $\mathbb{P}$, Levy BI. Aminoguanidine treatment increases elasticity and decreases fluid filtration of large arteries from diabetic rats. J Clin Invest 1993;92:1407-11:

15. Odetti $\mathrm{P}$, Traverso $\mathrm{N}$, Cosso $\mathrm{L}$, Noberasco G, Pronzato MA, Marinari UM Good glycaemic control reduces oxidation and glycation end-products in collagen of diabetic rats. Diabetologia 1996;39:1440-47.

16. Vasan $S$, Zhang $X$, Zhang $X$, Kapurniotu A, Bernhagen J, Teichberg S, Basgen J, Wagle D, Shih D, Terlecky I, Bucala R, Cerami A, Egan J, Ulrich J. An agent cleaving glucose-derived protein crosslinks in vitro and in vivo. Nature 1996;382: $275-78$.

17. Benessiano J, Lévy BI, Michel JB. Instantaneous aortic blood flow measurements with range gated Doppler flowmeter in anesthetized rat. I Pharmacol Meth $1985 ; 14: 99-110$.

18. Lévy BI, Benessiano J, Poitevin P, Lukin L, Safar ME. Systemic arterial compliance in normotensive and hypertensive rats. J Cardiovasc Pharmacol 1985;7 (suppl. 2): $\$ 28-\$ 32$.

19. Liu Z, Brin KP, Yin FCP. Estimation of total arterial compliance: an improved method and evaluation of current methods: Am I Physiol 1986;251:H588-H600.

20. Gessner U. Vascular input impedance. In: Cardiovascular Fluid Dynamucs. Ed. Bergel DH (Academic Press, London) 1982;315-50.

21. Tardy Y, Hayoz D, Mignot JP, Richard P, Brunner HR, Meister JJ. Dynamic non invasive measurements of arterial diameter and wall thickness. I Hypert $1992 ; 10$ (suppl. 6):S105-09.

22. Caputo L, Tedgui A, Lévy BI. Control of carotid vasomotor tone by local renin angiotensin system in normotensive and hypertensive rats. Role of endothelium and flow. Circ Res 1997;77:303-09.

23. Kochakian $M$, Manjula BN, Egan JJ. Chronic dosing with aminoguanidine and novel advanced glycosylation end product-formation inhibitors ameliorates crosslinking of tail tendon collagen in STZ-induced diabetic rats. Diabetes $1996 ; 45$ : 1694-1700.

24. Neuman RE, Logan MA. The determination of collagen and elastin in tissue. J Biol Chem $1950 ; 186: 549-56$.

25. Boudoulas $\mathrm{H}$, Wooley, $\mathrm{CF}$. Elastic properties of the aorta: summing up and future directions. In: Functional abnomalities of the aorta. Eds. Boudoulas H, Toutouzas P, Woolley CF (Futura Publishing Co., Inc., Armonk, NY), 1996;377-84.

26. Brownlee M. Glycation and diabetic complications. Diabetes 1994;43:836-41.

27. Lino $K$, Yoshinari $M$, Yamamoto $M$, Kaku $K$, Doi $Y$, lchikawa $K$, Iwase $M$, Fujishima $M$. The effect of glycated collagen on proliferation of human smooth muscle cells in vitro. Diabetologia 1996;39:800-06.

28. Gilcrease $\mathrm{MZ}$, Hoover RL. Examination of monocyte adherence to endothelium under hyperglycemic conditions. Diabetologia 1992;35:160-64. 
29. The Diabetes Control and Complications Trial Research Group. The effect of intensive treatment of diabetes on the development and progression of long-term complications in insulin-dependent diabetes. N Engl J Med 1993;329:977-86.

30. Drickamer K. Breaking the curse of AGEs. Nature 1996;382:211-12.

31. MacDonald E, Lee WK, Hepburn S, Bell J, Scott PJ, Dominiczak MH. Advanced glycosylation end products in the mesenteric artery. Clin Chem 1992;38:530-33. 


\section{Chapter 7}

\section{General discussion}




\section{General discussion}

In 1921, Banting and Best succeeded in the isolation of insulin. Its subsequent use in the treatment of diabetes was of vital importance for patients suffering from this life threatening disease. As people with diabetes started to live longer due to insulin therapy, development of vascular complications became evident. Even in patients who manage to maintain their blood glucose levels as close to normal as possible, sooner or later vascular dysfunction may occur. Although there is growing insight in the mechanisms involved in the pathogenesis of these complications, many topics remain obscure or controversial. More importantly, despite the increasing knowledge, there are still no pharmacological agents available for diabetic patients, that prevent the development of vascular complications. The studies presented in this thesis attempt to further elucidate mechanisms that underlie micro- and macrovascular complications in diabetes. Specific attention is paid to the contribution of advanced glycation end products (AGEs) in the development and exacerbation of these complications.

\section{The streptozotocin model for the study of diabetic complications}

In all our studies, the streptozotocin-induced diabetic rat was used as a model for type 1 diabetes. This model was first described by Rakieten and co-workers ${ }^{1}$. The model offers many practical advantages such as availability, group homogeneity, applicability of complicated techniques and use of experimental pharmacological compounds. The development of vascular abnormalities is often much more rapid than in humans with diabetes because the animals are chronically exposed to very high blood sugar concentrations. Moreover, they manage to survive with chronic hyperglycaemia without daily insulin supplementation. On the other hand, a model is never a copy of the real situation. Mechanisms that seem very important in the development of vascular complications in experimental diabetes, such as the accumulation of sorbitol, may later prove to be less important in the human situation $^{2}$. Because of insulin deprevation, weight loss is a common phenomenon in these rats, together with hyperphagia, polydipsia and possibly dehydration and cell shrinkage ${ }^{3,4}$. This means that, by using this model, one has to be very conscientious in designing experiments and interpreting results. 
In this thesis, the following research questions were investigated:

1. Does a six weeks period of hyperglycaemia lead to changes in microvascular reactivity in the streptozotocin-induced diabetic rat and is AGE accumulation involyed ?

2. Is the NO-dependent cyclic GMP production in the carotid artery influenced by long-term diabetes and does AGE accumulation play a prominent role in this ?

3. Does an intact endothelium play a protective role in vascular complications in experimental diabetes?

4. What is the effect of hemodynamic changes and AGE accumulation on arterial mechanical properties in experimental diabetes?

5. Are hemodynamic mechanisms responsible for the adaptations in vascular morphology during experimental diabetes?

6. Is it possible to reverse disturbances in hemodynamics during experimental diabetes by means of pharmacological interference with AGE metabolism?

In the next paragraphs, an effort is made to give an integrated view on the separate studies in this thesis.

\section{Vascular complications in experimental diabetes}

We observed different types of diabetes-induced vascular abnormalities, in small and large arteries and arterioles and after different diabetes-durations. Six weeks after diabetes-onset, we found microvascular dysfunctions in response to endothelium-dependent and -independent vasodilators (chapter 2). In small arteries located in the mesenteric vascular bed, morphological changes, i.e. outward remodeling, accompanied with changes in mechanical properties were established 7-9 weeks after diabetes-onset (chapter 3). An investigation of morphological changes that occur along the vascular tree after 3 months of diabetes is described in chapter 5. Most of the arteries displayed an inward hypotrophic remodeling, except for the small mesenteric arteries and the thoracic aorta. Small mesenteric arteries showed an outward hypertrophic remodeling, whereas no changes occured in the thoracic aorta of diabetic rats compared to age-matched control rats. Along with these vascular structural changes, hemodynamic dysfunction occured as well: reductions in cardiac index, stroke volume index and a reduced vascular elasticity (chapters 5 and 6).

Several mechanisms may be involved in the development of the observed vascular disturbances. In this thesis, particular attention was paid to the influence of advanced glycation end products (AGEs). During the past years, many studies highlighted the prominent role of elevated concentrations of circulating and tissue AGEs in diabetic complications. However, direct measurement of the total amount 
of AGEs involved in the development of vascular complications is still difficult to perform. On the one hand, AGEs are a large group of heterogeneous compounds, of which only a small part is identified until now $w^{5}$. On the other hand, the methods that were used in the past are not generally available and/or reliable ${ }^{6}$. Therefore, in most of our studies, we used pharmacological tools to inhibit formation of AGEs to obtain more insights in the contribution of AGEs in vascular dysfunction.

\section{Pharmacological interventions with AGEs}

Preventive treatment with aminoguanidine is known to inhibit formation of AGEs? Apart from this action, several other effects of the drug have been described (see table 3, chapter 1), which complicates a clear interpretation of the results. In chapter 2 , we demonstrated that the disturbed microvascular relaxation was not prevented by chronic aminoguanidine treatment. Moreover, a reduced sensitivity to nitrovasodilators in the de-endothelialized carotid artery of diabetic rats, was also not improved by chronic preventive treatment with aminoguanidine (chapter 4). On the other hand, earlier studies performed by our group showed that aminoguanidine treatment was able to reduce excessive vascular permeability and to increase elasticity of large arteries in diabetic rats ${ }^{\mathrm{z}, 9}$.

Because aminoguanidine has no effect on already formed AGEs ${ }^{10}$, and because turnover rate of proteins on which AGEs accumulate is very slow", additional drugs that interfere with AGEs which are already formed on blood and tissue proteins are needed to adequately prevent or reduce vascular disturbances in diabetes. AGE breakers seem to be the appropriate candidate to perform this task. Curative 3 week-treatment with ALT-711, a breaker of AGE crosslinks, drastically improved large artery properties of rats which had already been diabetic for 9 weeks. Cardiac output and cardiac index, and systemic arterial compliance were significantly increased, whereas characteristic impedance was significantly reduced. In vitro measurements of carotid artery compliance and distensibility revealed an increased elasticity of this artery in AGE-breaker treated rats ${ }^{12}$ (chapter 6). Another study with this AGE breaker, performed by Vaitkevicius et al. ${ }^{13}$, showed a sustained reduction in arterial stiffness, as measured by pulse wave velocity, in old Rhesus monkeys. Furthermore, Asif and co-workers ${ }^{14}$ demonstrated that treatment with ALT-711 increased end-diastolic and stroke volume significantly in aged dogs, suggesting a potential clinical utility of this agent in reversing left ventricular stiffness in aging.

\section{Involvement of AGEs in vascular dysfunction}

Earlier studies of our group and others ${ }^{8,9}$ showed a link between AGEs and vascular permeability in diabetes. Our present studies indicate that AGEs are particularly involved in the disturbance of mechanical properties in large arteries, 
leading to a reduced elasticity. Because the extracellular matrix of the vessel wall of large arteries contains high amounts of proteins with a low turn-over rate, the vessel wall is prone to accumulation of AGEs in diabetes ${ }^{15}$.

Despite observations and hypotheses made by other authors ${ }^{16}$, a relation between ACE-formation and disturbances in microvascular relaxation was not observed in our study (chapter 2). Furthermore, we demonstrated that the disturbed cGMP production during stimulation with NO-donors in de-endothelialized arteries of diabetic rats was not improved by aminoguanidine treatment. This may indicate that different mechanisms underlie the alterations in mechanical properties and permeability yersus disturbances in (NO-mediated) vascular reactivity. Whereas disturbances in large artery mechanical and hemodynamic properties may be largely attributed to formation of AGEs, these structures seem, at least in the experimental conditions we used, not directly involved in attenuated vascular relaxation in experimental diabetes. We hypothesize that an increased production of oxygen free radicals was responsible for the reduced cGMP production in deendothelialized arteries of diabetic rats after stimulation with NO-donors. An impaired release or action of EDHF was suggested to be involved in the altered microvascular response to vasorelaxant agents. Possibly, an increase in oxidative stress may also interfere with the release or action of EDHF.

\section{Final remarks}

Undoubtedly, formation of AGEs are an important pathogenic factor in the development of vascular dysfunction in diabetes. The development of adequate methods to measure blood- and tissue AGEs would improve and facilitate AGErelated diabetes research enormously. Concerning the treatment of diabetic patients with drugs interfering with $\mathrm{AGE}$ formation or degradation, results are promising. The first clinical studies with aminoguanidine suggest that this agent will have positive effects on morbidity and mortality as well as quality of life of patients with diabetes mellitus (Alteon inc., personal communication). We foresee that the development of new drugs targeting AGE metabolism more specifically offer attractive new therapeutic opportunities in the treatment of vascular complications in diabetes. 


\section{References}

1. Rakieten N, Rakieten ML, Nadkarni MV. Studies on the diabetogenic action of streptozotocin. Cancer Chemother Rep 1963;29:91.

2. Frank RN. Perspectives in diabetes. The aldose reductase controversy. Diabetes 1994;43:169-72.

3. Velasco Plaza A, G-Granda T, Cachero MTG. Circadian rhythms of food and water intake and urine excretion in diabetic rats. Physiology and Behaviour 1993;54: $665-70$.

4. Friedman MI, Ramirez I. Food intake in diabetic rats: relationship to metabolic effects of insulin treatment. Physiology and Behaviour 1994;56:373-78.

5. Thornalley PJ. Cell activation by glycated proteins. AGE receptors, receptor recognition factors and functional classification of AGEs. Cell mol Biol 1998;44: 1013-23.

6. Dorrian CA, Cathcart S, Clausen J, Shapiro D, Dominiczak MH. Factors in human serum interfere with the measurement of advanced glycation endproducts. Cell mol Biol 1998;44:1069-79.

7. Brownlee $M_{3}$, Vlassara $H$, Kooney A, Ulrich $P$, Cerami A. Aminoguanidine prevents diabetes-induced arterial wall protein cross-linking. Science 1986;232: 1629-32.

8. Huijberts MSP, Wolffenbuttel BHR, Struijker Boudier HAJ, Crijns FRL, Nieuwenhuijzen Kruseman $\mathrm{AC}$, Poitevin P, Lévy BI. Aminoguanidine treatment increases elasticity and decreases fluid filtration of large arteries from diabetić rats. J Clin Invest 1993;92:1407-11.

9. Huijberts MSP, Wolffenbuttel BHR, Crijns FRL, Nieuwenhuijzen Kruseman AC, Bemelmans MHA, Struijker Boudier HAJ. Aminoguanidine reduces regional albumin clearance but not urinary albumin excretion in streptozotocin-diabetic rats. Diabetologia 1994;37:10-14.

10. Chen HJC, Cerami A. Mechanism of inhibition of advanced glycosylation by aminoguanidine in vitro. J Carbohydrate Chem 1993;12:731-42.

11. Vlassara $\mathrm{H}$. Recent progress in advanced glycation end products and diabetic complications. Diabetes 1997;46 (suppl. 2):S19-25.

12. Wolffenbuttel BHR, Boulanger CM, Crijns FRL, Huijberts MSP, Poitevin $P$, Swennen GNM, Vasan S, Egan JJ, Ulrich P, Cerami A, Lévy BI. Breakers of advanced glycation end products restore large artery properties in experimental diabetes. Proc Natl Acad Sci USA 1998;95:4630-34.

13. Vaitkevicius $P V$, Lane $M$, Ebersold $C$, Cerami $A$, Egan J, Vasan $S$, Ulrich $P$, Lakatta EG. A novel collagen crosslink breaker effects a sustained reduction in arterial stiffness in old primates. Circulation 1998;98 (suppl. 1):8-9.

14. Asif M, Egan J, Vasan S, Jyothirmayi GN, Masurekar MR, Lopez S, Williams C, Torres RL, Wagle D, Ulrich P, Cerami A, Brines M, Regan TJ. An advanced glycation endproduct cross-link breaker can reverse age-related increases in myocardial stffness. Proc Natl Acad Sci USA 2000;97:2809-13. 
15. Vlassara $H$, Bucala $R$, Striker $L$. Pathogenic effects of advanced glycosylation: biochemical, biologic, and clinical implications for diabetes and aging. Laboratory Investigation 1994; 70:138-51.

16. Bucala R, Tracey KJ, Cerami A. Advanced glycosylation products quench nitric oxide and mediate defective endothelium-dependent vasodilatation in experimental diabetes. I Clin Invest 1991;87:432-38. 
Chapter 8

\section{Summary}




\section{Summary}

Diabetes mellitus is a disease which is characterized by hyperglycaemia, a relative or absolute lack of insulin, and a propensity to vascular disease and neuropathy. Two forms of diabeties mellitus can be distinguished. Type 1 diabetes or insulindependent diabetes mellitus (IDDM) is characterized by its juvenile onset and a state of absolute insulin deficiency caused by destruction of the insulin producing pancreatic $\beta$ cells. Type 2 diabetes or non-insulin dependent diabetes mellitus (NIDDM) affects mainly older people. In NIDDM defects in insulin secretion coexist with a relative insulin resistance often related to obesity.

Two types of vascular disease have been described in diabetes. Microangiopathy, which affects capillaries and arterioles in the eye, the kidney and other organs, is relatively unique to diabetes. Macroangiopathy is morphologically very similar to atherosclerosis in nondiabetics, but is more extensive and occurs at an earlier age. The underlying mechanisms, that are involved in the development and deterioration of these diabetic complications are not yet clear. In this thesis, an attempt is made to further characterize diabetic vascular complications in an animal model for type 1 diabetes, i.e. the streptozotocin-induced diabetic rat. Furthermore, one possible mechanism, formation of advanced glycation end products (AGE), that may contribute to the development and exacerbation of the complications studied, is further investigated.

In chapter 2, we studied the effects of six weeks streptozotocin-induced diabetes on microvascular reactivity in male Wistar Rp rats. A dorsal microcirculatory chamber was implanted, which allows intravital microscopy of striated muscle arterioles of varying diameter in conscious animals. The effects of intravenous administration of the endothelium-dependent vasodilator acetylcholine and the potassium-channel opener levcromakalim, as well as the vasoconstricting effects of angiotensin II and norepinephrine were studied. Heart rate and mean arterial pressure (MAP) were measured during the drug infusions. The absolute change in MAP after drug administration tended to be lower in the diabetic rats compared to their nondiabetic littermates. Arteriolar vasodilator responses to acetylcholine and levcromakalim were attenuated in the diabetic animals, whereras vasoconstrictor responses were not influenced by the diabetic state. Chronic treatment with aminoguanidine, an inhibitor of AGE formation, had no influence on MAP or arteriolar reactivity in diabetic animals, which indicates that formation of AGEs is likely not involved in the microvascular disturbance observed after 6 weeks of diabetes.

In chapter 3 the mechanical properties of mesenteric conduit arteries were studied in rats with diabetes-duration of 7-9 weeks and compared with nondiabetic controls. A diabetes-induced increase in external diameter was clearly demonstrated in situ. 
Pressure-induced increases in diameter were significantly larger in diabetic arteries compared to nondiabetic control arteries in a pressure range of 25 to $75 \mathrm{mmHg}$. This lied to an increased arterial compliance in the diabetic animals, but no change in arterial distensibility. The same results were obtained after abolition of smooth muscle tone by poisoning with $\mathrm{KCN}$. The enhanced external diameter, termed outward remodeling, is likely caused by an increased flow to the small intestine due to hyperphagia in experimental diabetes. Normally, chronic increases in flow not only induce outward remodeling, but are usually accompanied by wall hypertrophy, to normalize circumferential wall stress that increases during the expansion of the vessels. A statistical significant wall hypertrophy was, however, not detected in mesenteric arteries of diabetic rats. Possibly, advanced glycosylation of regulating proteins, such as growth factors, interferes with the hypertrophic response normally seen in situations of elevated blood flow.

In chapter 4 the mechanism of a possible disturbance in endothelium-dependent and -independent relaxation in large arteries of 3 months diabetic rats was investigated more thoroughly. Nitric oxide, produced by the endothelium or generated by nitrovasodilators, activates soluble guanylate cyclace (sGC) to produce $3^{\prime}, 5^{\prime}$-cyclic guanosine monophosphate (cGMP). cGMP is the second messenger molecule which induces relaxation of vascular smooth muscle cells. Basal and stimulated cGMP concentrations were measured in intact and de-endothelialized carotid arteries of control and diabetic rats, untreated or treated with aminoguanidine or insulin for 10-12 weeks. In arteries with an intact endothelial layer, no differences in basal or stimulated cGMP concentration were found between diabetic and control rats. Deendothelialization led to a reduced sensitivity of diabetic arteries for stimulation with sodium-nitroprusside or S-nitroso- $\mathrm{N}$-acetyl-penicillamine, two nitrovasodilators that increase cGMP content independently of the endothelium. Insulin, but not aminoguanidine treatment could prevent this reduced response. This implies that in diabetes, loss of endothelial integrity may have more severe consequences on vascular function than in nondiabetic subjects. AGEs are probably not involved in this disturbance.

Chapter 5 describes the hemodynamic properties of concious diabetic rats and relates these findings to the morphology of several arteries along the vascular tree. Severe cardiac dysfunction and hemodynamic changes were demonstrated in diabetic rats after 3 months of hyperglycaemia. This was indicated by reductions in cardiac output, cardiac index, stroke volume index and maximal flow acceleration. Several arteries exhibited a hypotrophic inward remodeling, without a change in media-to-lumen ratio. However, no morphological changes were found in the thoracic aorta of diabetic rats compared to controls, despite severe reductions in cardiac output. Small mesenteric arteries displayed hypertrophic outward 
remodeling. These results indicate that hemodynamic changes in conscious diabetic rats were accompanied by heterogenous morphologic adaptations.

In chapter 6 investigations are described on a new pharmacologic tool that reacts with and cleaves covalently, AGE-derived protein cross-links. The hemodynamic properties of 3 months diabetic rats under anesthesia were investigated after curative treatment for 1 or 3 weeks with this AGE-breaker. Diabetes-induced increase of large artery stiffness, as measured by systemic arterial compliance, aortic impdance, and carotid compliance and distensibility were reversed after 3 weeks of treatment. This study implies some promising findings for future treatment of diabetic patients as well as aged people and people suffering from diseases involving AGE accumulation, such as Alzheimer disease.

Finally, an integrated view on the separate studies described in this thesis is given in the general discussion (chapter 7). Answers to the research questions, posed in the introduction (chapter $l$ ), are discussed. 


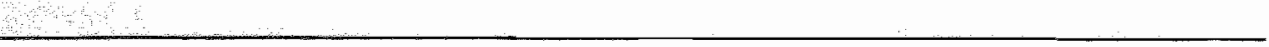




\section{Chapter 9}

\section{Samenvatting}




\section{Samenvatting}

Diabetes mellitus is een chronische ziekte die gekenmerkt wordt door hoge bloedsuikers, een relatieve of absolute afwezigheid van insuline, en een neiging tot vasculaire complicaties en neuropathie. Er worden twee vormen van diabetes onderscheiden. Type 1 diabetes of de insuline afhankelijke vorm van diabetes mellitus (IADM) wordt gekenmerkt door het ontstaan op jeugdige leeftijd en een toestand van absolute insuline-deficientie, veroorzaakt door destructie van insuline producerende $\beta$-cellen in de pancreas. Type 2 diabetes of niet insuline afhankelijke diabetes mellitus (NIADM) komt hoofdzakelijk woor bij ouderen. Hierbij treedt er een defect op in insuline secretie, waarbij ook sprake is van een relatieve ongevoeligheid van weefsels voor insuline, hetgeen (deels) samenhangt met de aanwezigheid van overgewicht.

Twee typen vasculaire complicaties komen voor bij diabetes patiënten. Bij microangiopathie zijn kleinere vaten aangetast, zoals capillairen en arteriolen in het oog, de nieren en andere organen. Deze vorm van vasculaire complicatie is relatief uniek voor mensen met diabetes. Macroangiopathie duidt op een aantasting van de grotere vaten en is morfologisch niet te onderscheiden van atherosclerose, zoals die voorkomt bij mensen zonder diabetes. Macroangiopathie is echter vaak uitgebreider aanwezig bij diabetes patiënten en komt ook voor op jongere leeftijd. De onderliggende mechanismen die betrokken zijn bij het ontstaan en de verdere ontwikkeling van deze vasculaire complicaties zijn nog niet volledig opgehelderd. Dit proefschrift beoogt deze diabetische vasculaire complicaties verder te karacteriseren met behulp van een dierlijk model voor type 1 diabetes, nl. de streptozotocine-geïnduceerde diabetische rat. Verder wordt één van de mogelijke mechanismen bestudeerd die betrokken zijn bij de ontwikkeling en verergering van complicaties. Het betreft de vorming van geglycosyleerde produkten. Glycosylering, een proces veroorzaakt door de reactie van circulerende suikers zoals glucose met eiwitten en anderen macromoleculen, interfereert met de functie van een aantal weefsels die belangrijk zijn voor het normaal functioneren van het cardiovasculaire systeem.

In hoofdstuk 2 worden de veranderingen in microvasculaire reactiviteit bestudeerd die optreden na 6 weken streptozotocine-geïnduceerde diabetes in Wistar Rp ratten. Ratten werden voorzien van een "dorsale microcirculatie kamer", die het mogelijk makkt kleine vaatjes in een dwarsgestreepte spier op de rug van de rat te bekijken met behulp van een microscoop. Op die manier konden diameterveranderingen gemeten worden in arteriolen van wakkere ratten, na intraveneuze toediening van vaatverwijders, zoals acetylcholine en levcromakalim, en vasoconstrictoren, zoals angiotensine II en noradrenaline. Tijdens de infusies van vasoactieve stoffen werden bloeddruk en hartfrequentie van de rat gemeten. De absolute verandering in 
gemiddelde arteriele druk leek wat lager te zijn bij de diabete ratten in vergelijking met de controles. Arteriolaire vasodilatatie die optradt na infusie van acetylcholine en levcromakalim was minder groot bij de diabeten, terwijl vasoconstrictie na infusie van angiotensine II en noradrenaline niet verschillend was tussen diabete en controle ratten. Chronische behandeling met aminoguanidine, een remmer van de vorming van glycosyleringsproducten, had geen invloed op gemiddelde arteriële druk en arteriolaire reactiviteit bij diabete ratten. Dit geeft aan dat de vorming van glycosyleringsproducten waarschijnlijk niet betrokken is bij de microvasculaire complicatie die optreedt na 6 weken diabetes.

Hoofdstuk 3 beschrijft de mechanische eigenschappen van mesenteriale geleidingsarteriën bij ratten met een diabetes-duur van 7-9 weken in vergelijking met controle ratten. De externe diameter van mesenteriale arteriën was significant groter bij diabete ratten, zowel de uitgangsdiameter als na opvoering van de druk in stappen van $25 \mathrm{mmHg}$ (range $0-150 \mathrm{mmHg}$ ). Een toegenomen compliantie werd vastgesteld in deze vaten, terwijl de distensibiliteit onveranderd bleef. Vergelijkbare resultaten werden verkregen na uitschakeling van de vaatspier tonus met behulp van KCN. De toegenomen externe diameter wordt waarschijnlijk veroorzaakt door een toegenomen doorbloeding van de dunne darm, tengevolge van hyperfagie bij diabete ratten. Dit proces waarbij de diameter toegenomen is noemt men uitwaartse remodellering. Meestal leidt een toegenomen doorbloeding niet enkel tot uitwaartse remodellering, maar ook tot hypertrofie van de vaatwand. Dit laatste treedt op em de circumferentiële wandspanning te normaliseren tijdens uitzetting van de vaten. Een statistisch significante hypertrofie van de vaatwand kon echter niet worden vastgesteld. Mogelijk interfereert glycosylering van eiwitten zoals groeifactoren met de hypertrofe respons die normaal optreedt na een chronische toename van de bloedtoevoer.

In hoofdstuk 4 werd dieper ingegaan op het mechanisme van een mogelijke verstoring in de endotheel-afhankelijke en -onafhankelijke relaxatie in grote arteriën van ratten met een diabetes duur van 3 maanden. Stikstofoxide, dat geproduceerd wordt door het endotheel of exogeen wordt toegediend, stimuleert het oplosbaar guanylaat cyclase tot de productie van $3^{\prime}, 5^{\prime}$-cyclisch guanosine monofosfaat (CGMP). CGMP is een boodschapper molecuul dat relaxatie van vaten induceert. Basale en gestimuleerde cGMP concentraties werden gemeten in intacte halsslagaders van diabete en controle ratten en in slagaders waarvan het endotheel was verwijderd. Er werden geen verschillen gevonden in cGMP concentratie tussen diabete en controle ratten in intacte halsslagaders. Verwijdering van het endotheel zorgde er echter voor dat de cGMP concentratie in vaten van diabete ratten significant lager was, na stimulatie met endotheel-onafhankelijke nitrovasodilatoren. Chronische behandeling met insuline voorkwam deze gereduceerde respons, 
behandeling met aminoguanidine had geen effect. Hieruit kon geconcludeerd worden dat beschadiging van de endotheellaag bij diabeten ernstige gevolgen kan hebben voor het normaal functioneren van vaten. Glycosyleringsproducten zijn waarschijnlijk niet betrokken bij deze vasculaire stoornis.

Hoofdstuk 5 behandelt de hemodynamische eigenschappen in wakkere diabete ratten en tracht deze bevindingen te koppelen aan de morfologische veranderingen die optreden in verschillende arteriên na 3 maanden diabetes. Ernstige hartafwijkingen en hemodynamische veranderingen werden aangetoond in de diabete ratten in vergelijking met controle ratten. Enkele bevindingen waren: een afname in absoluut en geïndexeerd hartminuutvolume, een gereduceerd geïndexeerd slagvolume en een afname in maximale versnelling van de bloedtoevoer. Bij verschillende arteriën werd een hypotrofe inwaartse remodellering vastgesteld, zonder verandering in wand-lumen ratio. Ondanks een ernstige afname in hartminuutvolume, werden deze morfologische aanpassingen niet teruggevonden bij de thoracale aorta. Kleine mesenteriaal arteriën vertoonden hypertrofe uitwaartse remodellering, waarschijnlijk tengevolge van een toegenomen doorbloeding van het mesenteriaal vaatbed. De resultaten van dit hoofdstuk tonen aan dat hemodynamische veranderingen in wakkere diabete ratten vergezeld worden door heterogene morfologische aanpassingen aan de vaten.

In hoofdstuk 6 worden de hemodynamische en mechanische eigenschappen beschreven van diabete ratten die curatief behandeld werden met een nieuw farmacologisch middel, dat ingrijpt op reeds gevormde glycosyleringsproducten. In tegenstelling tot aminoguanidine, dat de vorming van deze producten tegengaat, reageert dit middel met de irreversibele glycosyleringsproducten die zich opstapelen in allerlei weefsels onder invloed van hoge bloedsuikerspiegels en inactiveert het deze producten. De afgenomen elasticiteit van vaten die optreedt tengevolge van diabetes, was na 3 weken curatieve behandeling met dit farmacon opnieuw sterk toegenomen. Dit iniddel is waarschijnlijk veel belovend voor de toekomstige behandeling van zowel diabetes patiënten als oudere mensen en mensen met de ziekte van Alzheimer.

Tenslotte wordt in hoofdstuk 7 een geïntegreerde visie gegeven over de studies die in de experimentele hoofdstukken van dit proefschrift werden beschreven. De antwoorden op de onderzoeksvragen, gesteld in de inleiding (hoofdstuk 1), worden in dit hoofdstuk bediscussieerd. 


\section{Dankwoord}




\section{Dankwoord}

Vaak stond ik er alleen voor... Maar nog vaker werd ik omringd, gesteund en geholpen door mensen, aan welke ik langs deze weg mijn oprechte dank will betuigen.

Als eerste wil ik mijn co-promotor dr. Bruce Wolffenbuttel bedanken. Beste Bruce, met jou is alles begonnen! Door jou werd ik angeworven om te assisteren bij het promotieonderzoek van Maya Huijberts. Maar onmiddelijk deed je de belofte dat als alles goed zou meevallen, ik een eigen onderzoek zou mogen uitbouwen en ook promoveren. Dat laatste leek me toen nog onwaarschijnlijk. Maar mede door jouw steun is het nu toch zo ver gekomen. Dank je wel voor alle kansen die je mij hebt geboden.

Mijn eerste promotor, Prof. dr. Harry Struijker Boudier. Beste Harry, jij noemde jezelf ooit de vader van de AIO's bij farmacologie. En zo heb ik jou ook ervaren. Iemand die door zijn ruime ervaringen in de wetenschap mij met wijze raad bijstond bij de sturing van het onderzoek, de interpretatie van resultaten en bij het schrijven van artikels. Maar dat niet alleen. Als het een keer moeilijk ging, bood jij de spreekwoordelijke schouder om op te hwilen. Ook je interesse in en bekommernis om mijn persoonlijke welzijn deed enorm veel deugd.

Mijn tweede promotor, Prof. dr. Jo De Mey. Waarde landgenoot, beste Jo, ik heb een ontzettende bewondering voor jouw manier van wetenschap bedrijven. Af en toe was ik zelfs een tikkeltje jaloers op de Co van Jo \& Co. Jij was altijd bereid tot meedenken, als ik er zelf niet helemaal uitkwam. Het hoofdstuk over cGMP bepalingen is er woornamelijk door jouw impuls gekomen. We hebben vaak boeiende discussies gevoerd, waarvan ik veel heb opgestoken. Zo kwam het dat jij, ondanks dat het bij de aanvang van mijn promotieonderzoek nog niet vaststond, toch mijn promotor werd.

De commissie-leden, Prof. dr. P.W. de Leeuw, Prof. dr. M.J.A.P. Daemen en Prof. dr. G.I. van der Vusse, dank voor het beoordelen van het manuscript and Dr. A. Cerami and Prof. dr. B.I. Lévy, thank you for reading my thesis and your interest in my research work.

Prof. dr. Jos Smits, huidig voorzitter van de capaciteitsgroep Farmacologie en Toxicologie, en hoofd van het lab war ik het grootste deel van mijn dierexperimenteel onderzoek heb uitgevoerd. Beste Jos, mede dank zij jou heb ik me bij Farmacologie nooit een vreemde eend in de bijt gevoeld, integendeel. Ik kreeg, net als de AIO's van Farmacologie, een ruime werkplek zowel op het lab als in een zitkamer, waardoor ik efficiènt kon werken. Voor de hemodynamische experimenten in hoofdstuk 5 verleende jij de know-how en analytische ondersteuning. Ook Mia en Els, de "moeders" van farmacologie, ben ik dankbaar voor de ontelbare "kleine dingetjes" die even tussendoor voor mij gedaan werden.

Mijn paranimfen Jacques en Jenny. Beste Jacques, samen met Peter vormden wij geruime tijd de "ochtendploeg". Jullie waren steeds de eersten om mij op te beuren als er iets mislukte of als ik ergens ontevreden over was; maar ook de vele vreugdekreten deelde ik met jullie. Vele proefdier-kneepjes heb ik van jullie geleerd. Niets is onmogelijk, lijkt wel jullie motto als het op opereren of experimenteren aankomt. Ik denk met heimwee terug 
aan onze wele boeiende gesprekken in de data-analyse kamer, met als favoriete onderwerp het wel en wee van onze kinderen.

Beste Jenny, onze vriendschap begon bij farmacologie, waar we als beginnende AIO's lief en leed deelden. Als kamergenoot onhou ik vooral de diepzinnige gesprekken tijdens onze "picknick" binnenskamers. Jij koos een andere weg, maar onze vriendschap werd hechter dan ooit. En mocht ik ooit de wetenschap vaarwel zeggen, dan wordt ik vast een goede relatiebemiddelaar.

Bij vele proefdier experimenten kreeg ik assistentie. Eerst van Helma, van wie ik de kneepjes van het vak leerde, daarna van Dorette en als laatste van Iolente. Mijn oprechte dank. Had ik jullie hulp niet gekregen dan was ik waarschijnlijk nu nog kamertjes aan het implanteren. Ook de toemmalige student-assistenten Marc-Jan en Dave dank ik voor de vele uren video kijken en vaten analyseren.

Gabriëlle en Geertje van het lab Endocrinologie dank ik voor de grote aantallen glucosebepalingen, staart-dissecties en hulp bij "onuitvoerbare bepalingen". Maar ook voor de gezelligheid en de tractaties. De analisten van het Klinisch Chemisch Lab dank ik voor de vele $\mathrm{HbA}_{1 \mathrm{c}}$ bepalingen. De mensen van het CPV verdienen een pluim voor de goede zorgen voor de diabete ratten, die extra water, schone kooien en ook af en toe een spuitje nodig hadden.

Vele (ex-)collega's van farmacologie hebben mij geholpen door het geven van adviezen of het aanleren van technieken. Enkele wil ik hier met naam noemen en bedanken: Gregorio voor de histologische expertise, Ger en Rob voor het inwijden in biochemische technieken, Jan en Chris voor het oplossen van computerproblemen, Marjorie en Ben voor de boeiende discussies en tenslotte Debbie voor hulp bij taal- en andere problemen. Maar bovenal dank ik jullie allen voor de geweldige sfeer die maakt dat ik met plezier all die jaren heb doorgebracht bij farmacologie.

Tiny Wouters dank ik van harte voor het maken van de layout van dit proefschrift, ook onder moeilijke omstandigheden.

Mijn ouders wil ik bedanken voor de opvoeding die ze mij gaven en hun nimmer aflatende steun. Lieve mama en papa, jullie gaven mij de kans on te studeren en de vrijheid om te studeren wat ik zelf graag wilde. Helaas, papa, zelfs met dit getuig-schrift erbij zal het mij nog niet lukken om een kram recht in te slaan voor het spannen van een prikkeldraad. Maar ik denk dat ik dat nu ook niet meer nodig zal hebben.

Lieve Carlo, jij zorgde ervoor dat deze "carrière-moeder" een warme thuis had om thuis te komen. Het huishouden is jarenlang jouw eindverantwoordelijkheid geweest. Jouw motto : "een echte man moet alles kunnen" heb je in al zijn facetten waargemaakt (tenminste, tot je je vingers verbrandde aan het strijkijzer). Maar beloofd is beloofd, mijn eerstvolgende cursus wordt er eentje om gezond en lekker te leren koken.

Elia en Jona, mijn lieve schatten, jullie lieten er mij keer op keer aan denken dat er nog zo oneindig veel meer is. 


\section{Publicaties}




\section{Full Papers}

Crijns FRL, Struijker Boudier HAJ, Wolffenbuttel BHR. Arteriolar reactivity in conscious diabetic rats. Influence of aminoguanidine treatment. Diabetes 1998;47: 918-23.

Crijns FRL, Wolfenbuttel BHR, De Mey JGR, Struijker Boudier HAJ. Mechanical properties of mesenteric arteries in diabetic rats: consequences of outward remodeling. Am J Physiol 1999;276:H1672-H77.

Crijns FRL, Wolffenbuttel BHR, Schiffers PMH, Struijker Boudier HAJ, de Vente J, De Mey JGR. Altered cyclic GMP production in carotid arteries of streptozotocin-induced diabetic rats. submitted.

Crijns FRL, Wolffenbuttel BHR, De Mey JGR, Smits JFM, Struijker Boudier HAJ. Hemodynamics in conscious streptozotocin-induced diabetic rats: influence on vascular morphology. submitted.

Huijberts MSP, Wolffenbuttel BHR, Crijns FRL, Nieuwenhuijzen Kruseman AC,

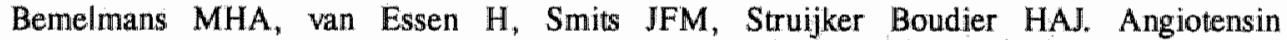
converting enzyme-inhibition reduces urinary albumen excretion but not regional albumin clearance in experimental diabetes. Eur J Pharmacol 1993;240:207-12.

Huijberts MSP, Wolffenbuttel BHR, Struijker Boudier HAJ, Crijns FRL, Nieuwenhuijzen Kruseman AC, Poitevin $\mathrm{P}$, Lếvy $\mathrm{BI}$. Aminoguanidine treatment increases elasticity and decreases fluid filtration of large arteries from diabetic rats. J Clin Invest 1993;92: 1407-11.

Huijberts MSP, Wolffenbuttel BHR, Crijns FRL, Nieuwenthuijzen Kruzeman AC, Bemelmans MHA, Struijker Boudier HAJ. Aminoguanidine reduces regional albumin clearance but not urinary albumin excretion in streptozotocin-diabetic rats. Diabetologia $1994 ; 37: 10-14$.

Struijker-Boudier HAJ, Crijns FRL, Stolte J, van Essen H. Assessment of the microcirculation in cardiovascular disease. Clinical Science 1996;91:131-39.

Wolffenbuttel BHR, Boulanger CM, Crijns FRL, Huijberts MSP, Poitevin P, Swennen GNM, Vasan S, Egan JI, Cerami A, Lévy BI. Breakers of advanced glycation endproducts restore large artery properties in experimental diabetes. Proc Natl Acad Sci USA $1998 ; 95: 4630-34$.

\section{Abstracts}

Crijns FRL, Huijberts MSP, Wolffenbuttel BHR and Struijker Boudier HAJ. In vivo arteriolar reactivity to vasodilators in experimental diabetes. Pharmacology \& Toxicology $1993 ; 72,52: 16$.

Crijns FRL, Huijberts MSP, wan Essen H, Struijker Boudier HAJ, Nieuwenhuijzen Kruzeman AC, Wolffenbuttel BHR. ACE-inhibitor therapy reduces microvascular hyperreactivity to angiotensin II in diabetic rats. Eur J Clin Invest 1993;23,S1:A41. 
Crijns FRL, Huijberts MSP, Struijker Boudier HAJ, Nieuwenhuijzen Kruzeman AC, Wolffenbuttel BHR. The effect of insulin treatment on changes in microvascular reactivity in experimental diabetes. Pharmacy World \& Science 1993; 15, SI:14.

Crijns FRL, Huijberts MSP, Struijker Boudier HAJ, Nieuwenthuijzen Kruzeman AC, Wolffenbuttel BHR. Insulin treatment restores disturbed microvascular reactivity in experimental diabetes. Eur J Clin Invest 1994;24,S2:A48.

Crijns FRL, Wolffenbuttel BHR, van Essen H, Struijker Boudier HAJ. Mesenteric artery changes in experimental diabetes. Diabetologia 1994;37, S1:A199.

Crijns FRL, Wolffenbuttel BHR, wan Essen H, Struijker Boudier HAJ. Conductance mesenteric artery changes in experimental diabetes. Pharmacology World \& Science $1994 ; 16: J 6$.

Crijns FRL, Wolffenbuttel BHR, Struijker Boudier HAJ. Aminoguanidine treatment increases arteriolar vasopressor responsiveness in rats. Diabetes 1995;44,S1,60A.

Crijns FRL, Wolffenbuttel BHR, wan Essen H, Struijker Boudier HAJ. ACE-inhibitor treatment does not reverse mesenteric artery changes in experimental diabetes. Diabetologia $1995 ; 38, \mathrm{~S} 1: \mathrm{A} 221$.

Crijns FRL, van Essen H, Struijker Boudier HAJ, Wolffenbuttel BHR. Chronic aminoguanidine treatment increases arteriolar reactivity to angiotensin II and norepinephrine in rats. Naunyn-Schmiedeberg's Archives of Pharmacology 1995;352:R26.

Crijns FRL, De Mey JGR, Janssen GMJ, Struijker Boudier HAJ, Wolffenbuttel BHR.

Altered arterial cyclic GMP production in experimental diabetes. Pharmacology World \& Science $1996 ; 18$ (suppl):5.

Crijns FRL, De Mey JGR, Schiffers PMH, Janssen GMJ, Struijker Boudier HAJ, Wolffenbuttel BHR. Cyclic GMP production in carotid arteries of diabetic rats. Chronic effects of aminoguanidine. Diabetologia 1996;39, S1:A286.

Crijns FRL, Wolffenbuttel BHR, van Ingen Schenau DS, Struijker Boudier HAJ De Mey JGR. Endothelium-independent cyclic GMP formation in carotid arteries of diabetic rats. J Vasc Res $1997 ; 34, \mathrm{S1}: 13$.

Crijns FRL, Wolffenbuttel BHR, van Ingen Schenau DS, Struijker Boudier HAJ, De Mey JGR. Endothelium-independent cyclic GMP formation in carotid arteries of diabetic rats. Diabetologia $1997 ; 40, \mathrm{S1}: 1572$.

Crijns FRL, Korstjens IJM, Struijker Boudier HAJ, Wolffenbuttel BHR. Streptozotocininduced diabetes in Dahl salt sensitive rats: a model that combines diabetes and hypertension. Diabetologia 1998;41,S1:A341. 


\section{Curriculum Vitae}




\section{Curriculum Vitae}

Francine R.L. Crijns

16 augustus 1967 Geboren te Genk, België

$1979 \cdot 1985$

Algemeen secundair onderwijs

Richting Latijn - Wetenschappen

Instituut Maria Opdracht te Maasmechelen, België

$1985-1989$

Licentiaat in de Wetenschappen, Groep Dierkunde

Specialisatie: fysiologie en moleculaire biologie

Katholieke Universiteit te Leuven, België

$1987-1990$

Aggregatie Hoger Secundair Onderwijs

Katholieke Universiteit te Leuven, Belgie

$1989-1990$

Leerkracht biologie, chemie, natuurkunde en aardrijkskunde Instituut Maria Opdracht te Maasmechelen, België

1990-1991

Wetenschappelijk medewerker

Natuurbeschermingsactie Limburg v.z.w. te Hasselt, België

$1991-1994$

Onderzoeksassistent

Capaciteitsgroep Interne Geneeskunde, Universiteit Maastricht

$1994-1998$

Assistente in opleiding

Capaciteitsgroep Interne Gieneeskunde, Cardiovascular Research Institute Maastricht, Universiteit Maastricht

1998.

Docente biologische en medische vakken

Hoger Laboratoriumonderwijs, Faculteit Techniek

Hogeschool Limburg te Heerlen 
